\section{Pacific Northwest}

National Laboratory

Operated by Battelle for the

U.S. Department of Energy

\title{
Laboratory Performance Evaluation Report of SEL 421 Phasor Measurement Unit
}

\author{
Z. Huang \\ T. Faris \\ K. Martin \\ J.F. Hauer \\ C.A. Bonebrake \\ J.M. Shaw
}

December 2007

Prepared for

the U.S. Department of Energy

under Contract DE-AC05-76RL01830 


\title{
DISCLAIMER
}

This report was prepared as an account of work sponsored by an agency of the United States Government. Neither the United States Government nor any agency thereof, nor Battelle Memorial Institute, nor any of their employees, makes any warranty, express or implied, or assumes any legal liability or responsibility for the accuracy, completeness, or usefulness of any information, apparatus, product, or process disclosed, or represents that its use would not infringe privately owned rights. Reference herein to any specific commercial product, process, or service by trade name, trademark, manufacturer, or otherwise does not necessarily constitute or imply its endorsement, recommendation, or favoring by the United States Government or any agency thereof, or Battelle Memorial Institute. The views and opinions of authors expressed herein do not necessarily state or reflect those of the United States Government or any agency thereof.

\author{
PACIFIC NORTHWEST NATIONAL LABORATORY \\ operated by \\ BATTELLE \\ for the \\ UNITED STATES DEPARTMENT OF ENERGY \\ under Contract DE-AC0576RL01830
}

Printed in the United States of America

Available to DOE and DOE contractors from the Office of Scientific and Technical Information,

P.O. Box 62, Oak Ridge, TN 37831-0062;

ph: (865) 576-8401

fax: (865) 576-5728

email: reports@adonis.osti.gov

\author{
Available to the public from the National Technical Information Service, \\ U.S. Department of Commerce, 5285 Port Royal Rd., Springfield, VA 22161 \\ ph: (800) 553-6847 \\ fax: (703) 605-6900 \\ email: orders@ntis.fedworld.gov \\ online ordering: http://www.ntis.gov/ordering.htm
}




\title{
Laboratory Performance Evaluation Report of SEL 421 Phasor Measurement Unit (PMU)
}

\author{
Z. Huang \\ T. Faris ${ }^{(1)}$ \\ K. Martin ${ }^{(1)}$ \\ J.F. Hauer \\ C.A. Bonebrake \\ J.M. Shaw
}

December 2007

Prepared for

the U.S. Department of Energy

Under Contract DE-AC05-76RL01830

Pacific Northwest National Laboratory

Richland, Washington 99352

(1) Bonneville Power Administration, Measurement Systems Group 


\section{SUMMARY}

Technology evaluation is a major element of the wide area measurement system (WAMS) effort to enhance measurement-based information resources for managing large power grids. Critical measurement devices, such as phasor measurement units (PMUs) and other advanced transducers, are evaluated through a combination of model studies, laboratory tests, and performance comparisons under field conditions.

Laboratory evaluation of PMU performance has the following immediate objectives:

A. Determine whether the PMU provides data of acceptable quality across a sufficiently broad frequency range.

B. Determine PMU response in sufficient detail that its behavior can be predicted over a full range of application conditions, many of which cannot be reproduced with laboratory tests.

Specific attention must be given to performance measures laid out in established guidelines or standards, such as the WECC phasor measurement requirements and the IEEE SynchroPhasor Standard C37.118.

This report presents the laboratory evaluation results of the SEL 421 PMU unit. The laboratory evaluation focuses only on the phasor measurement functionality of the SEL 421 unit. Though SEL 421 is capable of performing relay functions, they are beyond the scope of this report. The laboratory evaluation described in this report was performed with a standard relay test set using recorded files of precisely generated test signals. Test signals include steady-state waveforms to test amplitude, phase, and frequency accuracy; modulated signals to determine measurement and rejection bands; and step tests to determine timing and response accuracy.

The SEL 421 PMU unit has two filtering options: Narrow Band and Fast Response. It also has a frequency compensation function, which can be enabled or disabled by users. All four setting combinations are examined in the report, in test series A through D:

Test Series A: Narrow Band with Frequency Compensation off

Test Series B: Narrow Band with Frequency Compensation on

Test Series C: Fast Response with Frequency Compensation off

Test Series D: Fast Response with Frequency Compensation on

The measurement accuracy for magnitude, phase and frequency of three-phase balanced voltage and current signals complies with both level 0 and level 1 requirements established in the IEEE SynchroPhasor Standard C37.118, except that frequency measurement with Test Series A does not meet level 1 requirements. Harmonic and out-ofband signal rejection performance with all four Test Series complies with level 0 requirements, while only Narrow Band setting achieves level 1 compliance.

Dynamic performance for SEL 421with Narrow Band filtering is very close to satisfying the WECC phasor measurement requirements. This is not the case for Fast Response filtering. Time delay with amplitude and phase modulation signals is about $2 \mathrm{~ms}$ on average with a maximum deviation of about $10 \mathrm{~ms}$. Time delay with frequency modulation signals is about $80 \mathrm{~ms}$ with a maximum deviation about $1 \mathrm{~ms}$. Fast Response filtering shows faster rising response in step tests than Narrow Band filtering, with the rising time being about $33 \mathrm{~ms}$ versus about $60 \mathrm{~ms}$.

Different PMU settings result in different measurement performance with certain advantages and disadvantages. In practical applications, the best PMU setting should be determined with consideration of specific application requirements. 


\section{Table of Contents}

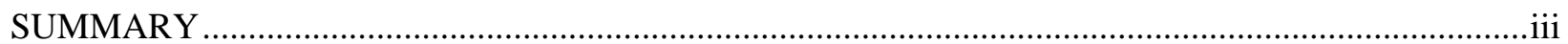

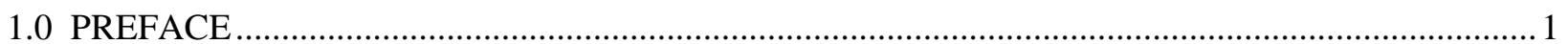

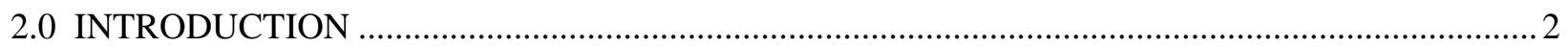

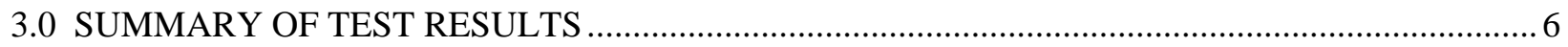

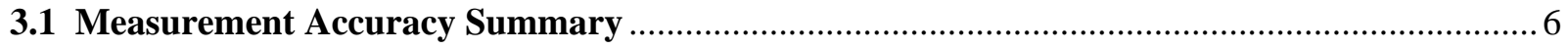

3.2 Harmonic and Out-of-Band Signal Rejection Summary …………………………………….

3.3 Modulated Signal Test Summary ……………………………………………………...

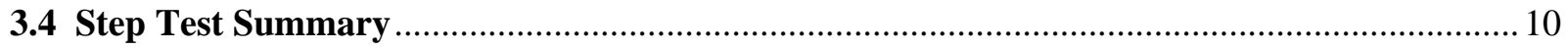

3.5 Relative Timing Summary …………………………………………………………….... 12

4.0 DETAILS OF TEST RESULTS AND MEASUREMENT PLOTS ………………………................ 13

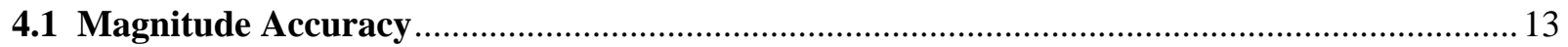

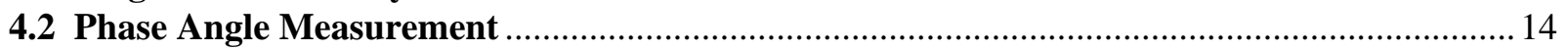

4.2.1 Phase Angle at Nominal Frequency ………………………………………………….... 14

4.2.2 Phase Angle Measurement Variation with Frequency ................................................................ 14

4.3 Frequency Response - Measurement Band ……………………………………………..... 15

4.4 Frequency Accuracy …………………………………………………………………... 16

4.5 Measurement of Unbalanced Signals ……………………………………………………... 18

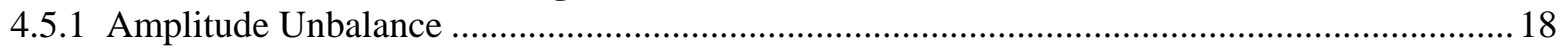

4.5.2 Phase Unbalance ……………………………………………………………………... 19

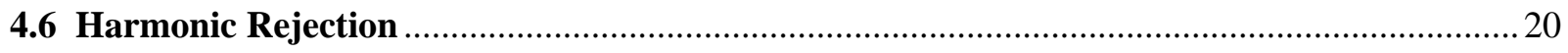

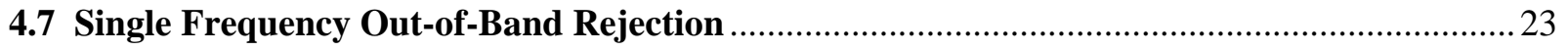

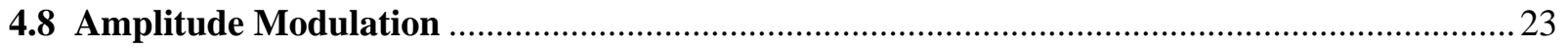

4.8.1 Amplitude Modulation with Nominal Frequency …………………………………………...2 23

4.8.2 Amplitude Modulation with off-Nominal Frequency ………………………………………...2 25

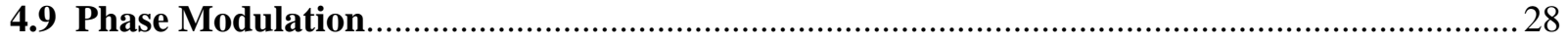

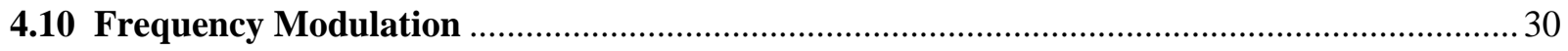

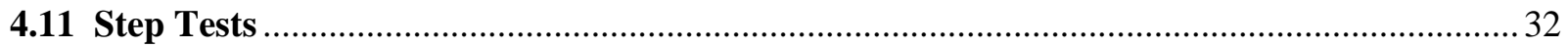

4.11.1 Amplitude Step Test ……………………………………........................................ 32

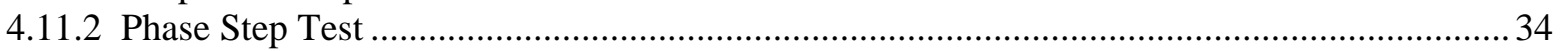

4.11.3 Frequency Step Test.................................................................................................. 35

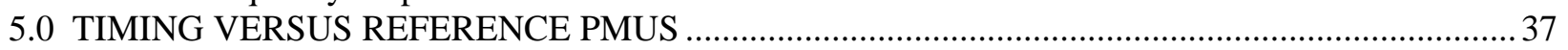

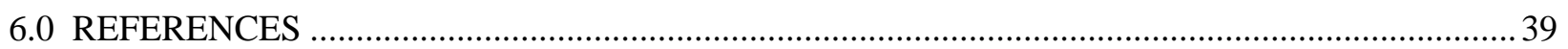

APPENDIX A: WECC Requirements for Monitoring Equipment.............................................................. 41

APPENDIX B: IEEE Guidelines for PMU Performance......................................................................... 45

APPENDIX C: PMU Types Used in Performance Comparisons .................................................................. 47

C.1 General Characteristics of the Macrodyne 1690M ……………………………………...... 47

C.2 General Characteristics of the ABB RES521 …………………………………………….... 50 


\section{Figures}

Figure 1. SEL 421 PMU vs. WECC Filtering Standard ....................................................................... 3

Figure 2. PMU Frequency Signals for 1.4 Hz Amplitude Modulation ................................................. 3

Figure 3. Steady -State Magnitude Response for Voltage ................................................................ 13

Figure 4. Steady-State Magnitude Response for Current ….............................................................. 13

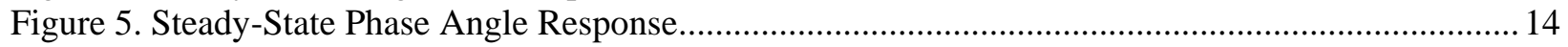

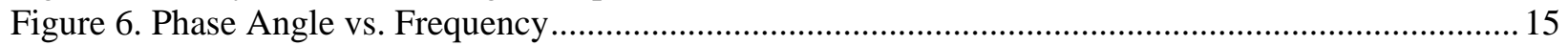

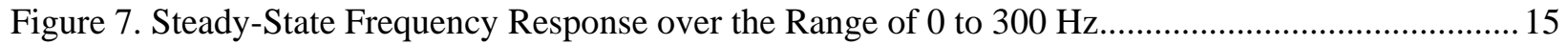

Figure 8. Steady -State Frequency Response over the Pass Band .......................................................... 16

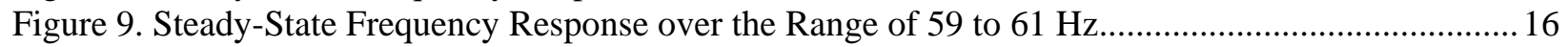

Figure 10. Frequency Measurement Error over the Reporting Range of 45 to $70 \mathrm{~Hz}$........................... 17

Figure 11. Frequency Measurement Error over the Range of 55 to $65 \mathrm{~Hz}$........................................ 17

Figure 12. Frequency Measurement Error over the Reporting Range of 59 to $61 \mathrm{~Hz}$............................ 17

Figure 13. Unbalanced Amplitude Response, Narrow Band with Frequency Compensation on ...............18

Figure 14. Unbalanced Amplitude Response, Fast Response with Frequency Compensation off ..............18

Figure 15. Unbalanced Amplitude Response at $60 \mathrm{~Hz}$....................................................................... 19

Figure 16. Unbalanced Phase Response, Narrow Band with Frequency Compensation on ....................... 19

Figure 17. Unbalanced Phase Response, Fast Response with Frequency Compensation off ......................20

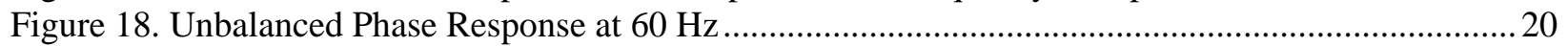

Figure 19. Response to Harmonic Distortion, Narrow Band, Frequency Compensation on .......................21

Figure 20. Response to Harmonic Distortion, Narrow Band, Frequency Compensation off......................21

Figure 21. Response to Harmonic Distortion, Fast Response, Frequency Compensation on.....................22

Figure 22. Response to Harmonic Distortion, Fast Response, Frequency Compensation off .....................22

Figure 23. Response to Harmonic Distortion at $60 \mathrm{~Hz}$...................................................................... 22

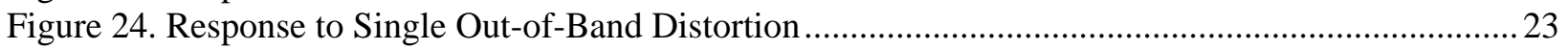

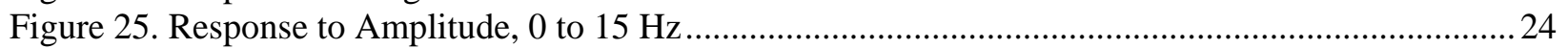

Figure 26. Amplitude Modulation Response, 15 to $180 \mathrm{~Hz}$................................................................24

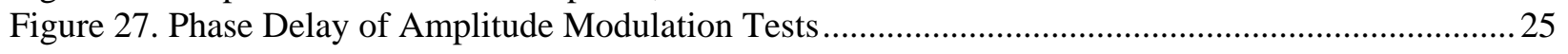

Figure 28. Phase Angle of Amplitude Modulation Tests........................................................................ 25

Figure 29. Off-Nominal Amplitude Modulation Response with the Setting of Fast Response, Frequency

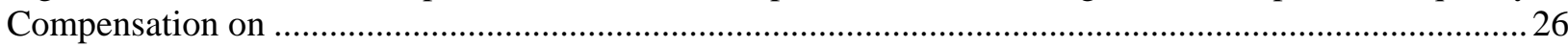

Figure 30. Off-Nominal Amplitude Modulation Response with the Setting of Fast Response, Frequency

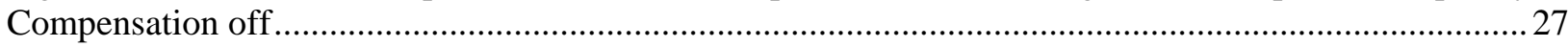

Figure 31. Off-Nominal Amplitude Modulation Response with the Setting of Narrow Band Response,

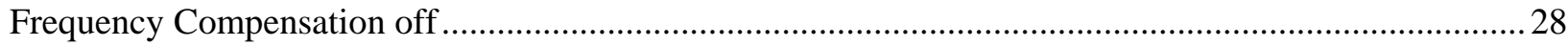

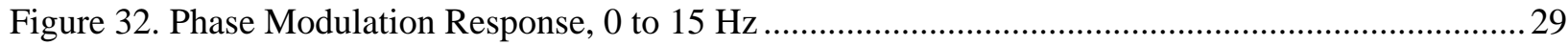

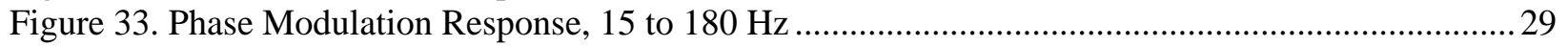

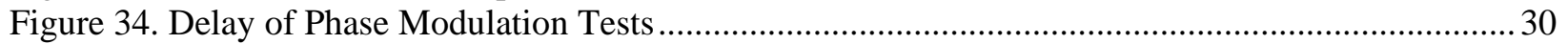

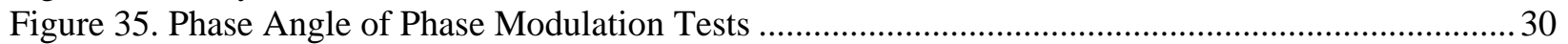

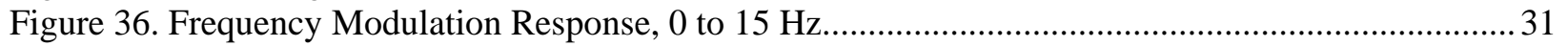

Figure 37. Frequency Modulation Response, 15-180 Hz .................................................................. 31

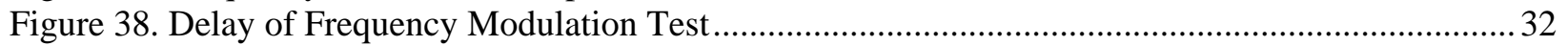

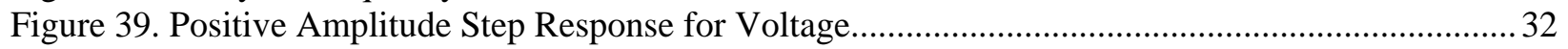

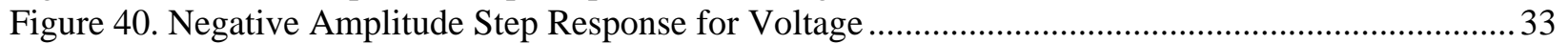

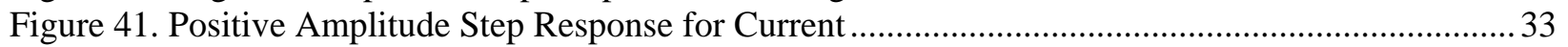

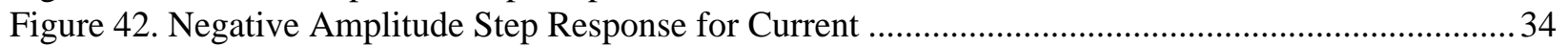

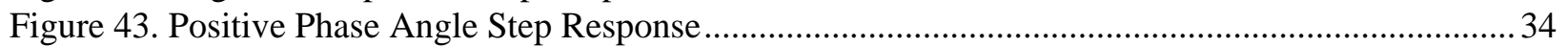

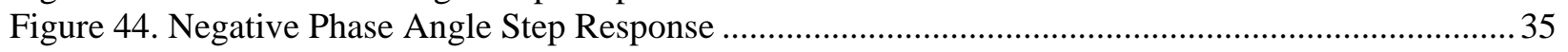

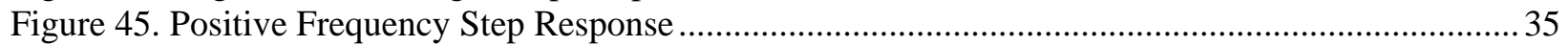


Figure 46. Negative Frequency Step Response . 36

Figure 47. PMU Frequency Signals for 1.4 Hz Amplitude Modulation, Test Series A ...........................38

Figure 48. Relative Phase of PMU Frequency Signals for 1.4 Hz Amplitude Modulation, Test Series A 38

Figure 49. $12 \mathrm{~Hz}$ Butterworth Filter vs. WECC Filtering Standard........................................................... 42

Figure 50. $6 \mathrm{~Hz}$ Butterworth Filter vs. WECC Filtering Standard........................................................ 43

Figure 51. Two Stage Fourier Filter Approximating that of the Macrodyne 1690M PMU..................... 47

Figure 52. Model PMU_Box1X4X30 vs. Measured Response for the Macrodyne 1690M.................... 48

Figure 53. Macrodyne 1690M vs. WECC Filtering Standard ............................................................... 48

Figure 54. Modulation of Balanced 60.06 Hz Carrier, Macrodyne 1690M............................................. 49

Figure 55. Modulation of Balanced 60.06 Hz Carrier, PMU Model PMU_Box1\&4X30 ....................... 49

Figure 56. ABB RES4521 Filter Options (Adaptive Logic off) …......................................................... 50

Figure 57. PMU Voltage Response to AM Modulation Scan:............................................................. 51

Figure 58. PMU Frequency Response to AM Modulation Scan: .......................................................... 51 


\section{Tables}

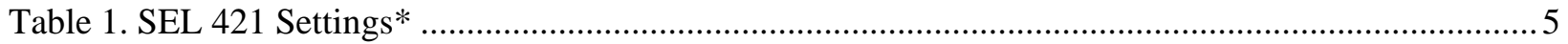

Table 2. Measurement Accuracy with the Setting of Narrow Band, Frequency Compensation on .............. 6

Table 3. Measurement Accuracy with the Setting of Narrow Band, Frequency Compensation off............. 6

Table 4. Measurement Accuracy with the Setting of Fast Response, Frequency Compensation on ........... 7

Table 5. Measurement Accuracy with the Setting of Fast Response, Frequency Compensation off ........... 7

Table 6. Harmonic and Out-of-Band Signal Rejection Summary with the Setting of Narrow Band,

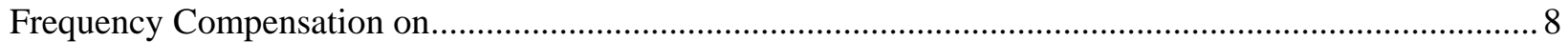

Table 7. Harmonic and Out-of-Band Signal Rejection Summary with the Setting of Narrow Band,

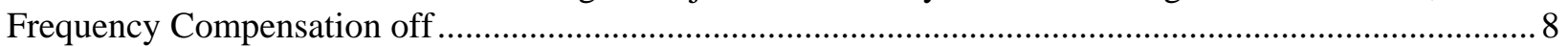

Table 8. Harmonic and Out-of-Band Signal Rejection Summary with the Setting of Fast Response,

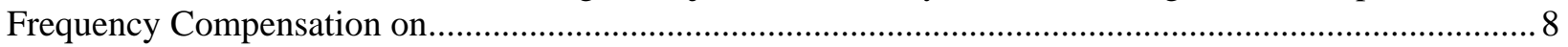

Table 9. Harmonic and Out-of-Band Signal Rejection Summary with the Setting of Fast Response,

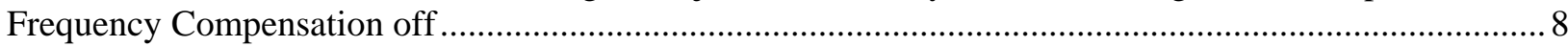
Table 10. Modulated Signal Test Summary in the Pass Band with the Setting of Narrow Band, Frequency Compensation on - Pass Band

Table 11. Modulated Signal Test Summary in the Pass Band with the Setting of Narrow Band, Frequency

Compensation on - Out-of-Band Rejection.

Table 12. Modulated Signal Test Summary in the Pass Band with the Setting of Narrow Band, Frequency

Compensation off - Pass Band .

Table 13. Modulated Signal Test Summary in the Pass Band with the Setting of Narrow Band, Frequency

Compensation off - Out-of-Band Rejection ............................................................................................ 9

Table 14. Modulated Signal Test Summary in the Pass Band with the Setting of Fast Response,

Frequency Compensation on - Pass Band 10

Table 15. Modulated Signal Test Summary in the Pass Band with the Setting of Fast Response,

Frequency Compensation on - Out-of-Band Rejection... 10

Table 16. Modulated Signal Test Summary in the Pass Band with the Setting of Fast Response, Frequency Compensation off - Pass Band 10

Table 17. Modulated Signal Test Summary in the Pass Band with the Setting of Fast Response, Frequency Compensation off - Put-of-Band Rejection

Table 18. Step Test Summary with the Setting of Narrow Band, Frequency Compensation on .................11

Table 19. Step Test Summary with the Setting of Narrow Band, Frequency Compensation off ...............11

Table 20. Step Test Summary with the Setting of Fast Response, Frequency Compensation on................11

Table 21. Step Test Summary with the Setting of Fast Response, Frequency Compensation off ...............12

Table 22. Relative Delays of PMU Frequency Signals for 1.4 Hz Angle Modulation, Test Series A ....... 12

Table 23. Relative Delays of PMU Frequency Signals for 1.4 Hz Angle Modulation, Test Series A .......37

Table 24. Relative Delays of PMU Frequency Signals for $0.28 \mathrm{~Hz}$ Angle Modulation, Test Series A .... 37

Table 25 Influence Quantities and Allowable Error Limits for Compliance Levels 0-1 _...................... 45 


\subsection{PREFACE}

Technology evaluation is a major element of the wide area measurement system (WAMS) effort to enhance measurement-based information resources for managing large power grids (Bonneville Power Administration 1999, Hauer et al. 2007). Critical measurement devices, such as phasor measurement units (PMUs) and other advanced transducers, are evaluated through a combination of model studies, laboratory tests, and performance comparisons under field conditions (Martin 1992, Hauer 1996, Hauer, et al. 2004).

New or revised PMU types are often tested in tandem with other PMU types (or PMU models) that are well understood, and in common use. This provides cross calibration data that may be needed to adjust some measurements to achieve better consistency among different instrument types (Hauer 2001). Also, by comparing results from the unit against those of earlier tests, one can readily establish that the present tests are being performed consistently.

Reference units for the Western Electricity Coordinating Council (WECC) purposes are usually Macrodyne 1690M, a simulation model (called PMU_Box1X4X30) that closely replicates dynamic response of the 1690M (Hauer et al 2004), and the ABB RES521. As mentioned above, we use them as reference units because they are wellunderstood PMU types and models. The use of them as reference units does not imply any superior performance over others. Bonneville Power Administration (BPA) installations of this ABB unit usually set it for filter \#2 and frequency tracking on.

Laboratory evaluation of PMU performance has the following immediate objectives:

A. Determine whether the PMU provides data of acceptable quality across a sufficiently broad frequency range.

B. Determine PMU response in sufficient detail that its behavior can be predicted over a full range of application conditions, many of which cannot be reproduced with laboratory tests.

Laboratory tests should characterize PMU performance to the degree that, when needed, an approximate model can be developed for its signal processing algorithm(s). Specific attention must also be given to performance measures laid out in established guidelines or standards, as established by the WECC and the Institute of Electrical and Electronics Engineers (IEEE) (Martin 2004, IEEE Standard 2006). 


\subsection{INTRODUCTION}

The laboratory tests described in this report were performed with a standard relay test set using recorded files of precisely generated test signals. The identification of specific vendor's equipment/software, etc. is for research documentation only and does not constitute an endorsement of these items. The test set provides test signals at a level and in a format suitable for input to a PMU that accurately reproduces the signals in both signal amplitude and timing. Test set outputs are checked to confirm the accuracy of the output signal. The recorded signals include both current and voltage waveforms and a digital timing track used to relate the PMU measured value with the test signal. Test signals include steady-state waveforms to test amplitude, phase, and frequency accuracy; modulated signals to determine measurement and rejection bands; and step tests to determine timing and response accuracy. Relative timing and waveform distortion can also be extracted from the modulated signals through Prony analysis. Additional tests are included as necessary to fully describe the PMU operation. Testing is done with a BPA phasor data concentrator (PDC), which provides communication support and monitors data input for dropouts and data errors.

An overview of dynamic performance for the SEL 421 is provided by Figure 1, which shows that narrow band filtering for this unit is very close to satisfying the WECC standard. This is not the case for "fast response" filtering, where signal components above the Nyquist frequency produce substantial outputs that are easily mistaken for types of system behavior other than what they actually represent.

PMUs of different types appear to use a wide variety of algorithms to produce their output signals for local frequency (FreqL). The timing of instrument level frequency signals is often found to be inconsistent between PMUs of different types, between PMUs of the same type that have been set differently, and between the frequency signal and the associated phasors.

Figure 2 compares these signals for the SEL 421 against those of the ABB reference unit. Frequencies estimated from voltage angles (shown as EFreqL_FD) are closely consistent, which must be true for the voltage phasors themselves. This is not true for the direct frequency measurements shown as FreqL, which later results show to lag the voltage phasors by up to 100 msec. Such discrepancies seem typical for all PMU types, so measured frequencies are best replaced by consistent estimates when a wide area profile of system behavior is needed. 


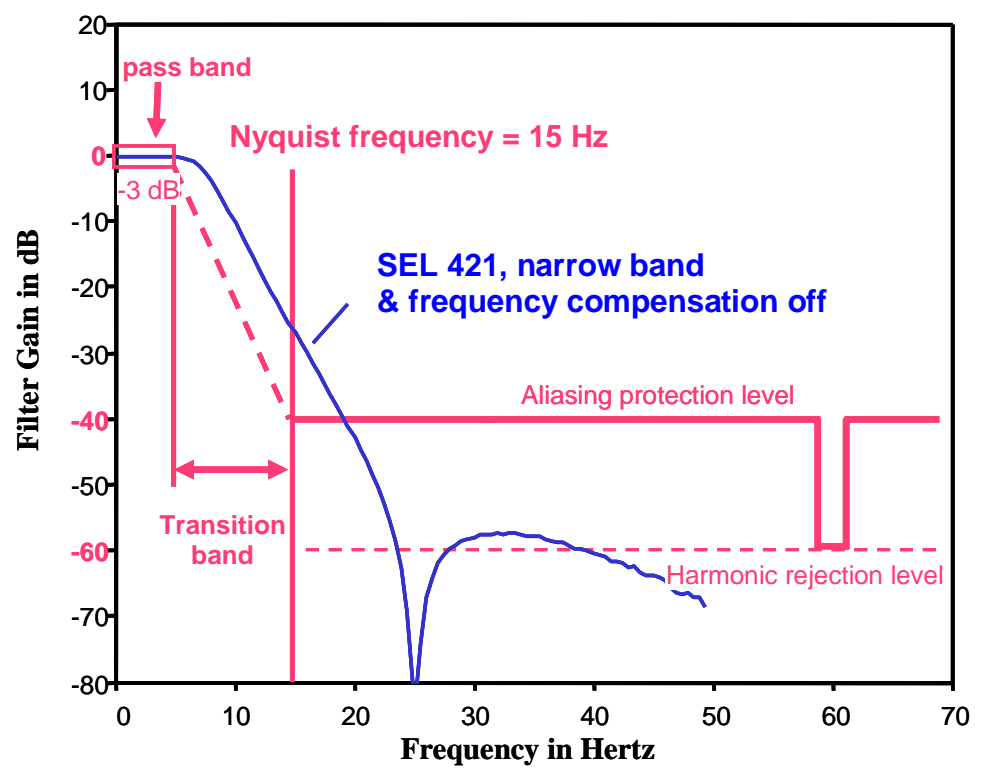

Figure 1. SEL 421 PMU vs. WECC Filtering Standard (Narrow band with frequency compensation off)

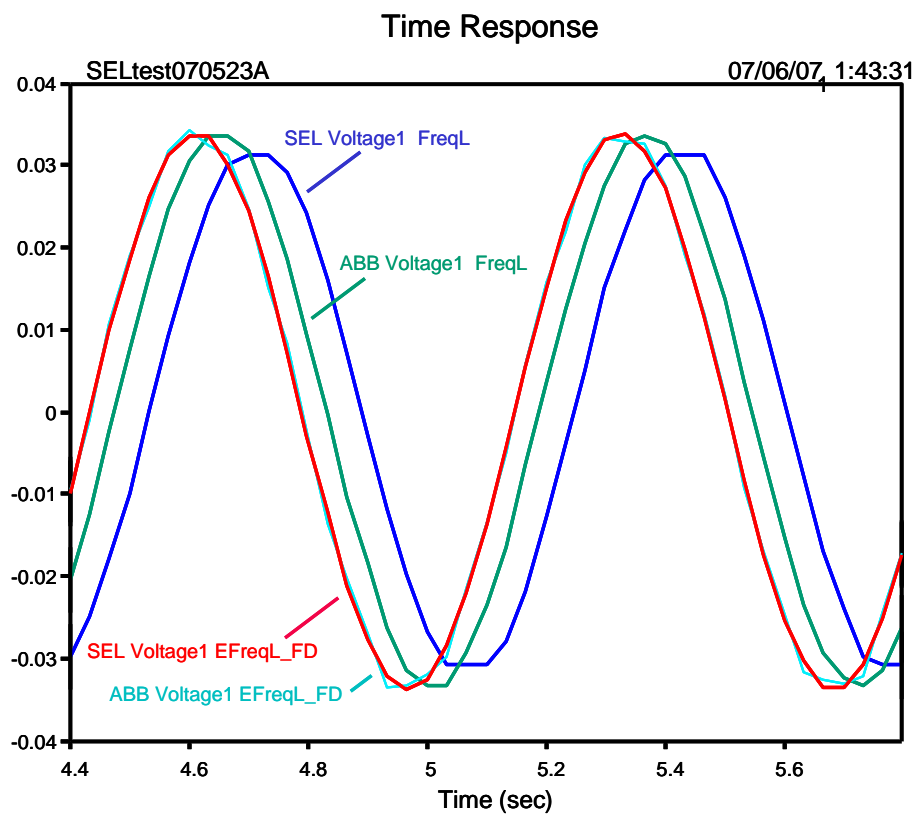

Figure 2. PMU Frequency Signals for $1.4 \mathrm{~Hz}$ Amplitude Modulation

(Narrow band with frequency compensation off)

An initial test of SEL 421 PMU was performed in 2005. This is a re-test after SEL 421 PMU was updated. All four setting combinations are examined, in test series A through D:

Test Series A: Narrow Band with Frequency Compensation off Test Series B: Narrow Band with Frequency Compensation on Test Series C: Fast Response with Frequency Compensation off Test Series D: Fast Response with Frequency Compensation on 
Other settings of SEL 421, shown in Table 1, remain the same throughout the test. $\quad\left({ }^{*}\right)$ value denotes fields for the settings defined above. The ABB RES521 unit was used as a reference was set to filter \#2, with frequency tracking on.

The summary in Section 3 provides basic results for all four SEL setting combinations, followed by detailed test results and plots. 
Table 1. SEL 421 Settings*

\begin{tabular}{|c|c|c|}
\hline Setting & Description & Value \\
\hline EPMU & $\begin{array}{l}\text { Enable Synchronized Phasor Measurement (Y, } \\
\mathrm{N})\end{array}$ & $\mathrm{Y}$ \\
\hline MFRMT & Message Format (C37.118, FM) & C37.118 \\
\hline MRATE & $\begin{array}{l}\text { Messages per Second }\{1,2,5,10,25 \text {, or } 50 \\
\text { when NFREQ }:=50\}\{1,2,4,5,10,12,15,20 \text {, } \\
30 \text {, or } 60 \text { when NFREQ }:=60\}\end{array}$ & 30 \\
\hline PMAPP & $\begin{array}{l}\text { PMU Application ( } \mathrm{F}=\text { Fast Response, } \mathrm{N}= \\
\text { Narrow Bandwidth) }\end{array}$ & * \\
\hline PHCOMP & Frequency-Based Phasor Compensation $(\mathrm{Y}, \mathrm{N})$ & $*$ \\
\hline PMSTN & Station Name (16 characters) & $\begin{array}{l}\text { STATION } \\
\text { A }\end{array}$ \\
\hline PMID & PMU Hardware ID (1-65534) & 1 \\
\hline $\begin{array}{l}\text { PHDATA } \\
\mathrm{V}\end{array}$ & Phasor Data Set, Voltages (V1, ALL, NA) & V1 \\
\hline VCOMP & $\begin{array}{l}\text { Voltage Angle Compensation Factor ( }-179.99 \\
\text { to } 180 \text { degrees) }\end{array}$ & 0 \\
\hline PHDATAI & Phasor Data Set, Currents (I1, ALL, NA) & I1 \\
\hline PHCURRc & Current Source (IW, IX, BOTH, COMB) & IW \\
\hline IWCOMP & $\begin{array}{l}\text { IW Angle Compensation Factor ( }-179.99 \text { to } \\
180 \text { degrees) }\end{array}$ & 0 \\
\hline IXCOMP & $\begin{array}{l}\text { IX Angle Compensation Factor (-179.99 to } 180 \\
\text { degrees) }\end{array}$ & 0 \\
\hline PHNRd & $\begin{array}{l}\text { Phasor Numeric Representation ( } \mathrm{I}=\text { Integer, } \mathrm{F} \\
\text { = Floating point) }\end{array}$ & I \\
\hline PHFMTd & $\begin{array}{l}\text { Phasor Format }(\mathrm{R}=\text { Rectangular coordinates, } \mathrm{P} \\
=\text { Polar coordinates })\end{array}$ & $\mathrm{R}$ \\
\hline FNR & $\begin{array}{l}\text { Frequency Numeric Representation ( } \mathrm{I}= \\
\text { Integer, } \mathrm{F}=\text { Float) }\end{array}$ & $\mathrm{I}$ \\
\hline NUMANA & Number of Analog Values (0-8) & 0 \\
\hline NUMDSW & Number of 16-bit Digital Status Words $(0,1,2)$ & 1 \\
\hline TREA1 & Trigger Reason Bit 1 (SELogic Equation) & NA \\
\hline TREA2 & Trigger Reason Bit 2 (SELogic Equation) & NA \\
\hline TREA3 & Trigger Reason Bit 3 (SELogic Equation) & NA \\
\hline TREA4 & Trigger Reason Bit 4 (SELogic Equation) & NA \\
\hline PMTRIG & Trigger (SELogic Equation) & NA \\
\hline
\end{tabular}

*: During the course of the test, only SEL 421 phasor functions are active. All other functions including relay functions are NOT part of the test and are NOT in operation. 


\subsection{SUMMARY OF TEST RESULTS}

This section summarizes the performance of the SEL 421 PMU under all the tests performed.

\subsection{Measurement Accuracy Summary}

Measurement accuracy tests determine the accuracy of the PMU under a variety of steady-state signal conditions. The signal is changed in value, held for a period of time to be sure all measurements have settled to a steady-state value, and then the PMU measurement is recorded for comparison with the value of the generated signal. The results of measurement accuracy tests are shown in Table 2 to Table 5.

Table 2. Measurement Accuracy with the Setting of Narrow Band, Frequency Compensation on

\begin{tabular}{|l|l|l|l|c|c|}
\cline { 3 - 6 } \multicolumn{2}{c|}{} & \multicolumn{2}{l|}{ Results - absolute error } & \multicolumn{2}{l|}{ C37.118 compliance } \\
\hline Test & Range, nominal & Typical & Full range & Level 0 & Level 1 \\
\hline \hline Voltage magnitude & $0.1-1.2 \mathrm{PU}, 70 \mathrm{~V}$ & $0.091 \%$ & $0.125 \%$ & $\mathrm{Y}$ & $\mathrm{Y}$ \\
\hline Current magnitude & $0.1-2.0 \mathrm{PU}, 3 \mathrm{~A}$ & $0.356 \%$ & $0.397 \%$ & $\mathrm{Y}$ & $\mathrm{Y}$ \\
\hline Voltage phase angle & $-50-300^{\circ}, 0^{\circ}$ & $0.003^{\circ}$ & $0.007^{\circ}$ & $\mathrm{Y}$ & $\mathrm{Y}$ \\
\hline Phase angle vs. frequency & $55-65 \mathrm{~Hz}, 60 \mathrm{~Hz}$ & $\mathrm{NA}^{* * *}$ & $0.292^{\circ}$ & $-* *$ & - \\
\hline Frequency response (mag) & $55-65 \mathrm{~Hz}, 60 \mathrm{~Hz}$ & $\mathrm{NA}$ & $0.238 \%$ & $\mathrm{Y}$ & $\mathrm{Y}$ \\
\hline Frequency measurement & $45-75 \mathrm{~Hz}, 60 \mathrm{~Hz}$ & $0.70 \mathrm{mHz}$ & $5.0 \mathrm{mHz}$ & - & - \\
\hline Unbalanced magnitude & $0.8-1.2 \mathrm{PU}, 1 \mathrm{PU}$ & $0.088 \%$ & $0.101 \%$ & - & - \\
\hline Unbalanced phase & $0-360^{\circ}, 120^{\circ}$ & $0.052^{\circ}$ & $0.103^{\circ}$ & - & - \\
\hline
\end{tabular}

* PMU only reported frequency values from 48 to $72 \mathrm{~Hz}$ for this filter setting.

** “-” denotes that the test is not included in C37.118 criteria.

*** "NA" denotes that the item is not applicable.

Table 3. Measurement Accuracy with the Setting of Narrow Band, Frequency Compensation off

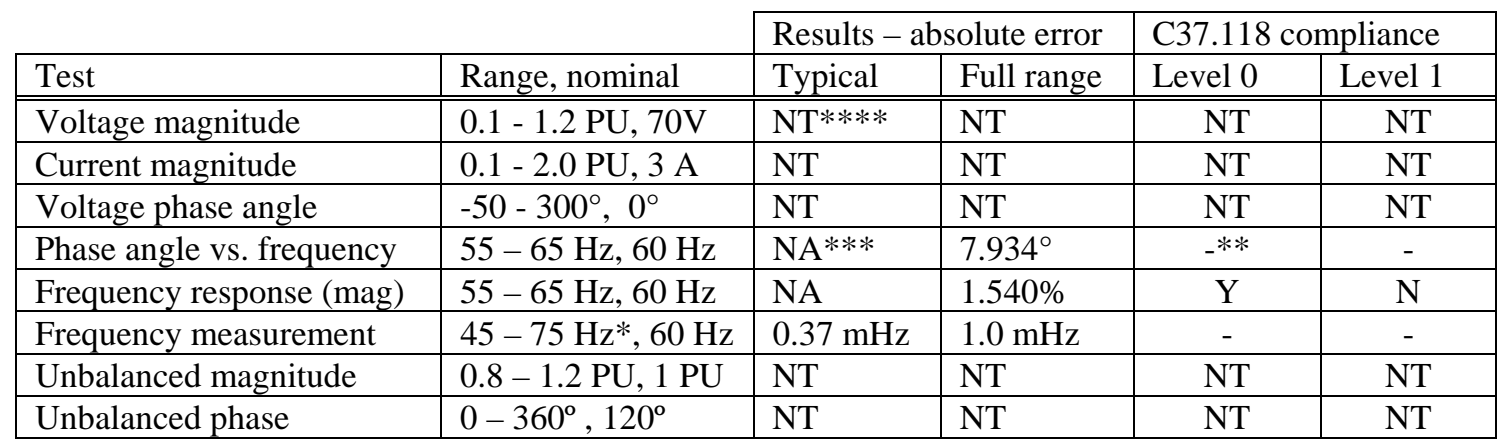

* PMU only reported frequency values from 48 to $72 \mathrm{~Hz}$ for this filter setting.

** “-" denotes that the test is not included in C37.118 criteria.

*** "NA" denotes that the item is not applicable.

**** "NT" denotes that the test is not performed as the performance is same as that in Table 2 above. 
Table 4. Measurement Accuracy with the Setting of Fast Response, Frequency Compensation on

\begin{tabular}{|l|l|l|l|c|c|}
\cline { 3 - 6 } \multicolumn{2}{c|}{} & \multicolumn{2}{l|}{ Results - absolute error } & \multicolumn{2}{l|}{ C37.118 compliance } \\
\hline Test & Range, nominal & Typical & Full range & Level 0 & Level 1 \\
\hline \hline Voltage magnitude & $0.1-1.2 \mathrm{PU}, 70 \mathrm{~V}$ & NT**** & NT & NT & NT \\
\hline Current magnitude & $0.1-2.0 \mathrm{PU}, 3 \mathrm{~A}$ & NT & NT & NT & NT \\
\hline Voltage phase angle & $-50-300^{\circ}, 0^{\circ}$ & NT & NT & NT & NT \\
\hline Phase angle vs. frequency & $55-65 \mathrm{~Hz}, 60 \mathrm{~Hz}$ & NA*** & $0.074^{\circ}$ & $-* *$ & - \\
\hline Frequency response (mag) & $55-65 \mathrm{~Hz}, 60 \mathrm{~Hz}$ & NA & $0.105 \%$ & Y & Y \\
\hline Frequency measurement & $45-75 \mathrm{~Hz}, 60 \mathrm{~Hz}$ & $0.23 \mathrm{mHz}$ & $1.0 \mathrm{mHz}$ & - & - \\
\hline Unbalanced magnitude & $0.8-1.2 \mathrm{PU}, 1 \mathrm{PU}$ & NT & NT & NT & NT \\
\hline Unbalanced phase & $0-360^{\circ}, 120^{\circ}$ & NT & NT & NT & NT \\
\hline
\end{tabular}

* PMU only reported frequency values from 48 to $72 \mathrm{~Hz}$ for this filter setting.

** “-" denotes that the test is not included in C37.118 criteria.

*** "NA" denotes that the item is not applicable.

**** "NT" denotes that the test is not performed as the performance is same as that in Table 5 below.

Table 5. Measurement Accuracy with the Setting of Fast Response, Frequency Compensation off

\begin{tabular}{|l|l|l|l|c|c|}
\cline { 3 - 6 } \multicolumn{2}{c|}{} & \multicolumn{3}{l|}{ Results - absolute error } & \multicolumn{2}{l|}{ C37.118 compliance } \\
\hline Test & Range, nominal & Typical & Full range & Level 0 & Level 1 \\
\hline \hline Voltage magnitude & $0.1-1.2 \mathrm{PU}, 70 \mathrm{~V}$ & $0.081 \%$ & $0.129 \%$ & $\mathrm{Y}$ & $\mathrm{Y}$ \\
\hline Current magnitude & $0.1-2.0 \mathrm{PU}, 3 \mathrm{~A}$ & $0.346 \%$ & $0.395 \%$ & $\mathrm{Y}$ & $\mathrm{Y}$ \\
\hline Voltage phase angle & $-50-300^{\circ}, 0^{\circ}$ & $0.007^{\circ}$ & $0.011^{\circ}$ & $\mathrm{Y}$ & $\mathrm{Y}$ \\
\hline Phase angle vs. frequency & $55-65 \mathrm{~Hz}, 60 \mathrm{~Hz}$ & $\mathrm{NA} * * *$ & $1.024^{\circ}$ & $-* *$ & - \\
\hline Frequency response (mag) & $55-65 \mathrm{~Hz}, 60 \mathrm{~Hz}$ & $\mathrm{NA}$ & $0.320 \%$ & $\mathrm{Y}$ & $\mathrm{Y}$ \\
\hline Frequency measurement & $45-75 \mathrm{~Hz}, 60 \mathrm{~Hz}$ & $0.20 \mathrm{mHz}$ & $1.0 \mathrm{mHz}$ & - & - \\
\hline Unbalanced magnitude & $0.8-1.2 \mathrm{PU}, 1 \mathrm{PU}$ & $0.067 \%$ & $0.084 \%$ & - & - \\
\hline Unbalanced phase & $0-360^{\circ}, 120^{\circ}$ & $0.052^{\circ}$ & $0.098^{\circ}$ & - & - \\
\hline
\end{tabular}

* PMU only reported frequency values from $48-72 \mathrm{~Hz}$ for this filter setting.

** “-” denotes that the test is not included in C37.118 criteria.

*** "NA" denotes that the item is not applicable or the test was not performed.

\subsection{Harmonic and Out-of-Band Signal Rejection Summary}

Rejection (filtering) of signal harmonics and signals that are out of the frequency band limited by the Nyquist sampling rate is critical to obtaining accurate measurements. Harmonic rejection tests are performed with a single harmonic at a time from the $2^{\text {nd }}(120 \mathrm{~Hz})$ to the $50^{\text {th }}(3000 \mathrm{~Hz})$ harmonic. The harmonic level is set at $10 \%$ of the fundamental set. Out-of-band signal rejection presented here is the maximum interference caused by either a single frequency interfering signal or amplitude modulation of the $60-\mathrm{Hz}$ power signal. Single frequency interference tests use a single additive tone (frequency) with $10 \%$ of the amplitude of the fundamental set at integer frequency values outside of the Nyquist band from 1 to $180 \mathrm{~Hz}$. For a 30 frame/sec data rate, these test frequencies will be 1 to 45 and 75 to $180 \mathrm{~Hz}$ (inclusive). Amplitude modulation is with a sine wave at a level of $10 \%$ the fundamental set at frequencies from the Nyquist frequency to $180 \mathrm{~Hz}$. For a 30-frame/sec data rate, these test frequencies will be 15 to $180 \mathrm{~Hz}$ (inclusive). Table 6 to Table 9 show the results of harmonic and out-of-band tests. 
Table 6. Harmonic and Out-of-Band Signal Rejection Summary with the Setting of Narrow Band, Frequency Compensation on

\begin{tabular}{|l|l|l|l|c|c|}
\cline { 3 - 6 } \multicolumn{2}{c|}{} & \multicolumn{2}{l|}{ Results - absolute error } & \multicolumn{2}{l|}{$\begin{array}{l}\text { C37.118 } \\
\text { compliance }\end{array}$} \\
\hline Test & Range & Typical & Full range & Level 0 & Level 1 \\
\hline \hline Harmonic rejection & Harmonics $120-3000 \mathrm{~Hz}$ & $-36.26 \mathrm{~dB}$ & $-32.96 \mathrm{~dB}$ & Y & Y \\
\hline Out-of-band, single freq & $1-180 \mathrm{~Hz}$ & NA & $-26.06 \mathrm{~dB}$ & Y & Y \\
\hline Out-of-band, modulated & $15-180 \mathrm{~Hz}$ & NA & $-29.43 \mathrm{~dB}$ & Y & Y \\
\hline
\end{tabular}

Table 7. Harmonic and Out-of-Band Signal Rejection Summary with the Setting of Narrow Band, Frequency Compensation off

\begin{tabular}{|l|l|l|l|c|c|}
\cline { 3 - 6 } \multicolumn{2}{c|}{} & \multicolumn{2}{l|}{ Results - absolute error } & \multicolumn{2}{l|}{$\begin{array}{l}\text { C37.118 } \\
\text { compliance }\end{array}$} \\
\hline Test & Range & Typical & Full range & Level 0 & Level 1 \\
\hline \hline Harmonic rejection & Harmonics $120-3000 \mathrm{~Hz}$ & $-33.07 \mathrm{~dB}$ & $-27.11 \mathrm{~dB}$ & Y & Y \\
\hline Out-of-band, single freq & $1-180 \mathrm{~Hz}$ & NA & $-26.06 \mathrm{~dB}$ & Y & Y \\
\hline Out-of-band, modulated & $15-180 \mathrm{~Hz}$ & NA & $-29.44 \mathrm{~dB}$ & Y & Y \\
\hline
\end{tabular}

Table 8. Harmonic and Out-of-Band Signal Rejection Summary with the Setting of Fast Response, Frequency Compensation on

\begin{tabular}{|c|c|c|c|c|c|}
\hline \multirow[b]{2}{*}{ Test } & \multirow[b]{2}{*}{ Range } & \multicolumn{2}{|c|}{ Results - absolute error } & \multicolumn{2}{|c|}{$\begin{array}{l}\text { C37.118 } \\
\text { compliance }\end{array}$} \\
\hline & & Typical & Full range & Level 0 & Level 1 \\
\hline Harmonic rejection & Harmonics $120-3000 \mathrm{~Hz}$ & $-41.72 \mathrm{~dB}$ & $-26.16 \mathrm{~dB}$ & $\mathrm{Y}$ & $\mathrm{Y}$ \\
\hline Out-of-band, single freq & $1-180 \mathrm{~Hz}$ & NA & $-4.671 \mathrm{~dB}$ & $\mathrm{Y}$ & $\mathrm{N}$ \\
\hline Out-of-band, modulated & $15-180 \mathrm{~Hz}$ & NA & $-5.494 \mathrm{~dB}$ & $\mathrm{Y}$ & $\mathrm{N}$ \\
\hline
\end{tabular}

Table 9. Harmonic and Out-of-Band Signal Rejection Summary with the Setting of Fast Response, Frequency Compensation off

\begin{tabular}{|l|l|l|l|c|c|}
\cline { 3 - 6 } \multicolumn{2}{c|}{} & \multicolumn{2}{l|}{ Results - absolute error } & \multicolumn{2}{l|}{$\begin{array}{l}\text { C37.118 } \\
\text { compliance }\end{array}$} \\
\hline Test & Range & Typical & Full range & Level 0 & Level 1 \\
\hline \hline Harmonic rejection & Harmonics $120-3000 \mathrm{~Hz}$ & $-42.21 \mathrm{~dB}$ & $-26.28 \mathrm{~dB}$ & Y & Y \\
\hline Out-of-band, single freq & $1-180 \mathrm{~Hz}$ & NA & $-4.682 \mathrm{~dB}$ & Y & N \\
\hline Out-of-band, modulated & $15-180 \mathrm{~Hz}$ & NA & $-5.494 \mathrm{~dB}$ & Y & N \\
\hline
\end{tabular}

\subsection{Modulated Signal Test Summary}

Modulated signals emulate power system equipment interactions and small signal oscillations. They provide a realistic way to assess the overall measurement capability and reject out-of-band interference. The frequency response of the demodulated signal determines phasor and frequency measurement pass bands. The pass band is given for $0.5 \mathrm{~dB}$, a realistic measurement range, and $3 \mathrm{~dB}$, a traditional bandwidth showing wide variation. Most PMUs exhibit a constant delay in the modulated signal, which gives a linear phase response. As summarized in Table 10 to Table 17, average and peak variation of delay is presented for easy measurement adjustment, and the measured phase angle response at 1 and $5 \mathrm{~Hz}$ is presented for easy comparison. 
Table 10. Modulated Signal Test Summary in the Pass Band with the Setting of Narrow Band, Frequency Compensation on - Pass Band

\begin{tabular}{|l|l|l|l|l|l|}
\hline Test & Test type & Range & Avg delay & $\begin{array}{l}\text { Delay } \\
\text { deviatio } \\
\text { n }\end{array}$ & $\begin{array}{l}\text { Phase angle, } \\
1 \mathrm{~Hz} \& 5 \mathrm{~Hz}\end{array}$ \\
\hline \hline Amplitude modulation & Passband, 3 dB & $0.1-7.74 \mathrm{~Hz}$ & $2.243 \mathrm{~ms}$ & $10.60 \mathrm{~ms}$ & $0^{\circ} \& 8^{\circ}$ \\
\hline & Passband, $0.5 \mathrm{~dB}$ & $0.1-5.99 \mathrm{~Hz}$ & $1.260 \mathrm{~ms}$ & $6.148 \mathrm{~ms}$ & $0^{\circ} \& 8^{\circ}$ \\
\hline Phase modulation & Passband, $3 \mathrm{~dB}$ & $0.1-7.73 \mathrm{~Hz}$ & $2.243 \mathrm{~ms}$ & $10.60 \mathrm{~ms}$ & $0^{\circ} \& 8^{\circ}$ \\
\hline & Passband, $0.5 \mathrm{~dB}$ & $0.1-5.94 \mathrm{~Hz}$ & $1.260 \mathrm{~ms}$ & $6.148 \mathrm{~ms}$ & $0^{\circ} \& 8^{\circ}$ \\
\hline Frequency modulation & Passband, 3 dB & $0.1-3.18 \mathrm{~Hz}$ & $83.61 \mathrm{~ms}$ & $1.108 \mathrm{~ms}$ & $30^{\circ} \& 160^{\circ}$ \\
\hline & Passband, $0.5 \mathrm{~dB}$ & $0.1-1.49 \mathrm{~Hz}$ & $83.40 \mathrm{~ms}$ & $0.551 \mathrm{~ms}$ & $30^{\circ} \& 160^{\circ}$ \\
\hline
\end{tabular}

Table 11. Modulated Signal Test Summary in the Pass Band with the Setting of Narrow Band, Frequency Compensation on - Out-of-Band Rejection

\begin{tabular}{|l|l|l|l|l|l|}
\hline Test & Range & $15-30 \mathrm{~Hz}$ & $30-60 \mathrm{~Hz}$ & $60-180 \mathrm{~Hz}$ & Full range \\
\hline \hline Amplitude modulation & $15-180 \mathrm{~Hz}$ & $-29.432 \mathrm{~dB}$ & $-55.658 \mathrm{~dB}$ & $-54.101 \mathrm{~dB}$ & $-29.432 \mathrm{~dB}$ \\
\hline Phase modulation & $15-180 \mathrm{~Hz}$ & $-29.430 \mathrm{~dB}$ & $-56.282 \mathrm{~dB}$ & $-31.679 \mathrm{~dB}$ & $-29.430 \mathrm{~dB}$ \\
\hline Frequency modulation & $15-180 \mathrm{~Hz}$ & $-46.897 \mathrm{~dB}$ & $-80 \mathrm{~dB}$ & $-80 \mathrm{~dB}$ & $-46.897 \mathrm{~dB}$ \\
\hline
\end{tabular}

Table 12. Modulated Signal Test Summary in the Pass Band with the Setting of Narrow Band, Frequency Compensation off - Pass Band

\begin{tabular}{|l|l|l|l|l|l|}
\hline Test & Test type & Range & Avg delay & $\begin{array}{l}\text { Delay } \\
\text { deviatio } \\
\text { n }\end{array}$ & $\begin{array}{l}\text { Phase angle, } \\
1 \mathrm{~Hz} \& 5 \mathrm{~Hz}\end{array}$ \\
\hline \hline Amplitude modulation & Passband, $3 \mathrm{~dB}$ & $0.1-7.74 \mathrm{~Hz}$ & $2.243 \mathrm{~ms}$ & $10.60 \mathrm{~ms}$ & $0^{\circ} \& 8^{\circ}$ \\
\hline & Passband, $0.5 \mathrm{~dB}$ & $0.1-5.99 \mathrm{~Hz}$ & $1.260 \mathrm{~ms}$ & $6.147 \mathrm{~ms}$ & $0^{\circ} \& 8^{\circ}$ \\
\hline Phase modulation & Passband, $3 \mathrm{~dB}$ & $0.1-7.73 \mathrm{~Hz}$ & $2.243 \mathrm{~ms}$ & $10.60 \mathrm{~ms}$ & $0^{\circ} \& 8^{\circ}$ \\
\hline & Passband, $0.5 \mathrm{~dB}$ & $0.1-5.94 \mathrm{~Hz}$ & $1.260 \mathrm{~ms}$ & $6.147 \mathrm{~ms}$ & $0^{\circ} \& 8^{\circ}$ \\
\hline Frequency modulation & Passband, $3 \mathrm{~dB}$ & $0.1-3.18 \mathrm{~Hz}$ & $83.61 \mathrm{~ms}$ & $1.108 \mathrm{~ms}$ & $30^{\circ} \& 160^{\circ}$ \\
\hline & Passband, $0.5 \mathrm{~dB}$ & $0.1-1.49 \mathrm{~Hz}$ & $83.40 \mathrm{~ms}$ & $0.551 \mathrm{~ms}$ & $30^{\circ} \& 160^{\circ}$ \\
\hline
\end{tabular}

Table 13. Modulated Signal Test Summary in the Pass Band with the Setting of Narrow Band, Frequency Compensation off - Out-of-Band Rejection

\begin{tabular}{|l|l|l|l|l|l|}
\hline Test & Range & $15-30 \mathrm{~Hz}$ & $30-60 \mathrm{~Hz}$ & $60-180 \mathrm{~Hz}$ & Full range \\
\hline \hline Amplitude modulation & $15-180 \mathrm{~Hz}$ & $-29.437 \mathrm{~dB}$ & $-55.561 \mathrm{~dB}$ & $-54.101 \mathrm{~dB}$ & $-29.437 \mathrm{~dB}$ \\
\hline Phase modulation & $15-180 \mathrm{~Hz}$ & $-29.442 \mathrm{~dB}$ & $-54.368 \mathrm{~dB}$ & $-31.672 \mathrm{~dB}$ & $-29.442 \mathrm{~dB}$ \\
\hline Frequency modulation & $15-180 \mathrm{~Hz}$ & $-46.897 \mathrm{~dB}$ & $-80 \mathrm{~dB}$ & $-80 \mathrm{~dB}$ & $-46.897 \mathrm{~dB}$ \\
\hline
\end{tabular}


Table 14. Modulated Signal Test Summary in the Pass Band with the Setting of Fast Response, Frequency Compensation on - Pass Band

\begin{tabular}{|l|l|l|l|l|l|}
\hline Test & Test type & Range & Avg delay & $\begin{array}{l}\text { Delay } \\
\text { deviatio } \\
\text { n }\end{array}$ & $\begin{array}{l}\text { Phase angle, } \\
1 \mathrm{~Hz} \& 5 \mathrm{~Hz}\end{array}$ \\
\hline \hline Amplitude modulation & Passband, 3 dB & $0.1-14.23 \mathrm{~Hz}$ & $1.239 \mathrm{~ms}$ & $4.912 \mathrm{~ms}$ & $0^{\circ} \& 1.5^{\circ}$ \\
\hline & Passband, $0.5 \mathrm{~dB}$ & $0.1-11.01 \mathrm{~Hz}$ & $0.713 \mathrm{~ms}$ & $3.075 \mathrm{~ms}$ & $0^{\circ} \& 1.5^{\circ}$ \\
\hline Phase modulation & Passband, $3 \mathrm{~dB}$ & $0.1-14.03 \mathrm{~Hz}$ & $1.239 \mathrm{~ms}$ & $4.912 \mathrm{~ms}$ & $0^{\circ} \& 1.5^{\circ}$ \\
\hline & Passband, $0.5 \mathrm{~dB}$ & $0.1-10.94 \mathrm{~Hz}$ & $0.713 \mathrm{~ms}$ & $3.075 \mathrm{~ms}$ & $0^{\circ} \& 1.5^{\circ}$ \\
\hline Frequency modulation & Passband, 3 dB & $0.1-3.18 \mathrm{~Hz}$ & $83.46 \mathrm{~ms}$ & $0.492 \mathrm{~ms}$ & $30^{\circ} \& 145^{\circ}$ \\
\hline & Passband, $0.5 \mathrm{~dB}$ & $0.1-1.58 \mathrm{~Hz}$ & $83.40 \mathrm{~ms}$ & $0.551 \mathrm{~ms}$ & $30^{\circ} \& 145^{\circ}$ \\
\hline
\end{tabular}

Table 15. Modulated Signal Test Summary in the Pass Band with the Setting of Fast Response, Frequency Compensation on - Out-of-Band Rejection

\begin{tabular}{|l|l|l|l|l|l|}
\hline Test & Range & $15-30 \mathrm{~Hz}$ & $30-60 \mathrm{~Hz}$ & $60-180 \mathrm{~Hz}$ & Full range \\
\hline \hline Amplitude modulation & $15-180 \mathrm{~Hz}$ & $-5.494 \mathrm{~dB}$ & $-34.400 \mathrm{~dB}$ & $-53.952 \mathrm{~dB}$ & $-5.494 \mathrm{~dB}$ \\
\hline Phase modulation & $15-180 \mathrm{~Hz}$ & $-5.506 \mathrm{~dB}$ & $-16.310 \mathrm{~dB}$ & $-35.074 \mathrm{~dB}$ & $-7.367 \mathrm{~dB}$ \\
\hline Frequency modulation & $15-180 \mathrm{~Hz}$ & $-21.709 \mathrm{~dB}$ & $-52.616 \mathrm{~dB}$ & $-80 \mathrm{~dB}$ & $-21.709 \mathrm{~dB}$ \\
\hline
\end{tabular}

Table 16. Modulated Signal Test Summary in the Pass Band with the Setting of Fast Response, Frequency Compensation off - Pass Band

\begin{tabular}{|l|l|l|l|l|l|}
\hline Test & Test type & Range & Avg delay & $\begin{array}{l}\text { Delay } \\
\text { deviatio } \\
\text { n }\end{array}$ & $\begin{array}{l}\text { Phase angle, } \\
1 \mathrm{~Hz} \& 5 \mathrm{~Hz}\end{array}$ \\
\hline \hline Amplitude modulation & Passband, $3 \mathrm{~dB}$ & $0.1-14.23 \mathrm{~Hz}$ & $1.239 \mathrm{~ms}$ & $4.912 \mathrm{~ms}$ & $0^{\circ} \& 1.5^{\circ}$ \\
\hline & Passband, $0.5 \mathrm{~dB}$ & $0.1-11.01 \mathrm{~Hz}$ & $0.713 \mathrm{~ms}$ & $3.075 \mathrm{~ms}$ & $0^{\circ} \& 1.5^{\circ}$ \\
\hline Phase modulation & Passband, $3 \mathrm{~dB}$ & $0.1-14.22 \mathrm{~Hz}$ & $1.274 \mathrm{~ms}$ & $5.076 \mathrm{~ms}$ & $0^{\circ} \& 1.5^{\circ}$ \\
\hline & Passband, $0.5 \mathrm{~dB}$ & $0.1-10.96 \mathrm{~Hz}$ & $0.744 \mathrm{~ms}$ & $3.044 \mathrm{~ms}$ & $0^{\circ} \& 1.5^{\circ}$ \\
\hline Frequency modulation & Passband, $3 \mathrm{~dB}$ & $0.1-3.18 \mathrm{~Hz}$ & $83.46 \mathrm{~ms}$ & $0.492 \mathrm{~ms}$ & $30^{\circ} \& 145^{\circ}$ \\
\hline & Passband, $0.5 \mathrm{~dB}$ & $0.1-1.58 \mathrm{~Hz}$ & $83.40 \mathrm{~ms}$ & $0.551 \mathrm{~ms}$ & $30^{\circ} \& 145^{\circ}$ \\
\hline
\end{tabular}

Table 17. Modulated Signal Test Summary in the Pass Band with the Setting of Fast Response, Frequency Compensation off - Put-of-Band Rejection

\begin{tabular}{|l|l|l|l|l|l|}
\hline Test & Range & $15-30 \mathrm{~Hz}$ & $30-60 \mathrm{~Hz}$ & $60-180 \mathrm{~Hz}$ & Full range \\
\hline \hline Amplitude modulation & $15-180 \mathrm{~Hz}$ & $-5.494 \mathrm{~dB}$ & $-34.485 \mathrm{~dB}$ & $-53.952 \mathrm{~dB}$ & $-5.494 \mathrm{~dB}$ \\
\hline Phase modulation & $15-180 \mathrm{~Hz}$ & $-5.506 \mathrm{~dB}$ & $-34.264 \mathrm{~dB}$ & $-31.798 \mathrm{~dB}$ & $-5.506 \mathrm{~dB}$ \\
\hline Frequency modulation & $15-180 \mathrm{~Hz}$ & $-21.709 \mathrm{~dB}$ & $-52.616 \mathrm{~dB}$ & $-80 \mathrm{~dB}$ & $-21.709 \mathrm{~dB}$ \\
\hline
\end{tabular}

\subsection{Step Test Summary}

Table 18 to Table 21 are the summary of step tests. Step tests start with a steady-state signal, which gives the PMU time to settle at an initial value, and then one of the parameters is stepped to a new value and held so the PMU can settle to the new value. These tests are actually performed in a repeated series with small delays in the actual step relative to measurement time. These repeated steps are then slipped back into a real time alignment to give a complete measurement curve. These tests illustrate the initial, transient, and final response in measurement time. 
From this, PMU timing relative to absolute time, input signals, and other PMUs can be assessed. It also illustrates overshoot and settling in measurement. Steps in magnitude and phase angle illustrate phasor measurement response, and frequency steps illustrate frequency measurement response. Measurement synchronization and interference between measurements can be observed from these tests.

Delay is defined as ("measured response" - "input step") measured at the $50 \%$ point, average of positive \& negative. This is somewhat arbitrary, but it corresponds to time centered in the measurement window. A negative delay means the response appears sooner than expected.

Rise time is defined as the time interval from the response at $5 \%$ to $95 \%$. Symmetry is the observation of ramp before and after mid point and between positive and negative steps. If symmetry is " $\mathrm{N}$ " (no), please refer to the detailed plots in the appendix for the particular cause.

Table 18. Step Test Summary with the Setting of Narrow Band, Frequency Compensation on

\begin{tabular}{|l|l|r|r|c|}
\hline Test & Step size, nominal value & \multicolumn{1}{|l|}{ Delay } & \multicolumn{1}{l|}{ Rise time } & \multicolumn{1}{c|}{ Symmetry } \\
\hline \hline Voltage magnitude step & $0.1 \mathrm{PU}, 70-77 \mathrm{~V}$ & $4.891 \mathrm{~ms}$ & $62.454 \mathrm{~ms}$ & $\mathrm{Y}$ \\
\hline Voltage magnitude step & $0.1 \mathrm{PU}, 70-63 \mathrm{~V}$ & $4.903 \mathrm{~ms}$ & $62.491 \mathrm{~ms}$ & $\mathrm{Y}$ \\
\hline Current magnitude step & $0.1 \mathrm{PU}, 3-3.3 \mathrm{~A}$ & $4.996 \mathrm{~ms}$ & $62.202 \mathrm{~ms}$ & $\mathrm{Y}$ \\
\hline Current magnitude step & $0.1 \mathrm{PU}, 3-2.7 \mathrm{~A}$ & $4.838 \mathrm{~ms}$ & $62.607 \mathrm{~ms}$ & $\mathrm{Y}$ \\
\hline Phase angle step (voltage) & $15^{\circ}, 0-15^{\circ}$ phase & $4.894 \mathrm{~ms}$ & $62.349 \mathrm{~ms}$ & $\mathrm{Y}$ \\
\hline Phase angle step (voltage) & $15^{\circ}, 0-345^{\circ}$ phase & $4.872 \mathrm{~ms}$ & $62.466 \mathrm{~ms}$ & $\mathrm{Y}$ \\
\hline Frequency magnitude step & $1 \mathrm{~Hz}, 60-61 \mathrm{~Hz}$ & $86.141 \mathrm{~ms}$ & $111.905 \mathrm{~ms}$ & $\mathrm{Y}$ \\
\hline Frequency magnitude step & $1 \mathrm{~Hz}, 60-59 \mathrm{~Hz}$ & $86.174 \mathrm{~ms}$ & $111.905 \mathrm{~ms}$ & $\mathrm{Y}$ \\
\hline
\end{tabular}

Table 19. Step Test Summary with the Setting of Narrow Band, Frequency Compensation off

\begin{tabular}{|l|l|r|r|c|}
\hline Test & Step size, nominal value & \multicolumn{1}{|l|}{ Delay } & \multicolumn{1}{|l|}{ Rise time } & Symmetry \\
\hline Voltage magnitude step & $0.1 \mathrm{PU}, 70-77 \mathrm{~V}$ & $4.867 \mathrm{~ms}$ & $62.547 \mathrm{~ms}$ & $\mathrm{Y}$ \\
\hline Voltage magnitude step & $0.1 \mathrm{PU}, 70-63 \mathrm{~V}$ & $4.903 \mathrm{~ms}$ & $62.617 \mathrm{~ms}$ & $\mathrm{Y}$ \\
\hline Current magnitude step & $0.1 \mathrm{PU}, 3-3.3 \mathrm{~A}$ & $4.926 \mathrm{~ms}$ & $62.198 \mathrm{~ms}$ & $\mathrm{Y}$ \\
\hline Current magnitude step & $0.1 \mathrm{PU}, 3-2.7 \mathrm{~A}$ & $4.917 \mathrm{~ms}$ & $62.436 \mathrm{~ms}$ & $\mathrm{Y}$ \\
\hline Phase angle step (voltage) & $15^{\circ}, 0-15^{\circ}$ phase & $4.879 \mathrm{~ms}$ & $62.410 \mathrm{~ms}$ & $\mathrm{Y}$ \\
\hline Phase angle step (voltage) & $15^{\circ}, 0-345^{\circ}$ phase & $4.880 \mathrm{~ms}$ & $62.383 \mathrm{~ms}$ & $\mathrm{Y}$ \\
\hline Frequency magnitude step & $1 \mathrm{~Hz}, 60-61 \mathrm{~Hz}$ & $86.141 \mathrm{~ms}$ & $112.128 \mathrm{~ms}$ & $\mathrm{Y}$ \\
\hline Frequency magnitude step & $1 \mathrm{~Hz}, 60-59 \mathrm{~Hz}$ & $86.174 \mathrm{~ms}$ & $112.128 \mathrm{~ms}$ & $\mathrm{Y}$ \\
\hline
\end{tabular}

Table 20. Step Test Summary with the Setting of Fast Response, Frequency Compensation on

\begin{tabular}{|l|l|r|r|c|}
\hline Test & Step size, nominal value & \multicolumn{1}{|l|}{ Delay } & \multicolumn{1}{l|}{ Rise time } & \multicolumn{1}{c|}{ Symmetry } \\
\hline \hline Voltage magnitude step & $0.1 \mathrm{PU}, 70-77 \mathrm{~V}$ & $2.503 \mathrm{~ms}$ & $33.743 \mathrm{~ms}$ & $\mathrm{Y}$ \\
\hline Voltage magnitude step & $0.1 \mathrm{PU}, 70-63 \mathrm{~V}$ & $2.502 \mathrm{~ms}$ & $33.828 \mathrm{~ms}$ & $\mathrm{Y}$ \\
\hline Current magnitude step & $0.1 \mathrm{PU}, 3-3.3 \mathrm{~A}$ & $2.525 \mathrm{~ms}$ & $33.870 \mathrm{~ms}$ & $\mathrm{Y}$ \\
\hline Current magnitude step & $0.1 \mathrm{PU}, 3-2.7 \mathrm{~A}$ & $2.428 \mathrm{~ms}$ & $33.609 \mathrm{~ms}$ & $\mathrm{Y}$ \\
\hline Phase angle step (voltage) & $15^{\circ}, 0-15^{\circ}$ phase & $2.484 \mathrm{~ms}$ & $33.684 \mathrm{~ms}$ & $\mathrm{Y}$ \\
\hline Phase angle step (voltage) & $15^{\circ}, 0-345^{\circ}$ phase & $2.518 \mathrm{~ms}$ & $33.693 \mathrm{~ms}$ & $\mathrm{Y}$ \\
\hline Frequency magnitude step & $1 \mathrm{~Hz}, 60-61 \mathrm{~Hz}$ & $85.938 \mathrm{~ms}$ & $98.049 \mathrm{~ms}$ & $\mathrm{Y}$ \\
\hline Frequency magnitude step & $1 \mathrm{~Hz}, 60-59 \mathrm{~Hz}$ & $85.938 \mathrm{~ms}$ & $98.049 \mathrm{~ms}$ & $\mathrm{Y}$ \\
\hline
\end{tabular}


Table 21. Step Test Summary with the Setting of Fast Response, Frequency Compensation off

\begin{tabular}{|l|l|r|r|c|}
\hline Test & Step size, nominal value & \multicolumn{1}{|l|}{ Delay } & \multicolumn{1}{|c|}{ Rise time } & Symmetry \\
\hline \hline Voltage magnitude step & $0.1 \mathrm{PU}, 70-77 \mathrm{~V}$ & $2.483 \mathrm{~ms}$ & $33.774 \mathrm{~ms}$ & $\mathrm{Y}$ \\
\hline Voltage magnitude step & $0.1 \mathrm{PU}, 70-63 \mathrm{~V}$ & $2.508 \mathrm{~ms}$ & $33.770 \mathrm{~ms}$ & $\mathrm{Y}$ \\
\hline Current magnitude step & $0.1 \mathrm{PU}, 3-3.3 \mathrm{~A}$ & $2.508 \mathrm{~ms}$ & $33.727 \mathrm{~ms}$ & $\mathrm{Y}$ \\
\hline Current magnitude step & $0.1 \mathrm{PU}, 3-2.7 \mathrm{~A}$ & $2.463 \mathrm{~ms}$ & $33.699 \mathrm{~ms}$ & $\mathrm{Y}$ \\
\hline Phase angle step (voltage) & $1^{\circ}, 0-15^{\circ}$ phase & $2.482 \mathrm{~ms}$ & $33.708 \mathrm{~ms}$ & $\mathrm{Y}$ \\
\hline Phase angle step (voltage) & $15^{\mathrm{o}}, 0-345^{\circ}$ phase & $2.490 \mathrm{~ms}$ & $33.701 \mathrm{~ms}$ & $\mathrm{Y}$ \\
\hline Frequency magnitude step & $1 \mathrm{~Hz}, 60-61 \mathrm{~Hz}$ & $85.938 \mathrm{~ms}$ & $98.049 \mathrm{~ms}$ & $\mathrm{Y}$ \\
\hline Frequency magnitude step & $1 \mathrm{~Hz}, 60-59 \mathrm{~Hz}$ & $87.072 \mathrm{~ms}$ & $98.030 \mathrm{~ms}$ & $\mathrm{Y}$ \\
\hline
\end{tabular}

\subsection{Relative Timing Summary}

PMUs of different types appear to use a wide variety of algorithms to produce their output signals for local frequency (FreqL). The timing of instrument level frequency signals are often found to be inconsistent between PMUs of different types, between PMUs of the same type that have been set differently, and between the frequency signal and the associated phasors.

This aspect of PMU timing can be examined very closely through Prony analysis of modulation response (Hauer et al 2004). Table 22 shows results for $1.4 \mathrm{~Hz}$ angle modulation during test series $\mathrm{A}$, with playback file FMod6006seriesA. The signals of type EFreqL_FD are estimated frequencies obtained by a forward difference of the associated voltage angles.

While the frequency estimates are closely consistent, the instrument level signals are significantly delayed by different amounts, and the SEL output exhibits noticeable attenuation. Results in Section 5 show that consistent results are obtained for angle modulation at $0.28 \mathrm{~Hz}$.

Very similar values were obtained for test series C, in which the SEL unit was set to narrow band (still with frequency compensation off). Brief examination of relative timing for amplitude modulation with playback file AMod6006seriesA showed that voltage magnitude signals from the two units tracked closely, with the SEL unit lagging the ABB unit by about 1 msec.

Table 22. Relative Delays of PMU Frequency Signals for 1.4 Hz Angle Modulation, Test Series A

\begin{tabular}{lllc} 
Signal & Freq in Hz & Res Angle & Rel. Delay (msec) \\
\hline SEL Voltage1 FreqL & 1.400 & 144.3898 & 100.01 \\
ABB Voltage1 FreqL & 1.400 & 174.0134 & 41.24 \\
SEL Voltage1 EFreqL_FD & 1.400 & 194.8977 & -0.20 \\
ABB Voltage1 EFreqL_FD & 1.400 & 194.7962 & 0.00
\end{tabular}




\subsection{DETAILS OF TEST RESULTS AND MEASUREMENT PLOTS}

This section provides more detailed results and plots of the tests, which support the summary tables presented in the previous section.

\subsection{Magnitude Accuracy}

Input voltage magnitude is scanned from 0.1 to $1.2 \mathrm{PU}$ relative to a $70 \mathrm{~V}$ nominal. Figure 3 shows that voltage measurement accuracy is within $0.15 \%$ over the test range. At the normal operation range $0.9-1.1 \mathrm{PU}$, the accuracy is about $0.1 \%$.

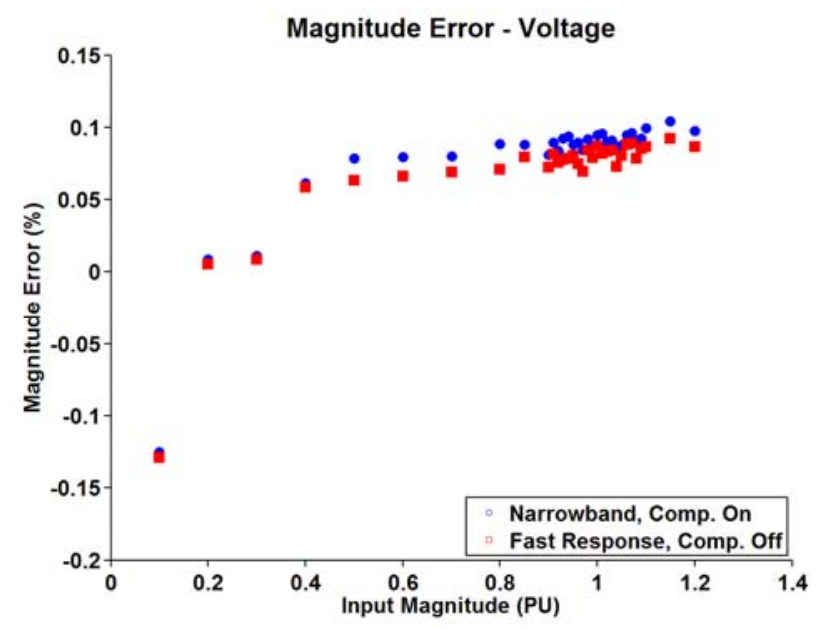

Figure 3. Steady -State Magnitude Response for Voltage

Input current magnitude is scanned from 0.1 to $2.0 \mathrm{PU}$ relative to a $3 \mathrm{~A}$ nominal. Current measurement accuracy is within $0.4 \%$ over the test range (Figure 4 ).

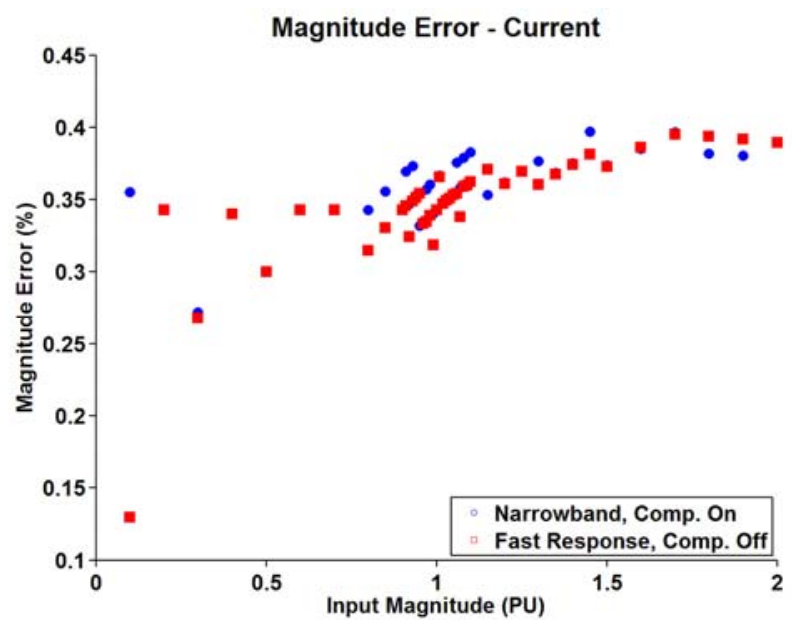

Figure 4. Steady-State Magnitude Response for Current 


\subsection{Phase Angle Measurement}

\subsubsection{Phase Angle at Nominal Frequency}

Input phase angle for both voltage and current is scanned from $-50^{\circ}$ to $300^{\circ}$ ( $350^{\circ}$ range), with voltage leading current by a constant $30^{\circ}$. The phase angle error of the voltage signal is shown in Figure 5, which is in a range of $0.002^{\circ}$ to $0.012^{\circ}$. In the case of fast response with frequency compensation off, the error is slightly higher.

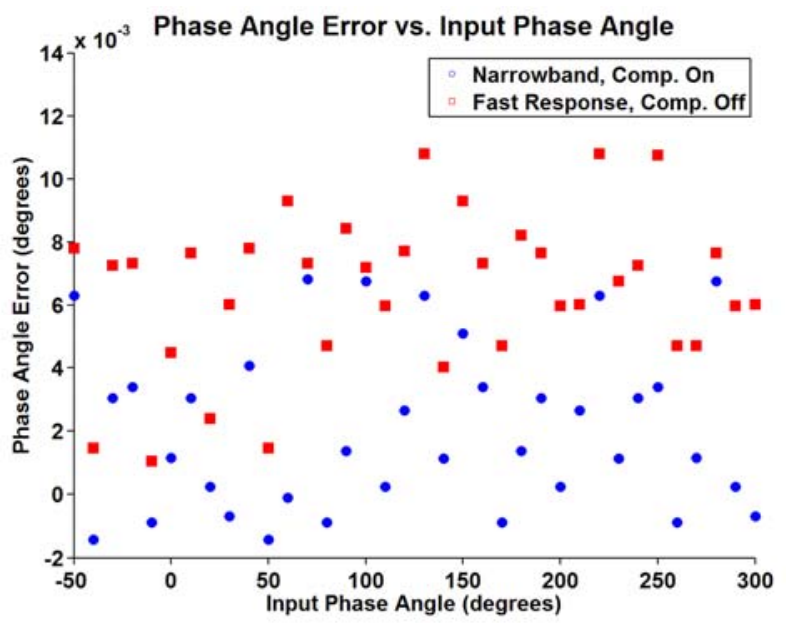

Figure 5. Steady-State Phase Angle Response

\subsubsection{Phase Angle Measurement Variation with Frequency}

Input frequency is scanned from 55 to $65 \mathrm{~Hz}$ with a fixed absolute phase angle. The change in the measured angle versus frequency is plotted in Figure 6. The largest error ranging from $\pm 8^{\circ}$ is associated with the setting of narrow band and frequency compensation off, but in the range of 59 to $61 \mathrm{~Hz}$, the error is minimal. Among the four settings, the setting of fast response and frequency compensation on has the smallest error. In general, fast response setting has smaller error than narrow band, and with frequency compensation on, the error is smaller than with frequency compensation off. 


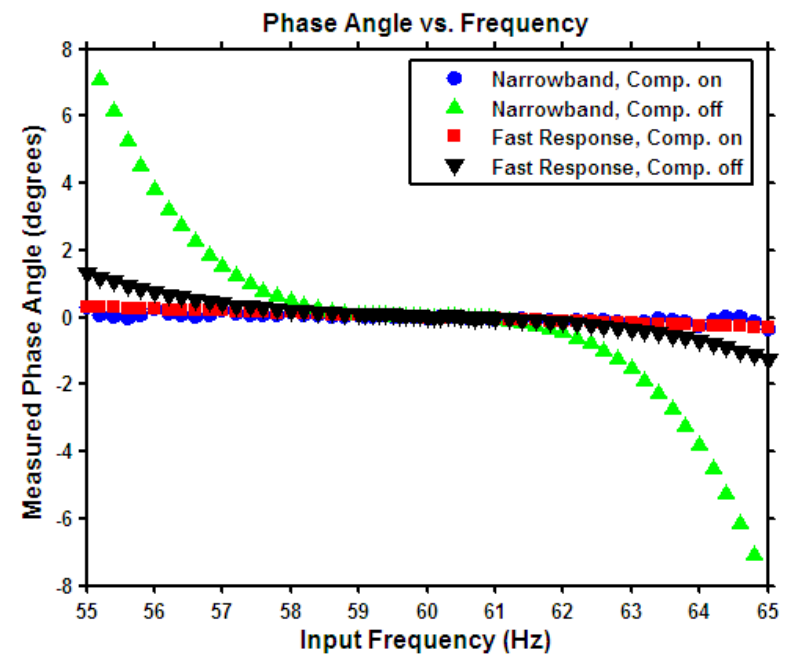

Figure 6. Phase Angle vs. Frequency

\subsection{Frequency Response - Measurement Band}

Input frequency is scanned from 10 to $300 \mathrm{~Hz}$, in intervals of $2 \mathrm{~Hz}$ except between 55 and $65 \mathrm{~Hz}$, where the interval is decreased to $0.1 \mathrm{~Hz}$. The test was performed for all four settings at $70 \mathrm{~V}$ nominal. Figure 7 shows the filtering characteristics derived from this frequency scan test. It can be seen that frequency compensation does not have much effect on the filtering characteristic. As one would expect, the narrow band setting gives a narrower pass band than the fast response setting. The pass bands are roughly 55 to $65 \mathrm{~Hz}$ for the narrow band setting and $50 \mathrm{Ho} 70 \mathrm{~Hz}$ for the fast response setting, as shown in Figure 8. Outside the pass band, the magnitude is well suppressed. A detailed view of the range 59 to $61 \mathrm{~Hz}$ is shown in Figure 9. The magnitude variations are within $0.05 \%$.

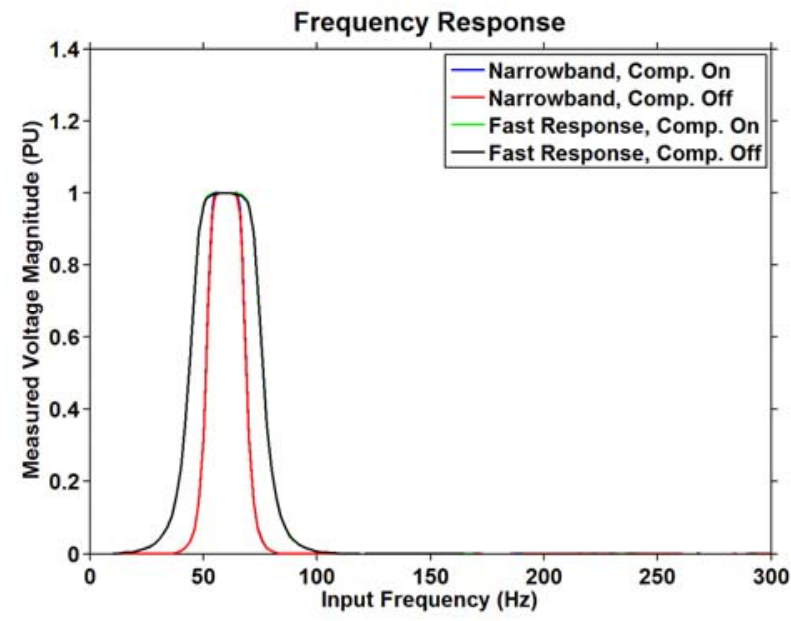

Figure 7. Steady-State Frequency Response over the Range of 0 to $300 \mathrm{~Hz}$

(The two "Narrow Band" curves overlap as in red. The two "Fast Response” overlap as in black.) 


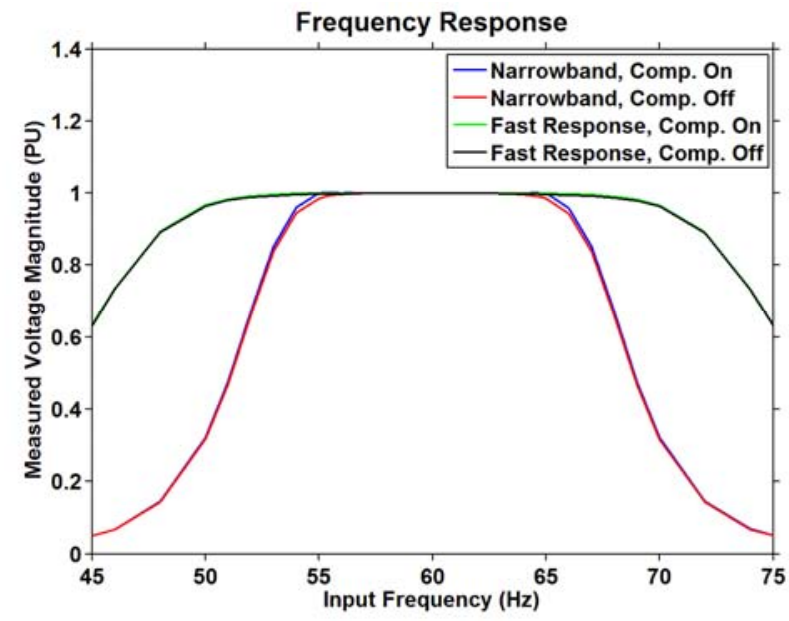

Figure 8. Steady -State Frequency Response over the Pass Band

(The two "Narrow Band" curves overlap as in red. The two "Fast Response" overlap as in green.)

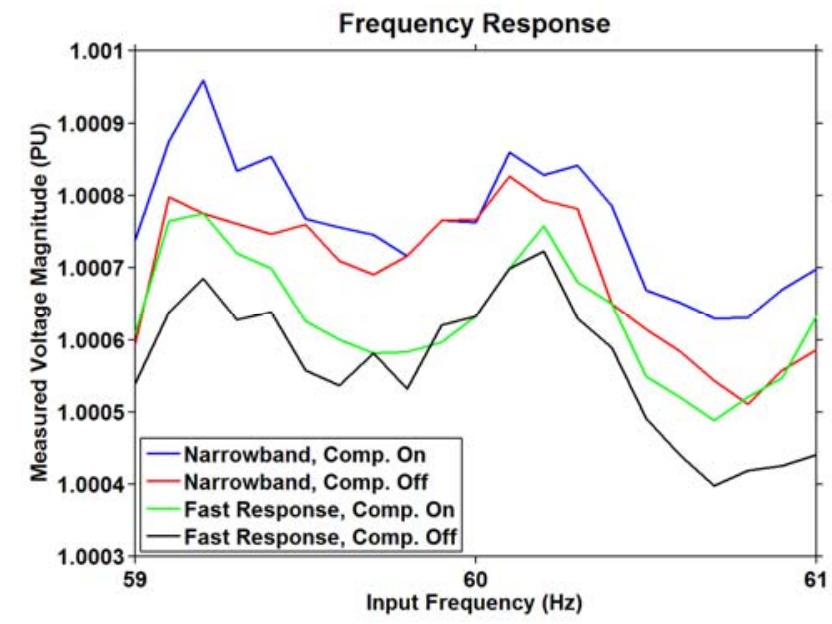

Figure 9. Steady-State Frequency Response over the Range of 59 to $61 \mathrm{~Hz}$

\subsection{Frequency Accuracy}

This tests the frequency measurement capability of the PMU. The frequency of the AC signal that the PMU uses for measuring frequency is over a practical measurement band in 2 to $0.1 \mathrm{~Hz}$ increments (finer increments near nominal). This will vary somewhat by vendor because they don't all measure frequency over the same bandwidth. C37.118 reporting with integer values spans frequency deviation $+/-32.767 \mathrm{~Hz}$ (frequency between $28 \mathrm{and} 92 \mathrm{~Hz}$ ). The SEL 421 PMU reported values from 45 to $70 \mathrm{~Hz}$. Figure 10 shows the frequency measurement error over the full reporting range of 45 to $70 \mathrm{~Hz}$. There is one outlier around $46 \mathrm{~Hz}$, which is most likely a measurement error. Detailed view of the range of 55 to $65 \mathrm{~Hz}$ is shown in Figure 11. The frequency error is well within $\pm 3 \mathrm{mHz}$. The setting of narrow band with frequency compensation on seems to have more randomness in the measurement error. Over the range of 59 to $61 \mathrm{~Hz}$, frequency measurement error is about $\pm 1 \mathrm{mHz}$. 


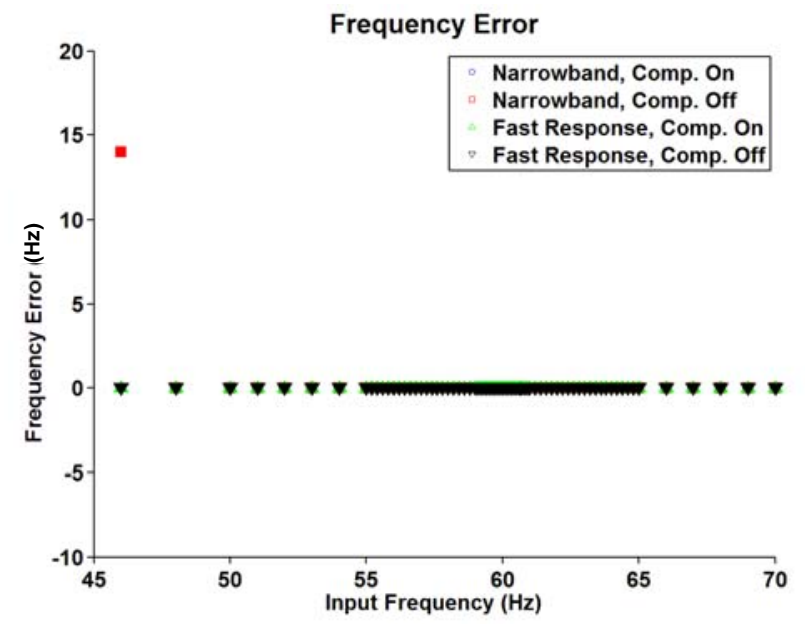

Figure 10. Frequency Measurement Error over the Reporting Range of 45 to $70 \mathrm{~Hz}$

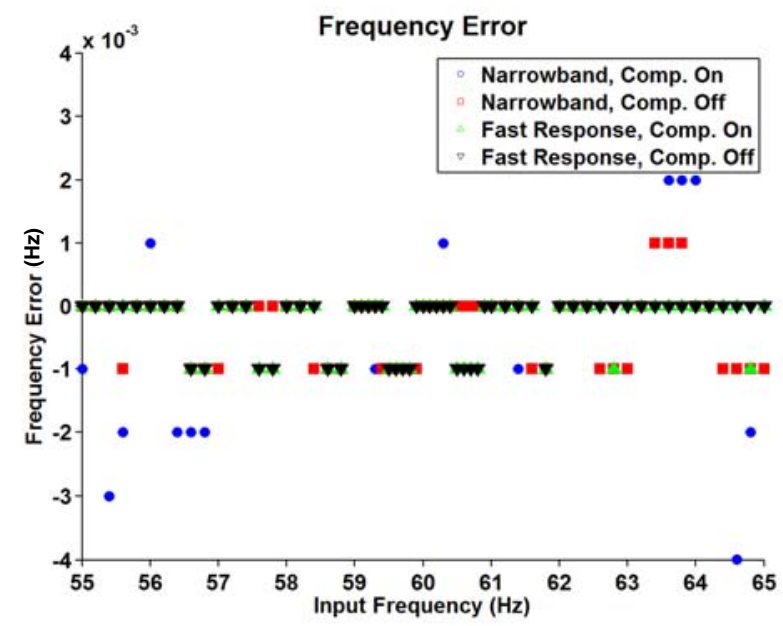

Figure 11. Frequency Measurement Error over the Range of 55 to $65 \mathrm{~Hz}$

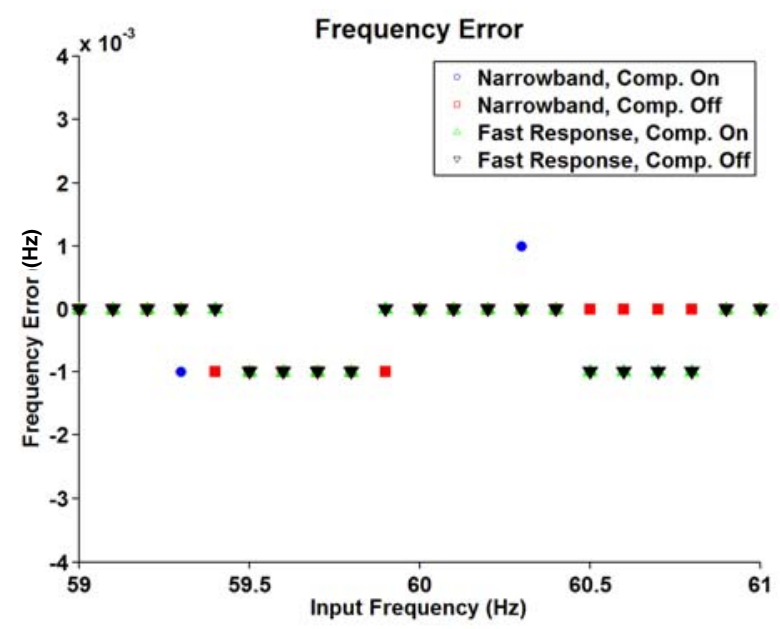

Figure 12. Frequency Measurement Error over the Reporting Range of 59 to $61 \mathrm{~Hz}$ 


\subsection{Measurement of Unbalanced Signals}

\subsubsection{Amplitude Unbalance}

Input phase C is varied from 0.8 to $1.2 \mathrm{PU}$ at three frequencies (59, 60, and $61 \mathrm{~Hz}$ ), and the measured positive sequence phasor is compared with the calculated input phasor. Figure 13 shows the amplitude response to the unbalanced input signals when the setting is narrow band with frequency compensation on. The measurement error bounds between $0.075 \%$ and $0.1 \%$. The largest errors are observed at $59 \mathrm{~Hz}$, and decrease as frequency increases. When the setting is fast response with frequency compensation off, the error ranges from $0.05 \%$ to $0.085 \%$, as shown in Figure 14. The largest errors are observed at $60 \mathrm{~Hz}$. Figure 15 compares the errors for these two different settings. The narrow band with frequency compensation on has slightly larger errors.

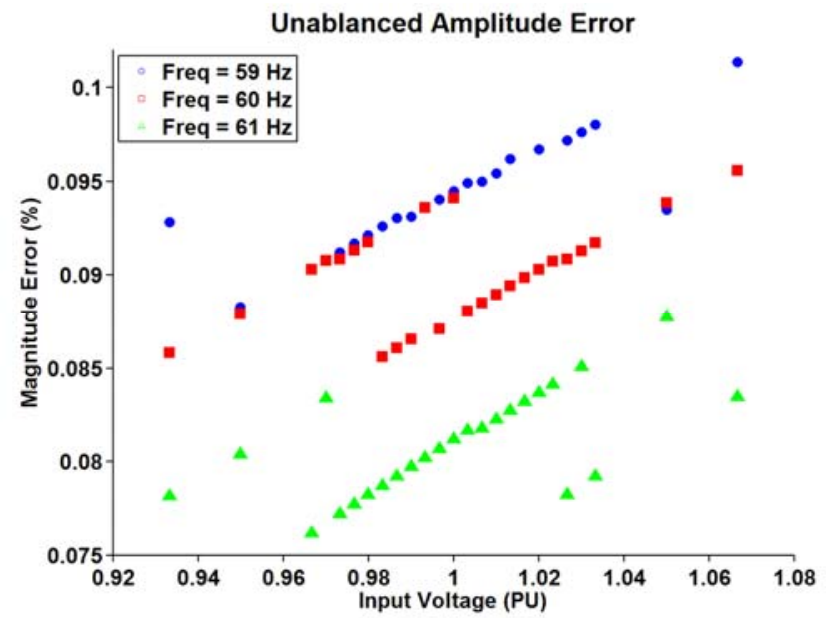

Figure 13. Unbalanced Amplitude Response, Narrow Band with Frequency Compensation on

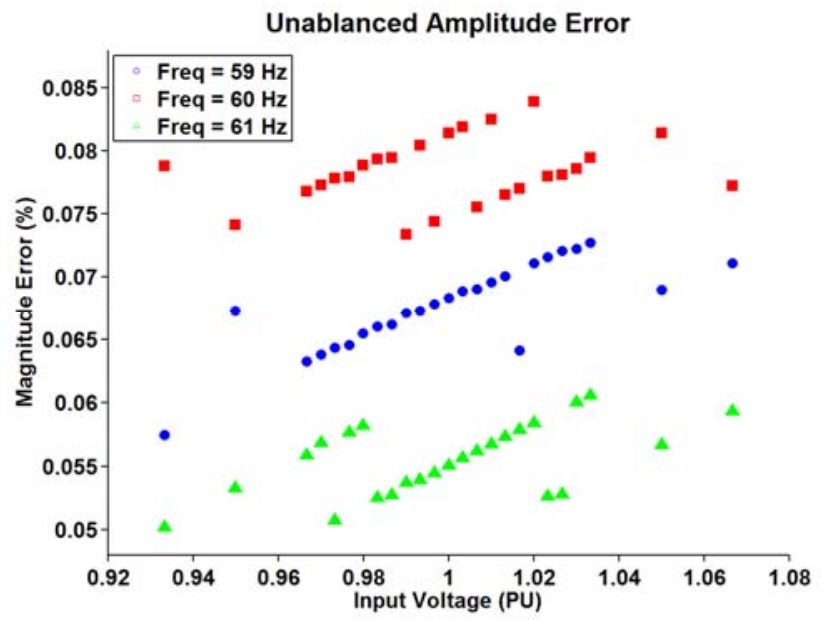

Figure 14. Unbalanced Amplitude Response, Fast Response with Frequency Compensation off 


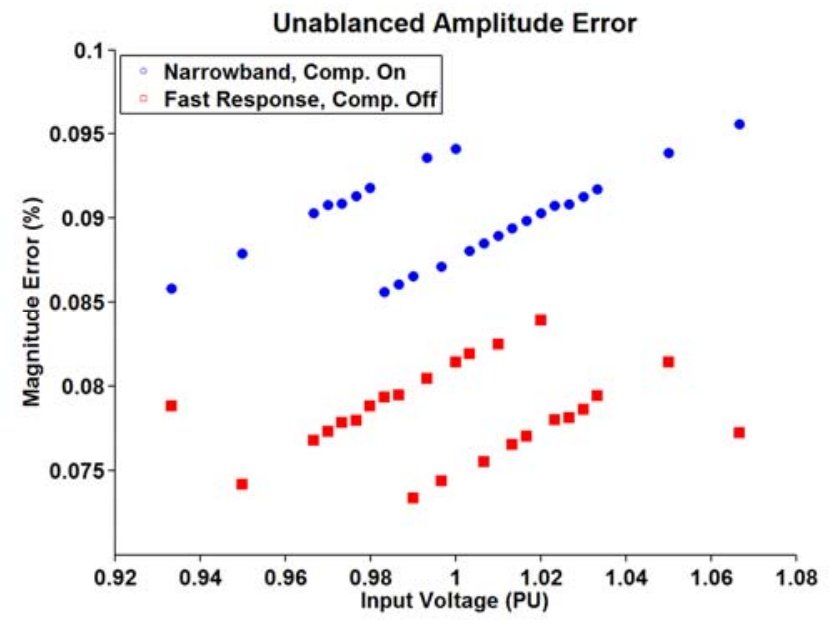

Figure 15. Unbalanced Amplitude Response at $60 \mathrm{~Hz}$

\subsubsection{Phase Unbalance}

Input phase $\mathrm{C}$ is varied from the nominal $120^{\circ}$ to $300^{\circ}$ relative to phase $\mathrm{A}$ in $10^{\circ}$ increments. The measured positive sequence phasor is compared with the theoretical phasor value (the nominal positive sequence phase angle is $-90^{\circ}$ ). Figure 16 and Figure 17 show the phase error for two different settings - narrow band with frequency compensation on and fast response with frequency compensation off. The errors are very similar for these two settings, ranging from $-0.05^{\circ}$ to $0.1^{\circ}$. Phase errors at $60 \mathrm{~Hz}$ are centered around $0^{\circ}$, while errors for 59 and $61 \mathrm{~Hz}$ are centered around $0.07^{\circ}$ and $-0.05^{\circ}$, respectively. Figure 18 shows the detailed errors when the frequency is $60 \mathrm{~Hz}$. The errors are in the range of $0.005^{\circ}$ to $0.04^{\circ}$, and are the same for both settings.

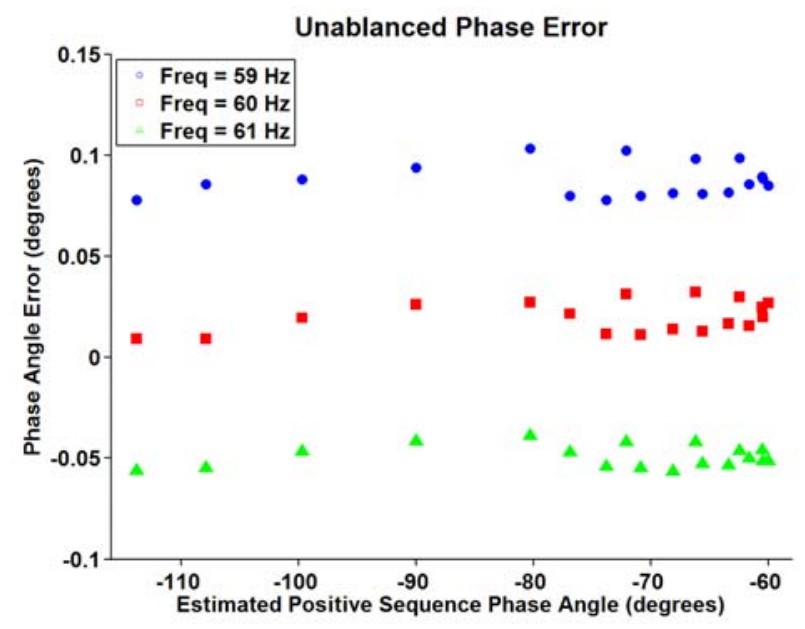

Figure 16. Unbalanced Phase Response, Narrow Band with Frequency Compensation on 


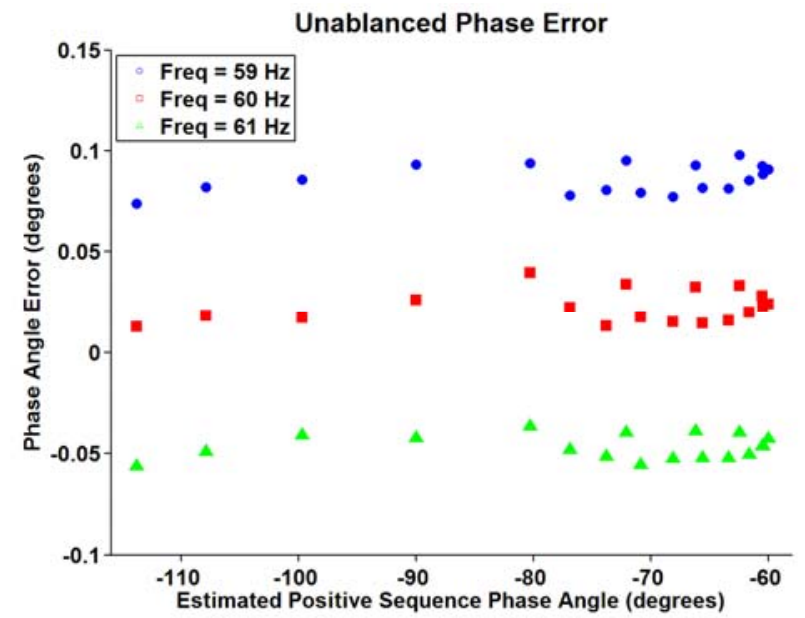

Figure 17. Unbalanced Phase Response, Fast Response with Frequency Compensation off

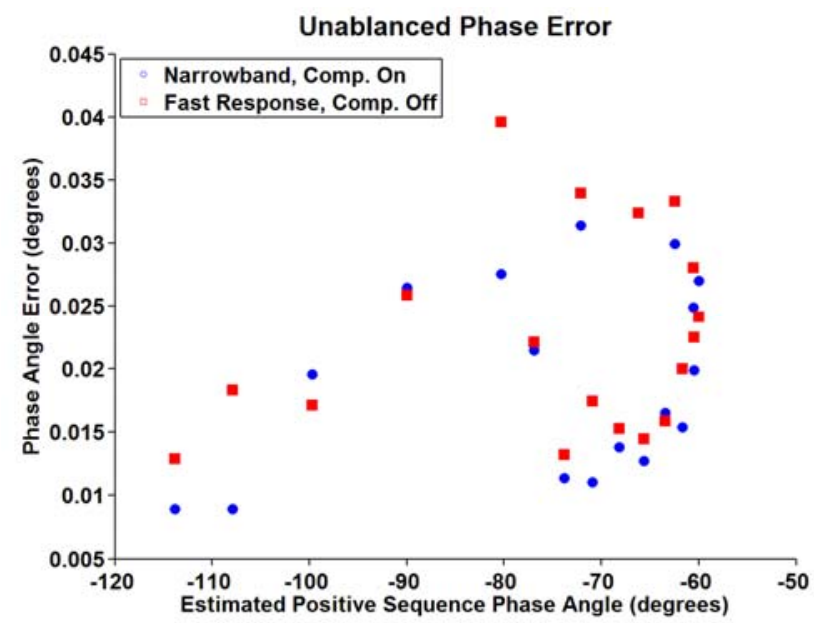

Figure 18. Unbalanced Phase Response at $60 \mathrm{~Hz}$

\subsection{Harmonic Rejection}

The PMU should filter out (reject) harmonics that could cause distortion of the measured signal (the fundamental). The $2^{\text {nd }}(120 \mathrm{~Hz})$ through the $50^{\text {th }}(3000 \mathrm{~Hz})$ harmonic — one at a time—at a $0.1 \mathrm{PU}(10 \%)$ level is added to the fundamental (1 PU). Each signal is held constant for 1 second, and the measurement error is the difference between the actual measurement and the measurement of the fundamental (no distortion). This process is repeated at three fundamental frequencies, $59.5 \mathrm{~Hz}, 60.0 \mathrm{~Hz}$, and $60.5 \mathrm{~Hz}$ to determine if the filtering is fixed at $60 \mathrm{~Hz}$ or follows the actual system frequency. With no filtering, $10 \%$ added signal should result in a $10 \%$ error, which is $0 \mathrm{~dB}$ in the plot. Level 1 of C37.118 compliance requires a 10\% harmonic to be reduced to $1 \%$ error, which is a $20 \mathrm{~dB}$ attenuation.

Results are shown in Figure 19 through Figure 22. Figure 22 in $\mathrm{dB}$ of rejection. For the narrow band setting, the PMU shows the best performance at $60 \mathrm{~Hz}-41 \mathrm{~dB}$, compared with $34 \mathrm{~dB}$ at 59.5 and $60.5 \mathrm{~Hz}$, with frequency compensation on (Figure 19). Similar performance is observed with frequency compensation off, except the rejection drops slightly to $30 \mathrm{~dB}$ when frequency is $59.5 \mathrm{and} 60.5 \mathrm{~Hz}$ (Figure 20). For the fast response setting, the harmonics are consistently attenuated by 40 to $44 \mathrm{~dB}$, except a few outliers (Figure 21 and Figure 22). The effect of frequency compensation is minimal. 
Figure 23 further compares the harmonic rejection performance at $60 \mathrm{~Hz}$ for all four settings. It confirms that fast response setting has slightly better harmonic rejection performance. Frequency compensation does not have noticeable effect.

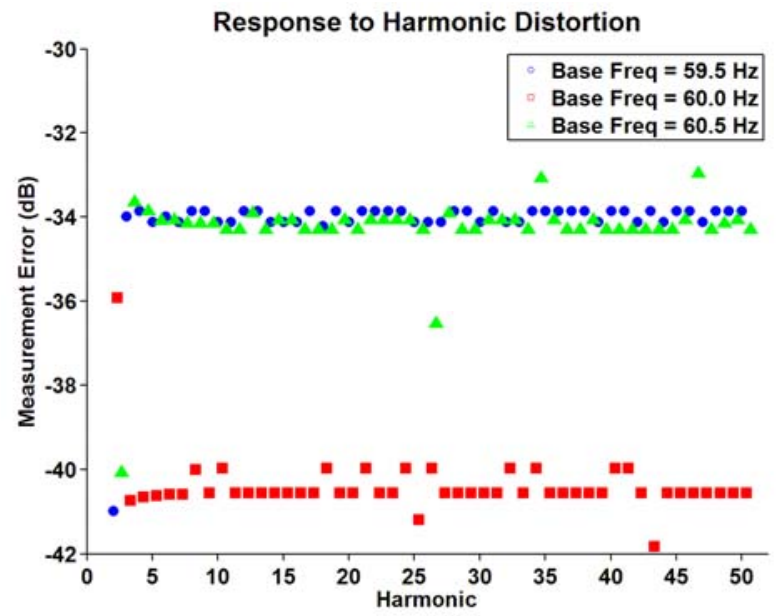

Figure 19. Response to Harmonic Distortion, Narrow Band, Frequency Compensation on

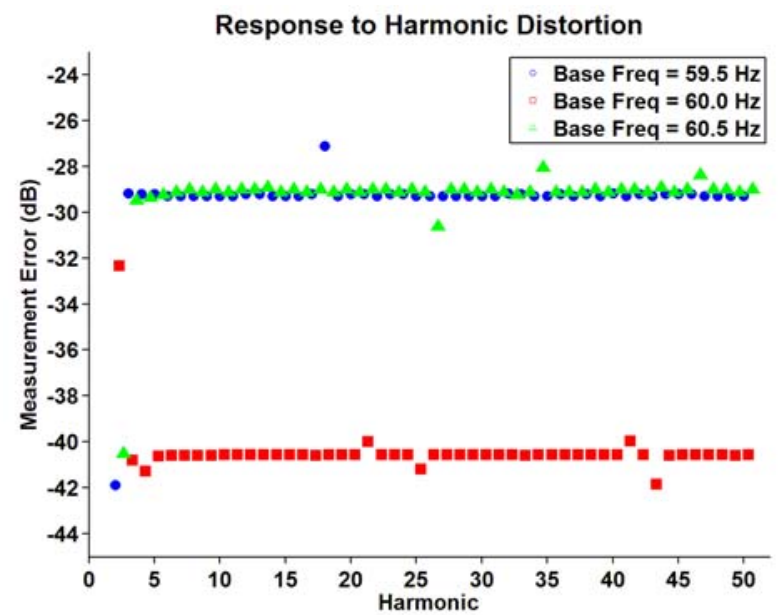

Figure 20. Response to Harmonic Distortion, Narrow Band, Frequency Compensation off 


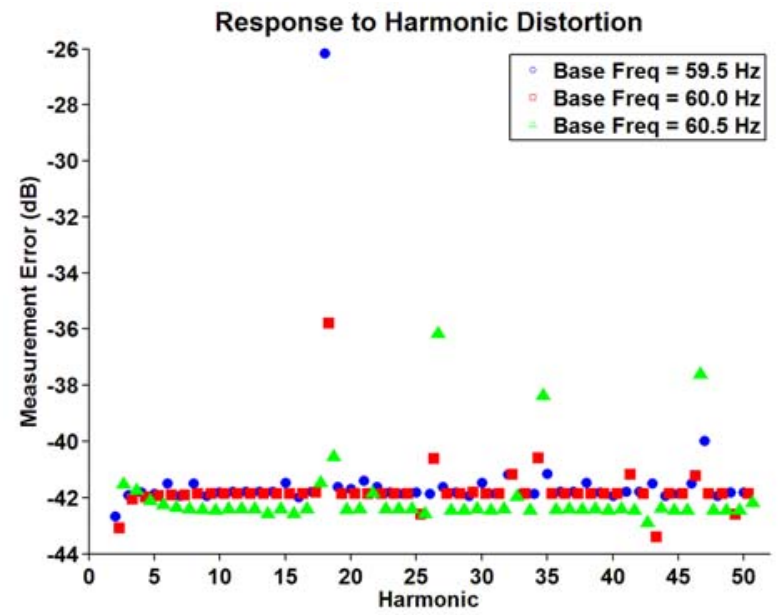

Figure 21. Response to Harmonic Distortion, Fast Response, Frequency Compensation on

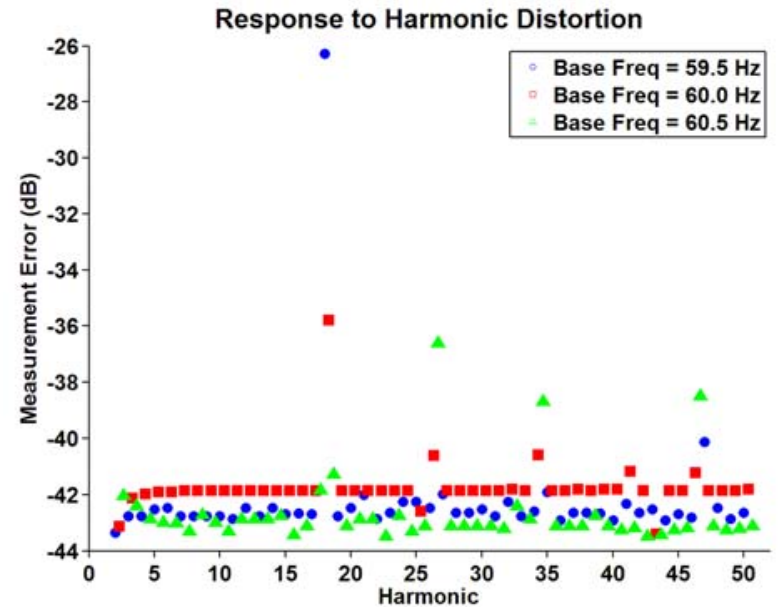

Figure 22. Response to Harmonic Distortion, Fast Response, Frequency Compensation off

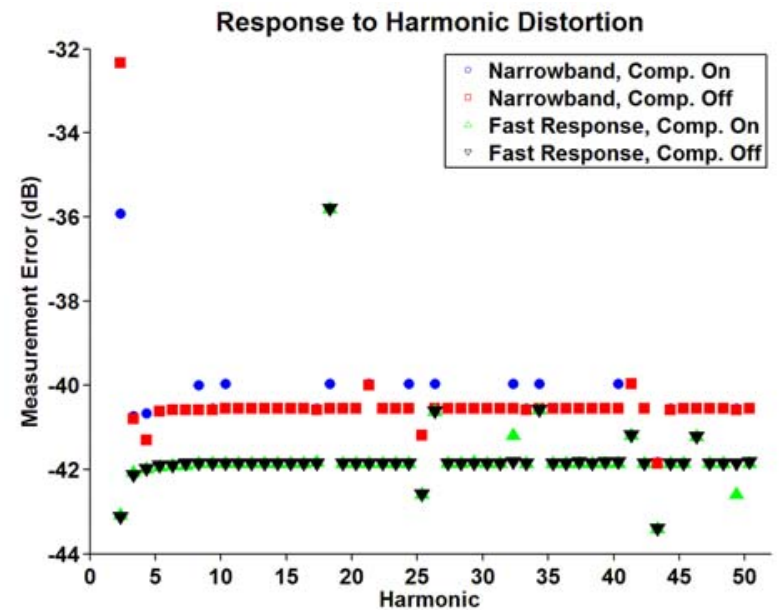

Figure 23. Response to Harmonic Distortion at $60 \mathrm{~Hz}$ 


\subsection{Single Frequency Out-of-Band Rejection}

A single frequency sinusoid at $0.1 \mathrm{PU}(10 \%)$ is added to the fundamental at $1 \mathrm{PU}$. The frequency of the sinusoid is varied from 1.5 to $179.5 \mathrm{~Hz}$, in $1 \mathrm{~Hz}$ increments and held for 1 second at each frequency. Maximum error is calculated as the difference between the actual measurement and the fundamental set only over the 1 second dwell.

Figure 24 shows the results of out-of-band rejection on a dB scale, where $0 \mathrm{~dB}$ represents no rejection. With the fast response setting, the amount of rejection approaches $5 \mathrm{~dB}$ at the Nyquist frequency. However, with the narrow band setting, the out-of-band distortion is suppressed at a level higher than $25 \mathrm{~dB}$. There is minimal difference between test results with frequency compensation on and off.

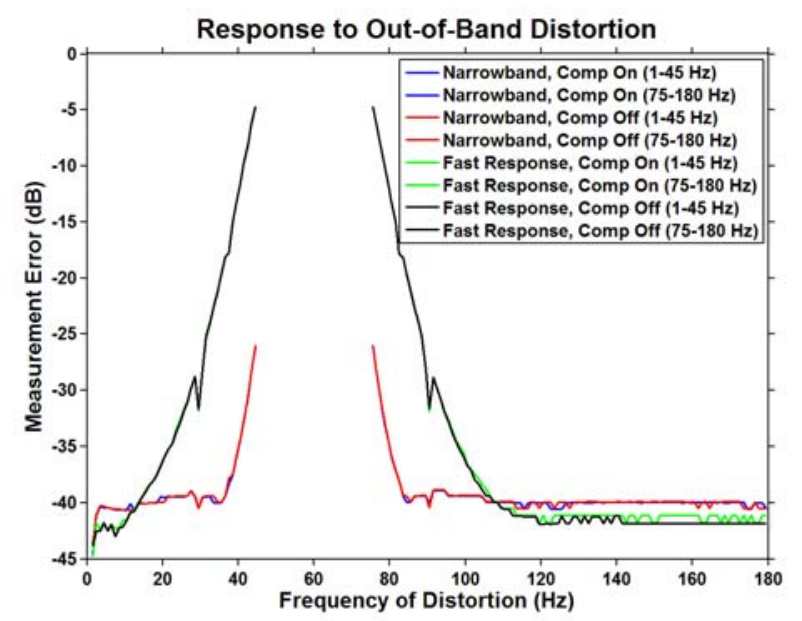

Figure 24. Response to Single Out-of-Band Distortion

(All “Narrow Band” curves overlap as in red. All "Fast Response” overlap as in black.)

\subsection{Amplitude Modulation}

\subsubsection{Amplitude Modulation with Nominal Frequency}

The test signal, with $70 \mathrm{~V}$ nominal, is sinusoidal waveforms with $12 \%$ amplitude modulated with the amplitude modulation frequency ranging from 0.1 to $180 \mathrm{~Hz}$. Figure 25 is the frequency response in the passband $(0 \mathrm{to} 15 \mathrm{~Hz})$ for the 30 sps data rate ( $15 \mathrm{~Hz}$ Nyquist). The fast response setting has a fairly flat response in this frequency range, while the narrow band setting shows a considerably faster roll-off. Frequency compensation does not have noticeable effect. 


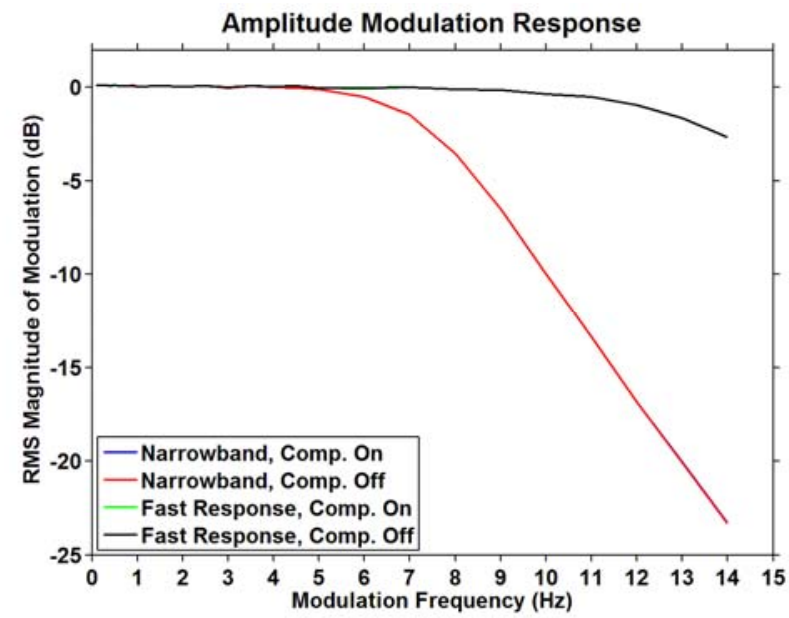

Figure 25. Response to Amplitude, 0 to $15 \mathrm{~Hz}$

(The two "Narrow Band” curves overlap as in red. The two "Fast Response” overlap as in black.)

In the rejection band ( 15 to $180 \mathrm{~Hz}$ for the $30 \mathrm{sps}$ data rate), the modulation is significantly suppressed by $70 \mathrm{~dB}$ when the modulation frequency is above $60 \mathrm{~Hz}$, as shown in Figure 26. For the frequency range of $15 \mathrm{to} 60 \mathrm{~Hz}$, the fast response setting has the rejection linearly drop from $\sim 5 \mathrm{~dB}$ to $\sim 65 \mathrm{~dB}$ on the $\mathrm{dB}$ scale. The narrow band setting suppressed the modulation much better (30 to $65 \mathrm{~dB}$ ).

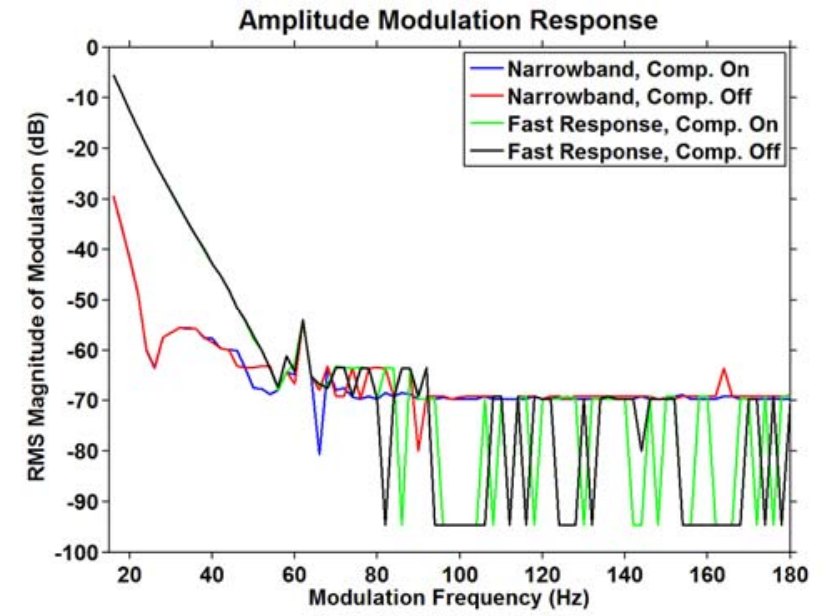

Figure 26. Amplitude Modulation Response, 15 to $180 \mathrm{~Hz}$

(The two "Narrow Band" curves overlap as in red. The two "Fast Response" overlap as in black.)

The phase delay of the modulation test, shown in Figure 27, starts with nearly $0 \mathrm{~ms}$ for about $2 \mathrm{~Hz}$, followed by variations up to $13 \mathrm{~ms}$ across the test band. The largest delay occurs at $9 \mathrm{~Hz}$ for the narrow band setting. Figure 28 shows the resulting phase response from the phase delay. The phase angle varies between 0 and $45^{\circ}$, with the largest angle being $45^{\circ}$ corresponding to the largest phase delay at $9 \mathrm{~Hz}$. 


\section{Delay of Amplitude Modulation}

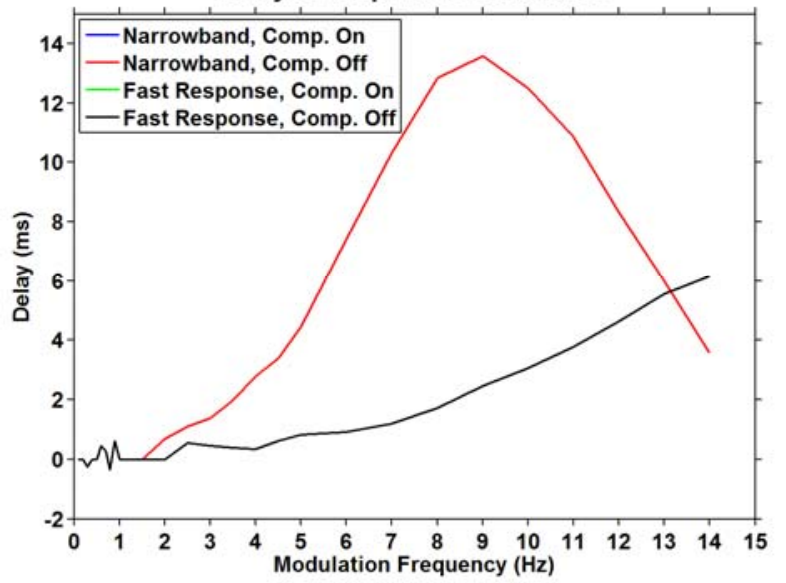

Figure 27. Phase Delay of Amplitude Modulation Tests

(The two "Narrow Band” curves overlap as in red. The two "Fast Response” overlap as in black.)

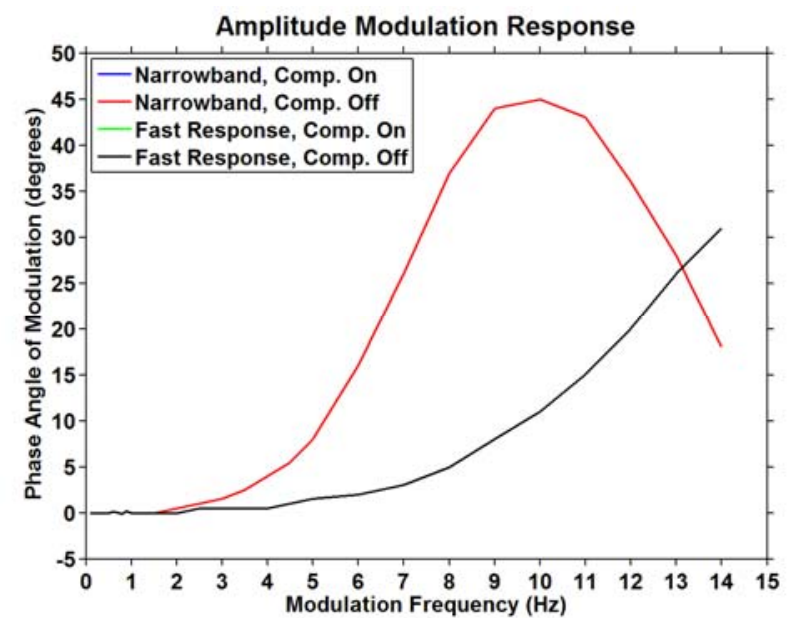

Figure 28. Phase Angle of Amplitude Modulation Tests

(The two "Narrow Band” curves overlap as in red. The two "Fast Response” overlap as in black.)

\subsubsection{Amplitude Modulation with off-Nominal Frequency}

This amplitude modulation uses the playback test file PMU_AMod6006seriesA. It is designed to examine aliasing effects, modulation harmonics, and noise levels of the PMU response. The modulated carrier is a balanced three phase sinusoidal waveform set arbitrarily to the off-nominal frequency of $60.06 \mathrm{~Hz}$; the modulation level is $10 \%$, at frequencies ranging from 0 to $45 \mathrm{~Hz}$ in the sequence [0, 0.28, 1.4, 6.64, 12.0, 15.0, 21.72, 28.7, 30.0, 30.85, 36.89, 45.0]. Each of these modulation frequencies is representative for a specific kind of power system behavior, or is a multiple of the Nyquist frequency.

Amplitude modulation results for the fast response setting are shown in Figure 29 and Figure 30; Figure 31 shows the result for narrow band setting. Observations include the following:

1) VMag, the voltage amplitude signal, has a strong output below the Nyquist frequency (15 Hz for $30 \mathrm{sps}$ reporting rate) as one would expect. However, when the device is set to fast response, it also shows 
significant response at some modulation frequencies that are above the Nyquist frequency. This indicates that system activity at such frequencies would be aliased to frequencies below $15 \mathrm{~Hz}$. The narrow band filter attenuates the signals above the Nyquist frequency properly. This is consistent with the response shown in Figure 25.

2) FreqL, the frequency measurement signal, should hold at $60.06 \mathrm{~Hz}$. However, with the fast response setting, there are anomalous outputs in this signal for amplitude modulation at and above the Nyquist frequency. Again the narrow band setting improves the results and only shows minimal anomalies.

3) The frequency measurement is different from estimated frequency (labeled as “EFreqL_FD”) calculated from phase angle measurements using the forward difference method. Results shown in Section 5 suggest that this is largely an effect of special filters used in the frequency measurement.

4) Frequency compensation does not have noticeable effect on the response. Discussions with the vendor indicate that the frequency compensation logic presently used in the SEL 421 adjusts the PMU gain and phase in accordance with off nominal frequencies, but does not yet completely address the asymmetric filtering, which leads to anomalous outputs in the PMU frequency channel.

The anomalous outputs in the frequency channel seem characteristic of nearly all PMUs on the market, and they are not regarded as a serious problem. The user should be aware of them, however, especially in control applications where low level activity above $5 \mathrm{~Hz}$ or so may be of interest.

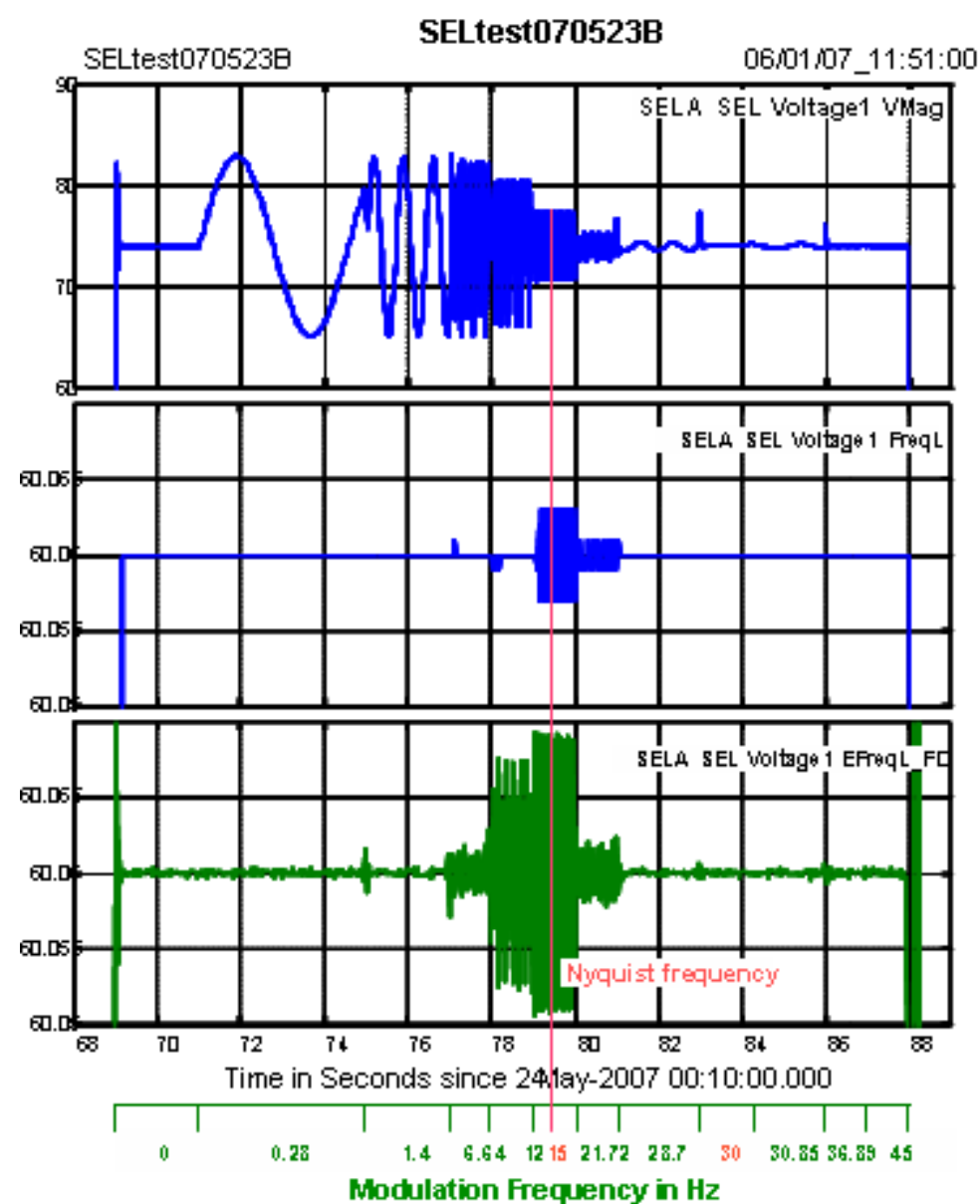

Figure 29. Off-Nominal Amplitude Modulation Response with the Setting of Fast Response, Frequency Compensation on 


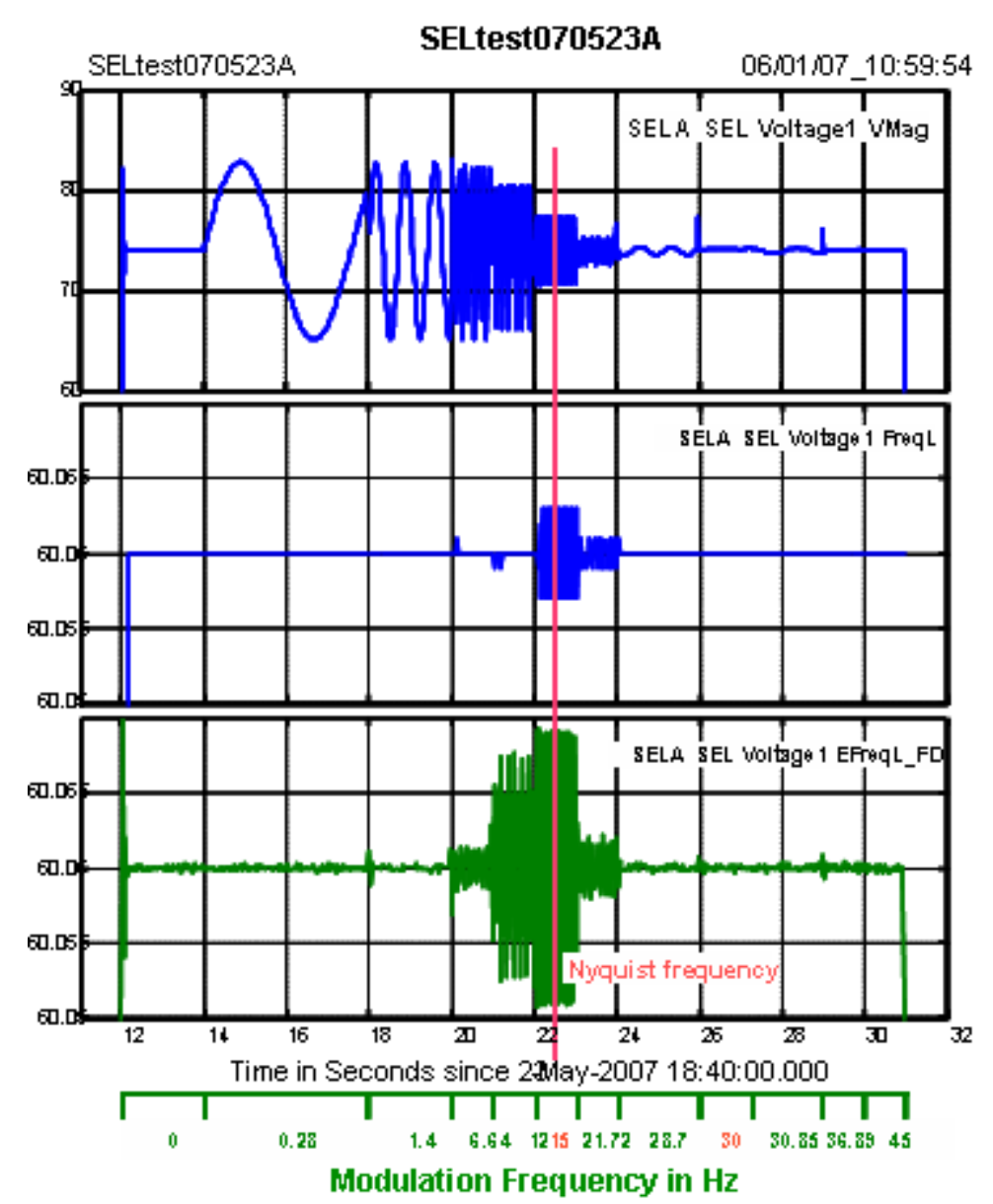

Figure 30. Off-Nominal Amplitude Modulation Response with the Setting of Fast Response, Frequency Compensation off 


\section{SELtest070523C}

SELtest0705230

$10 / 19 / 07 \_10: 39: 50$
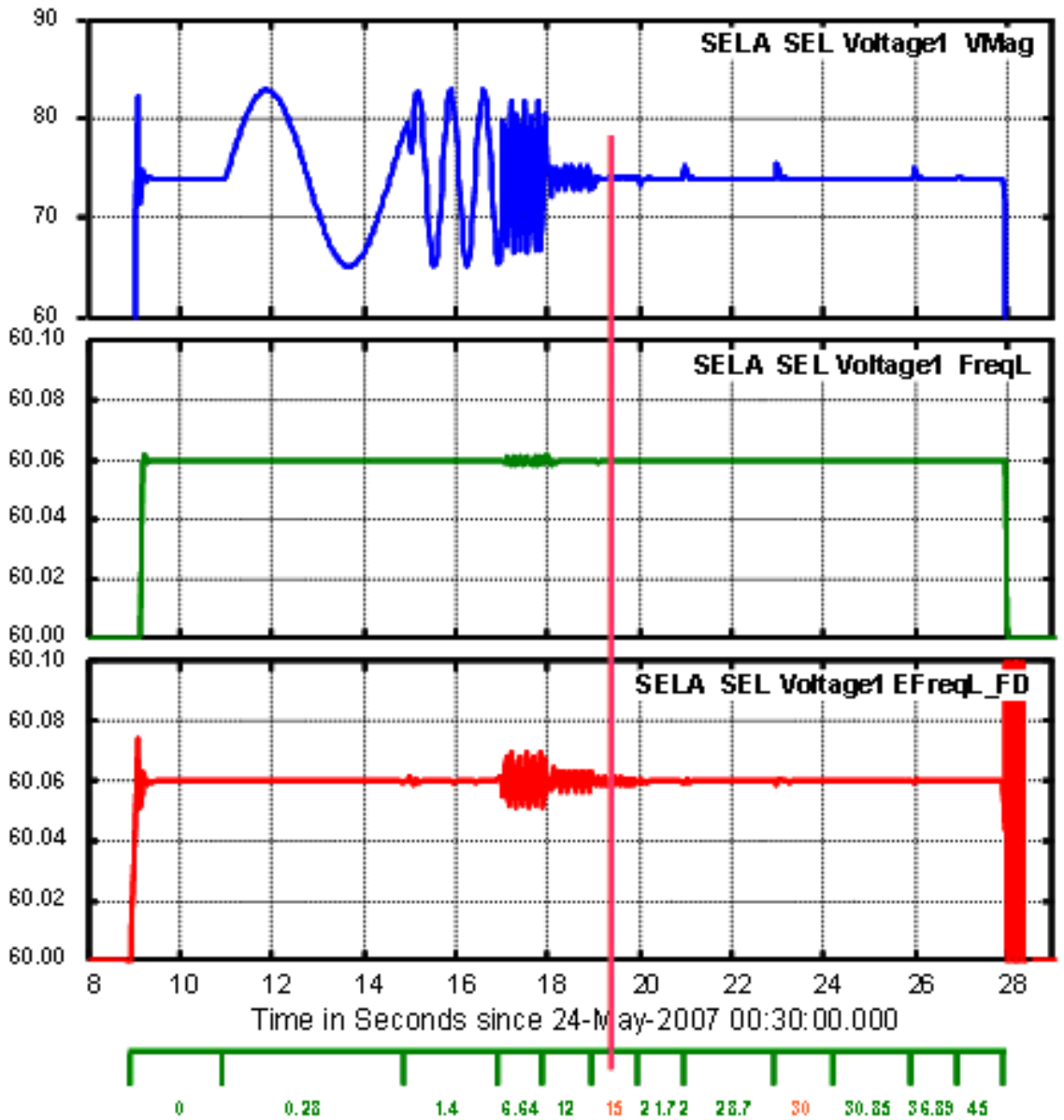

Modulation Frequency in $\mathrm{Hz}$

Figure 31. Off-Nominal Amplitude Modulation Response with the Setting of Narrow Band Response, Frequency Compensation off

\subsection{Phase Modulation}

The phase angle of a $70 \mathrm{~V}$ nominal test signal is modulated $\pm 5^{\circ}$ with the frequency of modulation varied from 0.1 to $180 \mathrm{~Hz}$. In the pass band, the phase modulation response closely resembles the response to amplitude modulation, as shown in Figure 32. In the frequency range of 15 to $180 \mathrm{~Hz}$ (Figure 33), the phase modulation response is still very similar to amplitude modulation, except large spikes are seen in the magnitude near $60 \mathrm{~Hz}$. 


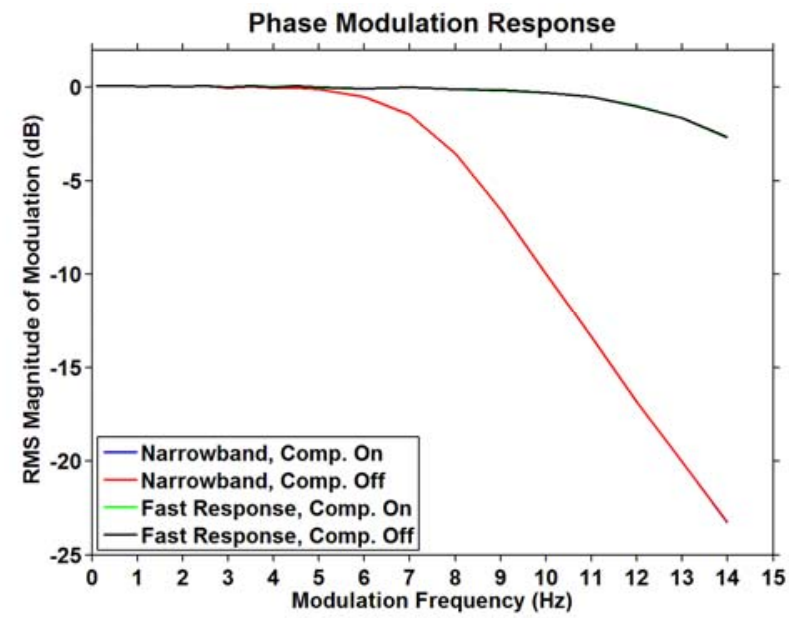

Figure 32. Phase Modulation Response, 0 to $15 \mathrm{~Hz}$

(The two "Narrow Band" curves overlap as in red. The two "Fast Response” overlap as in black.)

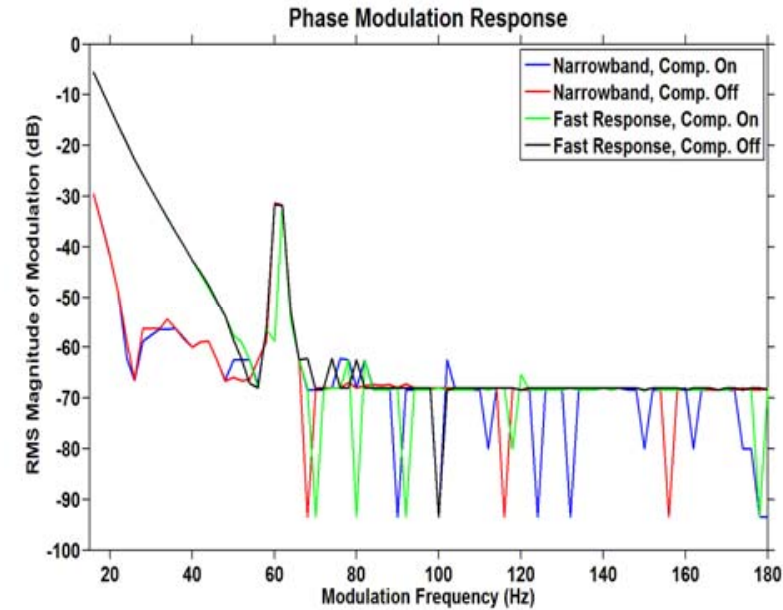

Figure 33. Phase Modulation Response, 15 to $180 \mathrm{~Hz}$

(The two "Narrow Band" curves overlap as in red. The two "Fast Response" overlap as in black.)

As with amplitude modulation, the phase delay and phase angle for phase modulation are shown to be nearly 0 below $1.5 \mathrm{~Hz}$ and then have large variations (Figure 34 and Figure 35). These characteristics are consistent with the results of amplitude modulation (Figure 27 and Figure 28). 


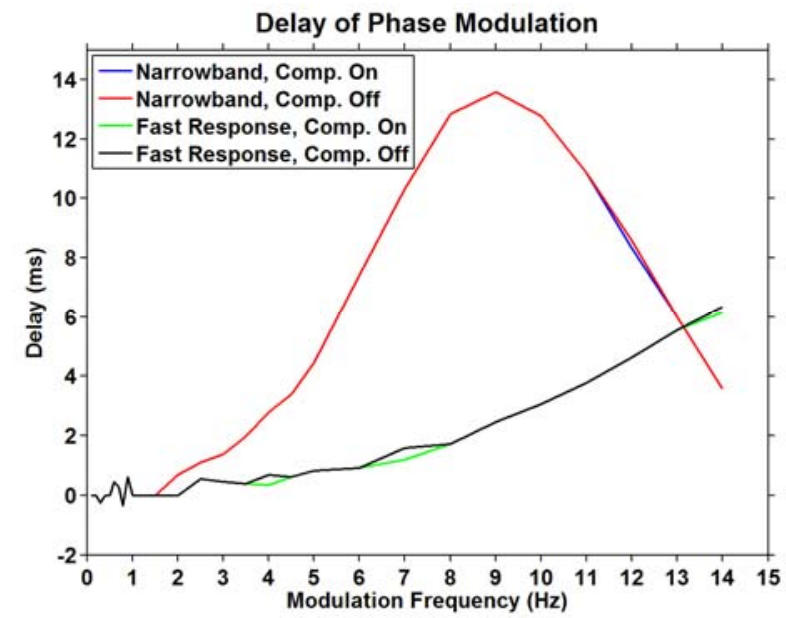

Figure 34. Delay of Phase Modulation Tests

(The two "Narrow Band" curves overlap as in red. The two "Fast Response" overlap as in black.)

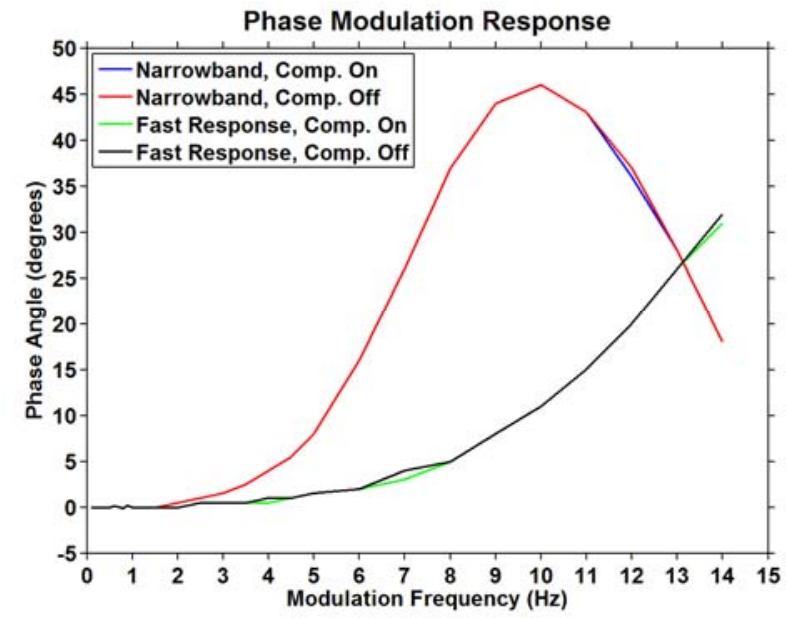

Figure 35. Phase Angle of Phase Modulation Tests

(The two "Narrow Band" curves overlap as in red. The two "Fast Response” overlap as in black.)

\subsection{Frequency Modulation}

The test signal, with $70 \mathrm{~V}$ nominal, is frequency modulated at $\pm 0.5 \mathrm{~Hz}$ with the modulation frequency varied from 0.1 to $180 \mathrm{~Hz}$. The previous modulation tests examine the phasor measurement response; this test examines the PMU frequency measurement. A $0 \mathrm{~dB}$ response indicates the measurement tracks the full range of $\pm 0.5 \mathrm{~Hz}$; as modulation frequency increases, the response range diminishes. Response to frequency modulation is shown in Figure 36 and Figure 37. It can be observed that the narrow band setting has less response than the fast response setting. Significant notches at the multiples of $6 \mathrm{~Hz}$ can be observed. Frequency compensation does not have noticeable effect on the response to frequency modulation. 


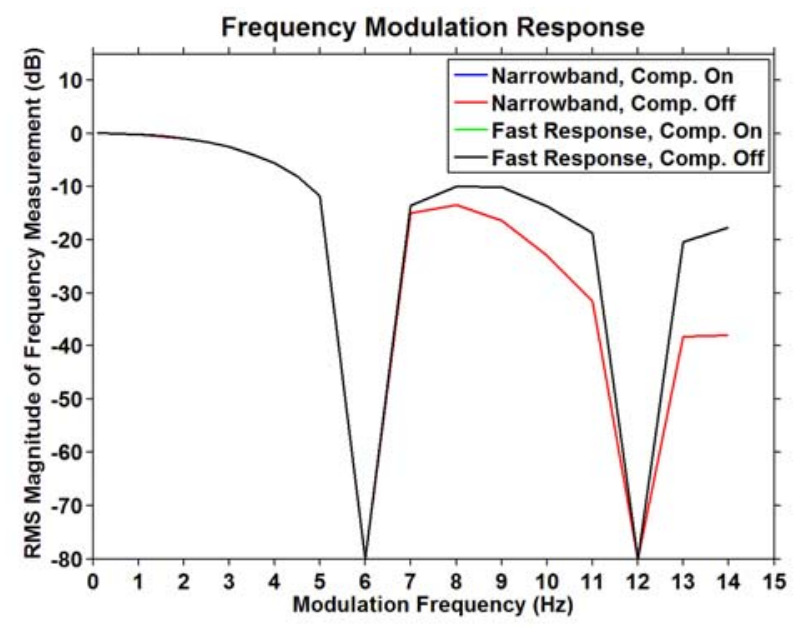

Figure 36. Frequency Modulation Response, 0 to $15 \mathrm{~Hz}$

(The two "Narrow Band" curves overlap as in red. The two "Fast Response” overlap as in black.)

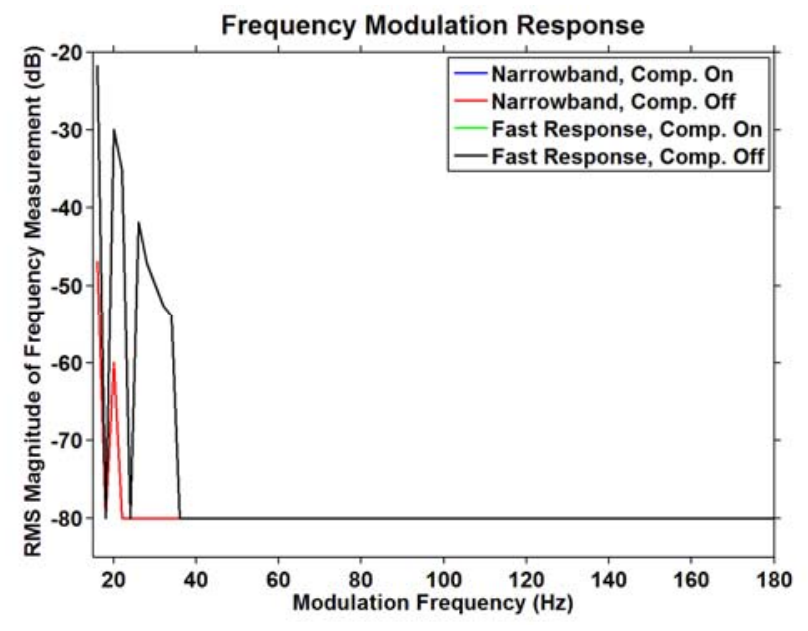

Figure 37. Frequency Modulation Response, 15-180 Hz

(The two "Narrow Band" curves overlap as in red. The two "Fast Response” overlap as in black.)

Delay in frequency modulation response is shown in Figure 38. With the fast response setting, the delay is about 84 ms until $5 \mathrm{~Hz}$ and then varies between 10 and $65 \mathrm{~ms}$. The narrow band setting has a slightly different delay. Frequency compensation does not have noticeable effect on the response to frequency modulation. 


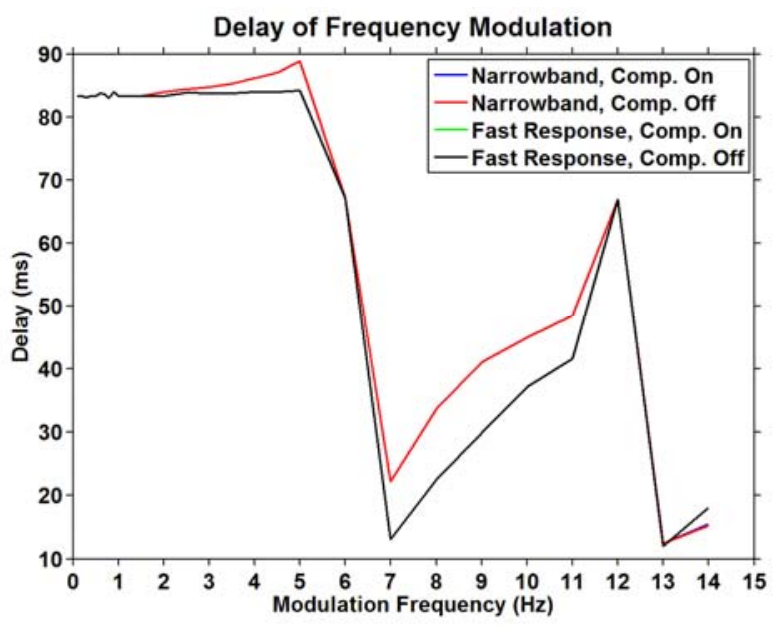

Figure 38. Delay of Frequency Modulation Test

(The two "Narrow Band" curves overlap as in red. The two "Fast Response" overlap as in black.)

\subsection{Step Tests}

Step tests are performed using a file that has repeated steps offset every $1 / 4$ cycle with appropriate settling and recovery times. Processing "slips" the repeated steps in place to produce a single, accurate response curve. In all tests, the step occurs at time 0 in the center of the plot.

\subsubsection{Amplitude Step Test}

The amplitude step test changes the signal amplitude from 1.0 to $1.1 \mathrm{PU}$ (70 to 77 volts, or 3.0 to $3.3 \mathrm{amps}$ ), followed by change from 1.0 to 0.9 PU (70 to 63 volts, or 3.0 to 2.7 amps). The step response plot in Figure 39 shows a slower increase in magnitude for the narrow band setting than the fast response setting. Both settings have significant overshoot, about $0.01 \mathrm{PU}$ (10\% of the step).

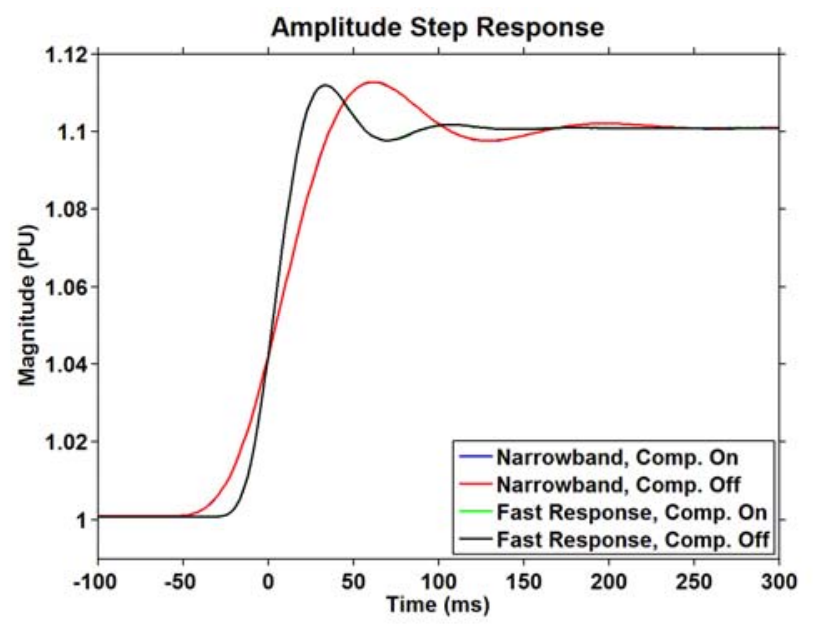

Figure 39. Positive Amplitude Step Response for Voltage

(The two "Narrow Band" curves overlap as in red. The two "Fast Response” overlap as in black.)

The PMU responds to a negative voltage step much like a positive one. This response is shown in Figure 40. 


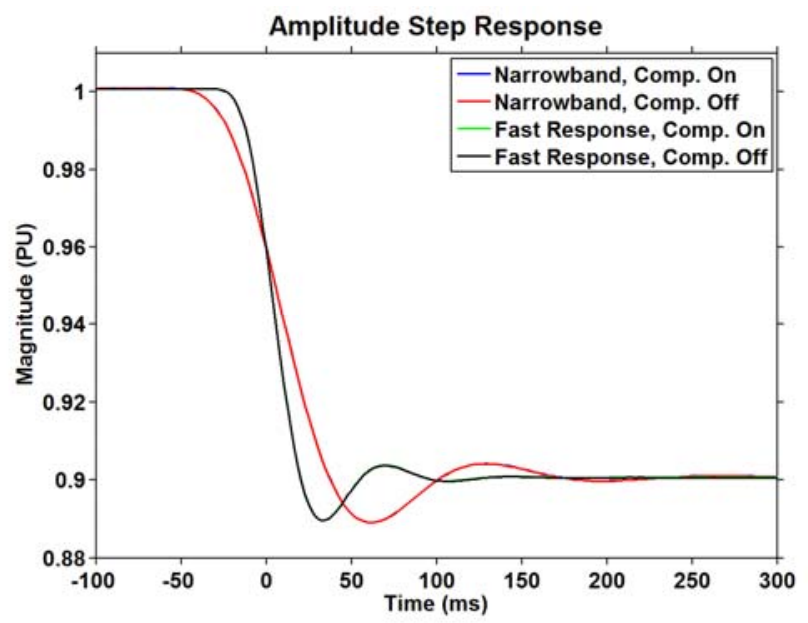

Figure 40. Negative Amplitude Step Response for Voltage

(The two "Narrow Band" curves overlap as in red. The two "Fast Response" overlap as in black.)

Responses to current steps (Figure 41 and Figure 42) have similar trends as the voltage tests. The narrow band setting has a slower response. Overshoot can be noticed in the plots.

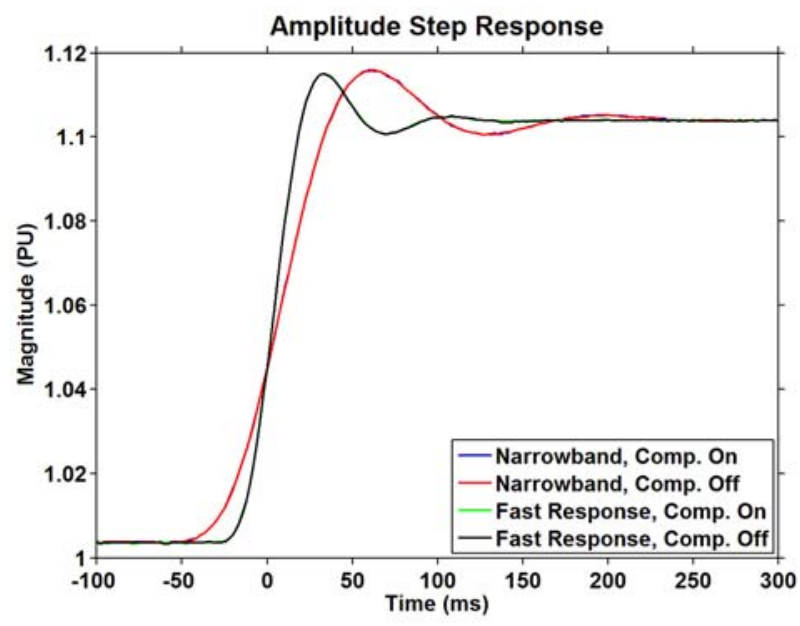

Figure 41. Positive Amplitude Step Response for Current

(The two "Narrow Band" curves overlap as in red. The two "Fast Response” overlap as in black.) 


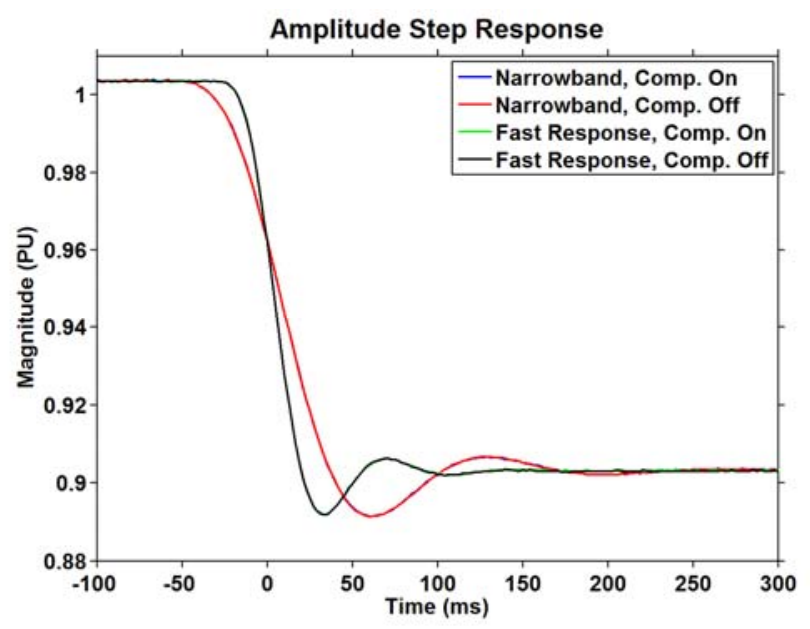

Figure 42. Negative Amplitude Step Response for Current

(The two "Narrow Band" curves overlap as in red. The two "Fast Response" overlap as in black.)

\subsubsection{Phase Step Test}

With the voltage signal of a constant $0^{\circ}$ phase, the phase angle in the current signal steps from $0^{\circ}$ to $15^{\circ}$, and from $0^{\circ}$ to $-15^{\circ}$. The results are shown in Figure 43 and Figure 44 for the positive and negative steps, respectively. The rise/fall times for a phase angle step are very similar to those in the amplitude step test. Overshoots are about $2^{\circ}$ (13\%).

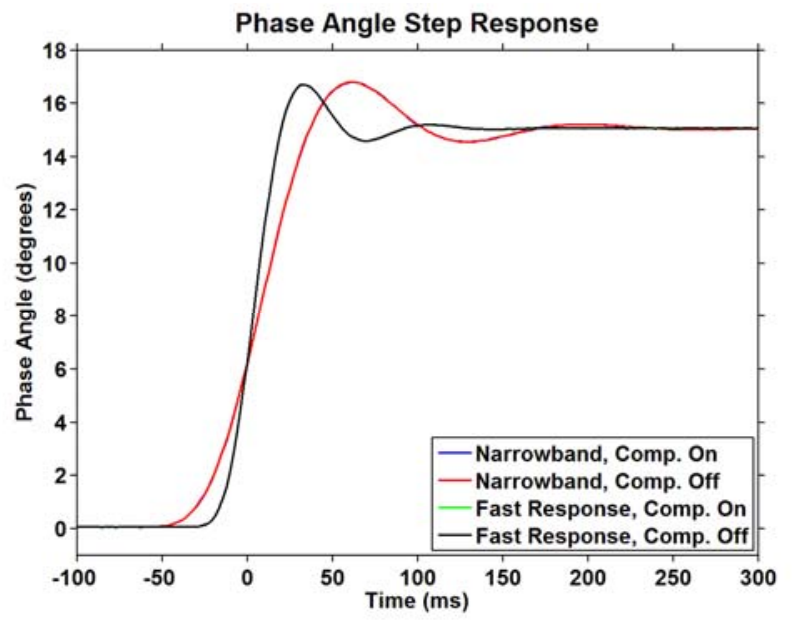

Figure 43. Positive Phase Angle Step Response

(The two "Narrow Band" curves overlap as in red. The two "Fast Response” overlap as in black.) 


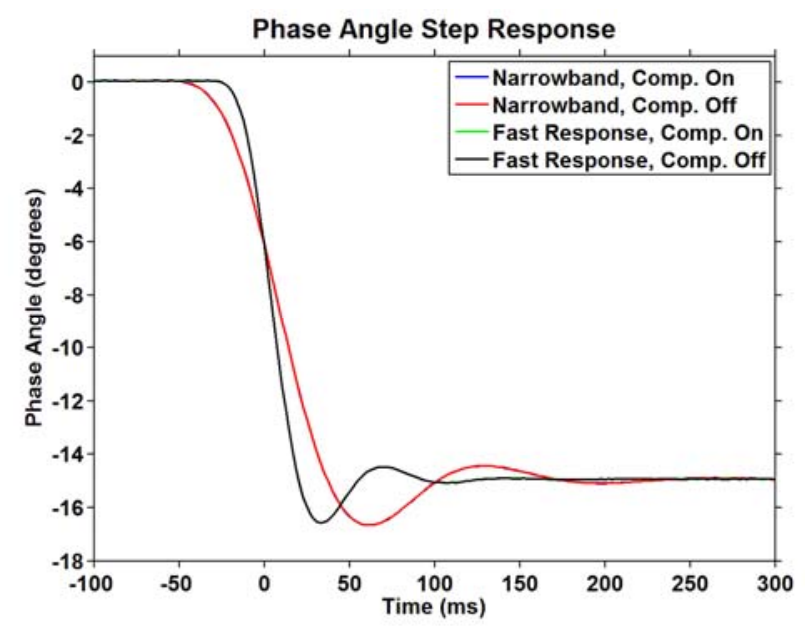

Figure 44. Negative Phase Angle Step Response

(The two "Narrow Band" curves overlap as in red. The two "Fast Response” overlap as in black.)

\subsubsection{Frequency Step Test}

The frequency in the voltage signal steps from 60 to $61 \mathrm{~Hz}$ and from 60 to $59 \mathrm{~Hz}$. As shown in Figure 45 and Figure 46, the narrow band setting has a slightly slower response than the fast response setting. The rise time is about 150 ms. With the narrow band setting, it also exhibits a noticeable overshoot. Frequency compensation does not have a noticeable effect on the response to frequency steps, except some slight variations when the frequency compensation is on with the fast response setting.

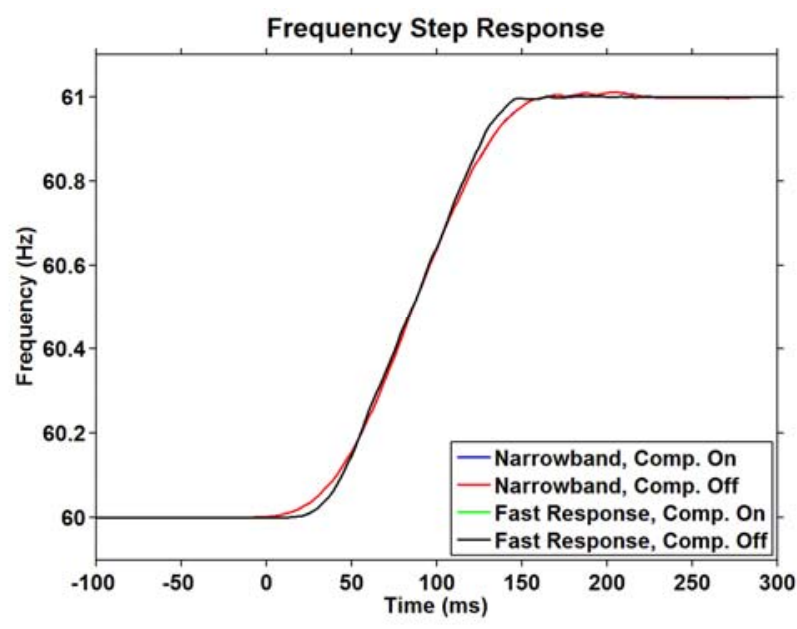

Figure 45. Positive Frequency Step Response

(The two "NarrowBand" curves overlap as in red. The two "Fast Response" overlap as in black.) 
Frequency Step Response

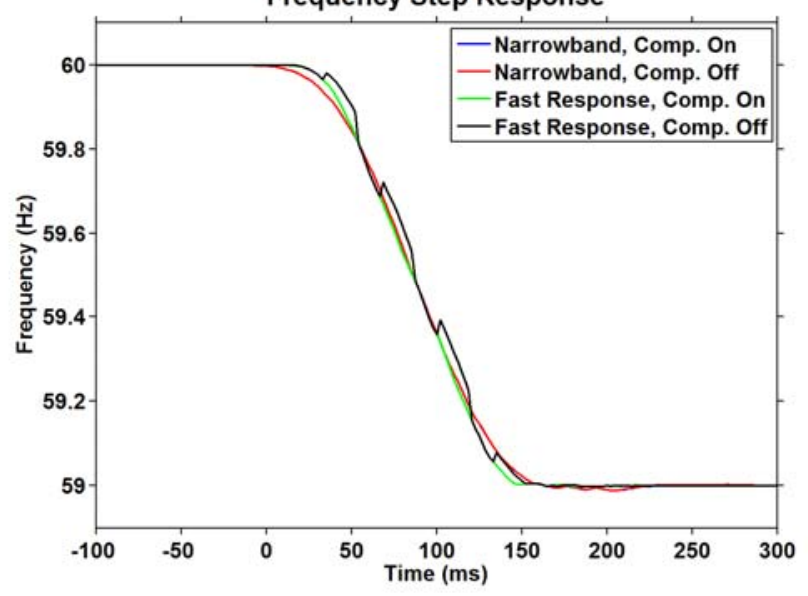

Figure 46. Negative Frequency Step Response

(The two "Narrow Band" curves overlap as in red. The two "Fast Response” overlap as in black.) 


\subsection{TIMING VERSUS REFERENCE PMUS}

PMUs of different types appear to use a wide variety of algorithms to produce their output signals for local frequency (FreqL). The timing of instrument level frequency signals is often found to be inconsistent between PMUs of different types, between PMUs of the same type that have been set differently, and between the frequency signal and the associated phasors.

This aspect of PMU timing can be examined very closely through Prony analysis of modulation response (Hauer et al. 2004). The methodology is illustrated in Figure 47 and Figure 48, for $1.4 \mathrm{~Hz}$ angle modulation of the SEL 421 during test series A. The playback file was FMod6006seriesA, and the RES521 was employed as a reference unit. In both cases, the signals of type EFreqL_FD are estimated frequencies obtained by a forward difference of the associated voltage angles.

While the frequency estimates are closely consistent, the instrument level signals are significantly delayed by different amounts, and the SEL output exhibits noticeable attenuation. Prony estimates for the delay are summarized in Table 23. Table 24 shows that consistent results are obtained by Prony analysis for angle modulation at $0.28 \mathrm{~Hz}$.

Very similar values were obtained for test series C, in which the SEL unit was set to fast response (still with frequency compensation off). Brief examination of relative timing for amplitude modulation with playback file AMod6006seriesA showed that voltage magnitude signals from the two units tracked closely, with the SEL unit lagging the ABB unit by about 1 msec.

Table 23. Relative Delays of PMU Frequency Signals for 1.4 Hz Angle Modulation, Test Series A

\begin{tabular}{lllc} 
Signal & Freq in Hz & Res Angle & Rel. Delay (msec) \\
\hline SEL Voltage1 FreqL & 1.400 & 144.3898 & 100.01 \\
ABB Voltage1 FreqL & 1.400 & 174.0134 & 41.24 \\
SEL Voltage1 EFreqL_FD & 1.400 & 194.8977 & -0.20 \\
ABB Voltage1 EFreqL_FD & 1.400 & 194.7962 & 0.00
\end{tabular}

Table 24. Relative Delays of PMU Frequency Signals for $0.28 \mathrm{~Hz}$ Angle Modulation, Test Series A

\begin{tabular}{lllc} 
Signal & Freq in Hz & Res Angle & Rel. Delay (msec) \\
\hline SEL Voltage1 FreqL & 0.2800 & -7.484 & 100.13 \\
ABB Voltage1 FreqL & 0.2800 & -1.596 & 41.72 \\
SEL Voltage1 EFreqL_FD & 0.2800 & 2.621 & -0.12 \\
ABB Voltage1 EFreqL_FD & 0.2800 & 2.609 & 0.00
\end{tabular}




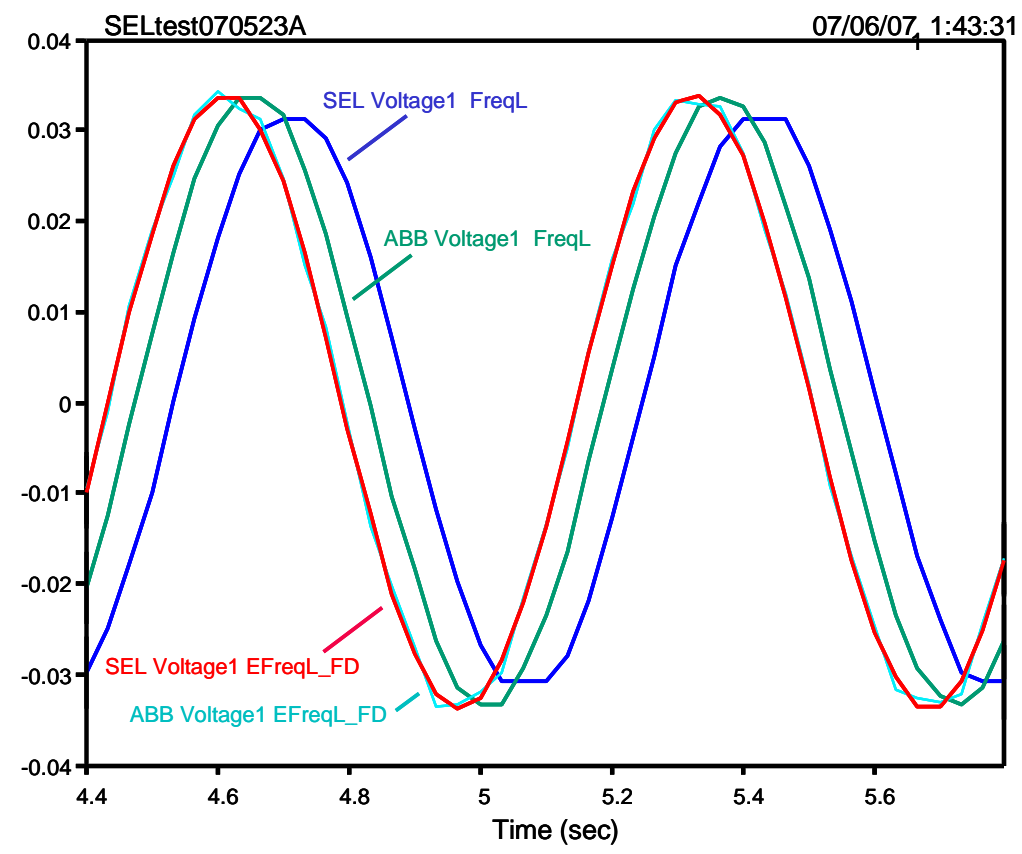

Figure 47. PMU Frequency Signals for 1.4 Hz Amplitude Modulation, Test Series A

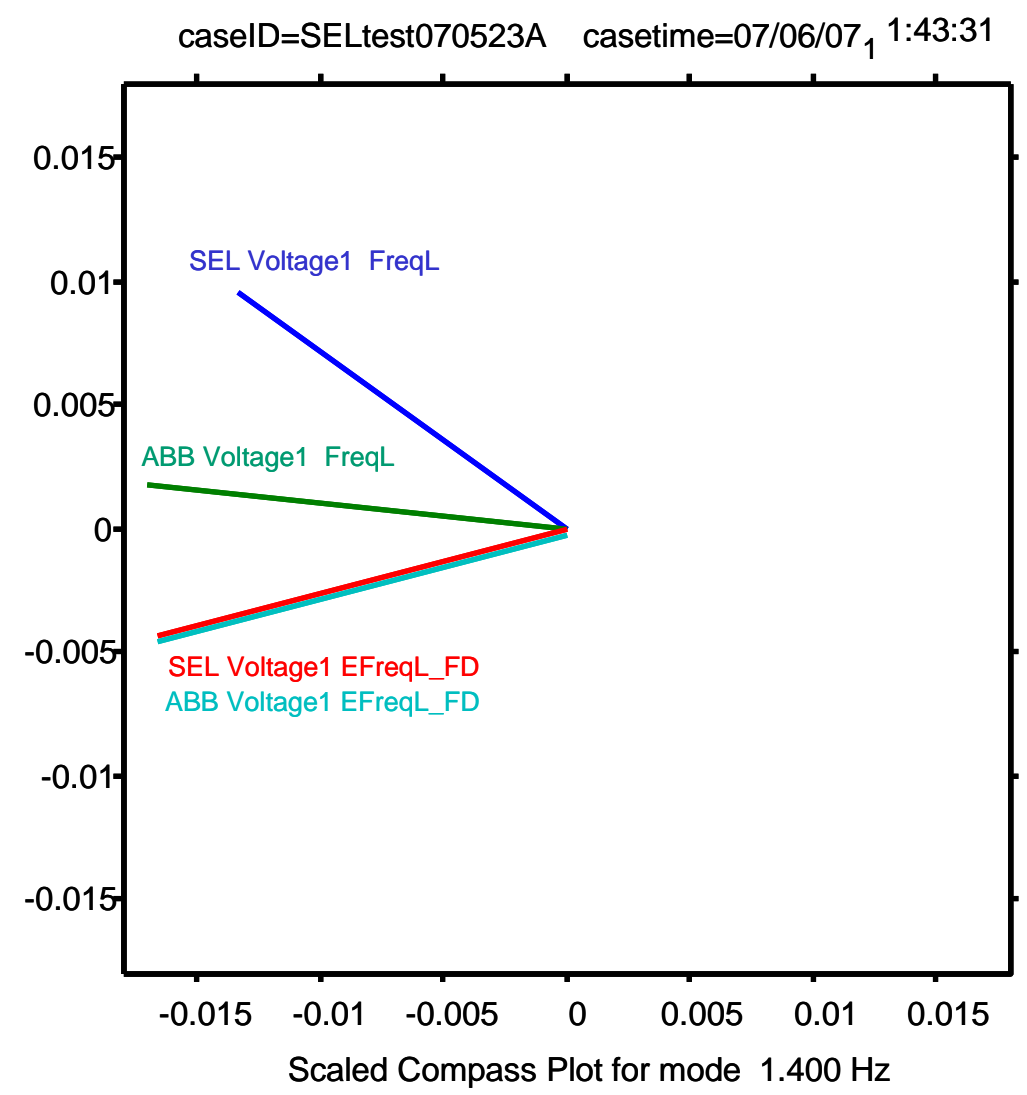

Figure 48. Relative Phase of PMU Frequency Signals for $1.4 \mathrm{~Hz}$ Amplitude Modulation, Test Series A 


\subsection{REFERENCES}

Bonneville Power Administration. 1999. Wide Area Measurements for Real-Time Control and Operation of Large Electric Power Systems - Evaluation And Demonstration Of Technology For The New Power System. Prepared for U.S. Department of Energy, January 1999. This report and associated attachments are available on compact disk.

Hauer, J. 1996. "Validation of Phasor Calculation in the Macrodyne PMU for California-Oregon Transmission Project Tests of March 1993.” IEEE Trans. Power Delivery, vol. 11, pp. 1224-1231, July 1996.

Hauer, J.F., K.E. Martin and H. Lee. 2004. "Evaluating the Dynamic Performance of Phasor Measurement Units: Experience in the Western Power System,. WECC Disturbance Monitoring Work Group, June 15, 2004.

Hauer, J. 2001. Use of Synchronized Phasor Measurements to Correct Timestamp and Filter Effects in Monitor Records Collected from Analog Instrumentation: Applied to Records of June 7, 2000 and August 10, 1996. Working Note for the WECC Modeling \& Validation Work Group, December 21, 2001

Hauer, J., W.A. Mittelstadt, K.D. Martin J.W. Burns, and H. Lee. 2007. Direct Analysis of Wide Area Dynamics. Prepared in association with the Disturbance Monitoring Work Group of the Western Electricity Coordinating Council. The Electric Power Engineering Handbook, edition 2, L. L. Grigsby ed., CRC Press, 2007.

IEEE Standard for Synchrophasors for Power Systems, IEEE Standard C37.118-2005, March 2006.

Martin, K.E. 1992. “Phasor Measurement System Test,” 1992 BPA Engineering Symposium, Vol. 2, pp. 689-704, Portland, Oregon.

Martin, K.E. 2004. WECC Disturbance/Performance Monitor Equipment: Proposed Standards for WECC Certification and Reimbursement. Draft report of the WECC Disturbance Monitoring Work Group, March 17, 2004.

Phadke, A.G., J.S. Thorp, and M.G. Adamiak. 1983. “A New Measurement Technique for Tracking Voltage Phasors, Local System Frequency, and Rate of Change of Frequency.” IEEE Transactions on Power Apparatus and Systems, vol. PAS-102, no. 5, pp. 1025-1038, May 1983. 


\section{APPENDIX A}

\section{WECC Requirements for Monitoring Equipment}




\section{APPENDIX A: WECC Requirements for Monitoring Equipment}

In 200,1 the WECC approved its Dynamic Performance and Disturbance Monitoring Plan to address North American Electric Reliability Corporation (NERC) Planning Standard I. F., System Adequacy and Security Disturbance Monitoring. Within this plan, the WECC established a reimbursement program to assist member utilities with the cost of equipment and maintenance associated with dynamic disturbance monitors at selected system locations. A monitor shall be judged as meeting basic WECC performance requirements if it satisfies the following technical criteria (Martin 2004):

- $\quad$ Frequency response of overall data acquisition:

- is $-3 \mathrm{~dB}$ or greater at $5 \mathrm{~Hz}$.

- does not exceed $-40 \mathrm{~dB}$ at frequencies above the Nyquist frequency ( a limit of $-60 \mathrm{~dB}$ is preferred)

- does not exceed -60 dB at frequencies that are harmonics of the actual power system operating frequency (for design purposes, assume all frequencies in the range of $59 \mathrm{~Hz}$ to $61 \mathrm{~Hz}$ )

- does not produce excessive ringing in records for step disturbances

- Data sampling rate:

- Overall frequency response requirements imply a minimum sample rate that is four to five times the -3 $\mathrm{dB}$ bandwidth of overall data acquisition

- For compatibility with other monitors, the sample rate should be an integer multiple of 20 or 30 samples per second (sps). A multiple of 30 sps is preferred.

- Numerical resolution and dynamic range:

- Resolution of the analog-to-digital (A/D) conversion process must be 16 bits or higher.

- Scaling of signals entering the A/D conversion should assure that 12 to 14 bits are actively used to represent them. Signals for which this scaling may overload the A/D during large transients may be recorded on two channels, in which one has less resolution but a greater dynamic range.

- Measurement noise must be within the normal limits of modern instrument technology. Noise levels for frequency transducers that are based upon zero-crossing logic tend to be unacceptable.

- Documentation for the data acquisition process:

- must be sufficiently detailed that overall quality of the acquisition system can be assessed

- must be sufficiently detailed that acquired records can be compensated for attenuation and phase lags introduced by the acquisition system

- The monitor or monitor system stores data continuously and retains the last 240 hours (10 days) at all times without operator intervention. A monitor that automatically erases the oldest file and stores the newest file will meet this criterion if the buffer area is 10 days or more. If the monitor requires an operator to remove old data to prevent storage overflow, a 60-day buffer is required to accommodate typical practices with monitor systems.

- The monitor is able to typically store event data files for $\mathbf{6 0}$ days without operator intervention. Because events are inherently unpredictable, this is only a 'typical' value based on operating experience. If the monitor stores continuous data, it does not have to store events.

- The monitor demonstrates synchronization to Universal Time (UTC) to a $100 \mu$ s level or better. Synchronization to GPS-based timing with suitable technique is preferred. Other approaches may be acceptable.

- Data access is by network, leased line, or dial-up with software for transfer, storage, and data archiving.

- Data formats are well defined and reasonable. Preferred formats for real-time data transfer are those equivalent to or meeting IEEE standards IEEE1344 or PC37.118 or the PDCstream format for concentrator 
output. the preferred file format is PhasorFile described in PhasorFileFormat.doc (*.dst) commonly in use in the WECC.

Figure 49 and Figure 50 represent the filtering requirements in graphical form and apply it to (IIR) Butterworth filters. In Figure 49, the filter is of order 4, with a $12 \mathrm{~Hz}$ bandwidth and an output rate of $60 \mathrm{sps}$. In Figure 50, the filter is of order 6 , with a $6 \mathrm{~Hz}$ bandwidth and an output rate of 30 sps.

These minimum requirements are indicated as sufficient for meeting WECC needs, but they may not be seen as necessary in some cases. They are intended as quantified guidelines for monitor evaluation, and they are deliberately stated in a simple manner. There are many underlying assumptions, plus considerable room for engineering judgment.

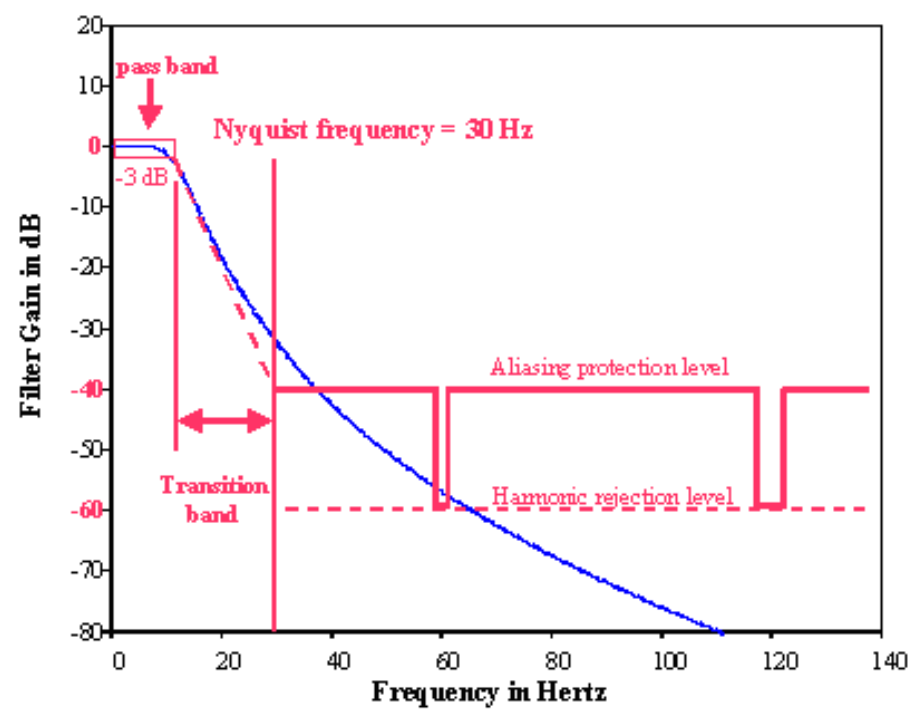

Figure 49. 12 Hz Butterworth Filter vs. WECC Filtering Standard

(sample rate $=60 \mathrm{sps})$ 


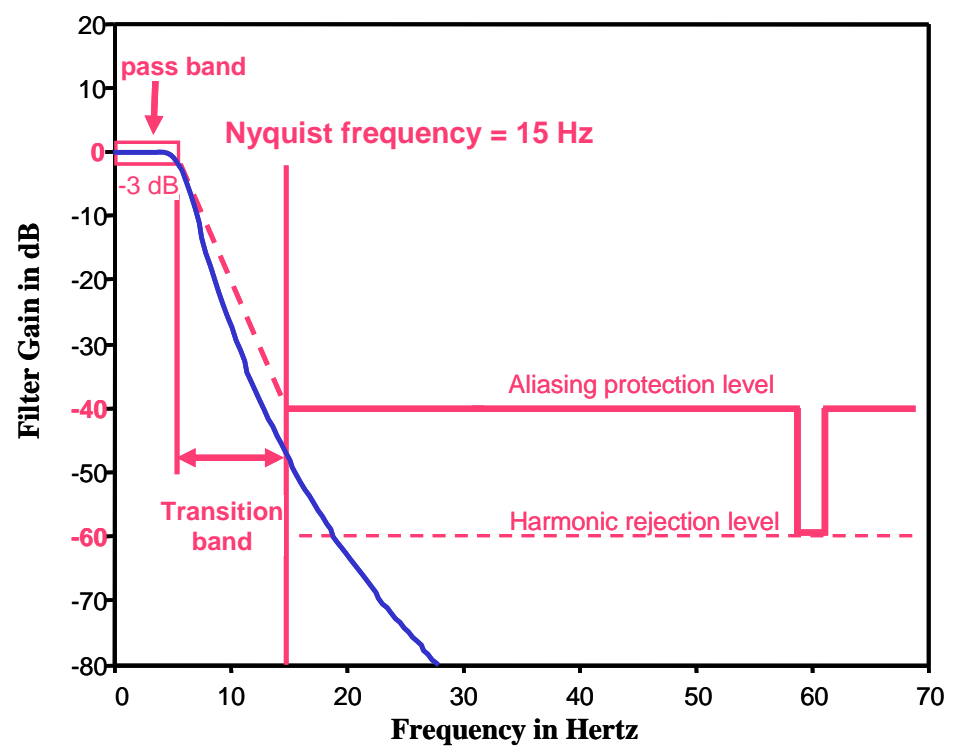

Figure 50. 6 Hz Butterworth Filter vs. WECC Filtering Standard

(sample rate $=30 \mathrm{sps}$ ) 


\section{APPENDIX B}

\section{IEEE Guidelines for PMU Performance}




\section{APPENDIX B: IEEE Guidelines for PMU Performance}

IEEE issued a synchrophasor measurement standard - IEEE C37.118 in 2005 (IEEE Standard 2006). This IEEE standard defines synchronized phasor measurements used in power system applications. It provides a method to quantify the measurement, tests to be sure the measurement conforms to the definition, and error limits for the test. The Standard employs the concept of "total vector error" (TVE) to quantify phasor measurement errors. The total vector error is defined as

$$
\mathrm{TVE}=\sqrt{ }\left[\left(\left(X_{\mathrm{r}}(\mathrm{n})-X_{\mathrm{r}}\right)^{2}+\left(X_{\mathrm{i}}(\mathrm{n})-X_{\mathrm{i}}\right)^{2}\right) /\left(X_{\mathrm{r}}^{2}+X_{\mathrm{i}}^{2}\right)\right]
$$

where $X_{\mathrm{r}}(\mathrm{n})$ and $X_{\mathrm{i}}(\mathrm{n})$ are the measured values, given by the measuring device, and $X_{\mathrm{r}}$ and $X_{\mathrm{i}}$ are the theoretical values of the input signal at the instant of time of measurement. " $r$ " and "i" denotes the real and imaginary parts of a phasor in rectangular form, respectively.

The Standard defines phasor measurement compliance levels for steady-state performance based on TVE, as shown in Table 25. These compliance definitions are used in this report to determine the compliance level of the tested PMU, as shown in Table 2 through Table 9. The Standard provides some brief descriptions about PMU dynamic performance tests, but no compliance levels for dynamic performance are defined. In this case, the WECC phasor requirements presented in Appendix A would serve as a good reference for evaluating PMU dynamic performance.

Table 25 Influence Quantities and Allowable Error Limits for Compliance Levels 0-1.

\begin{tabular}{|c|c|c|c|c|c|}
\hline \multirow[t]{3}{*}{ Influence quantity } & \multirow[t]{3}{*}{$\begin{array}{l}\text { Reference } \\
\text { condition }\end{array}$} & \multicolumn{4}{|c|}{$\begin{array}{l}\text { Range of influence quantity change with respect to reference and } \\
\text { maximum allowable TVE in percent }(\%) \text { for each compliance level }\end{array}$} \\
\hline & & \multicolumn{2}{|c|}{$\begin{array}{c}\text { Level } 0 \\
\end{array}$} & \multicolumn{2}{|c|}{$\begin{array}{l}\text { Level } 1 \\
\end{array}$} \\
\hline & & Range & TVE (\%) & Range & TVE (\%) \\
\hline Signal frequency & $F_{\text {nominal }}$ & $\pm 0.5 \mathrm{~Hz}$ & 1 & $\pm 5 \mathrm{~Hz}$ & 1 \\
\hline Signal magnitude & $100 \%$ rated & $80-120 \%$ rated & 1 & $10-120 \%$ rated & 1 \\
\hline Phase angle & 0 radians & $\pm \pi$ radians & 1 & $\pm \pi$ radians & 1 \\
\hline Harmonic distortion & $\begin{array}{l}<0.2 \% \\
(\mathrm{THD})\end{array}$ & $\begin{array}{l}1 \% \text {, any harmonic } \\
\text { up to } 50^{\text {th }}\end{array}$ & 1 & $\begin{array}{l}10 \% \text {, any harmonic } \\
\text { up to } 50^{\text {th }}\end{array}$ & 1 \\
\hline $\begin{array}{l}\text { Out of band interfering } \\
\text { signal, at frequency } \mathrm{f}_{\mathrm{i}} \\
\text { where }\left|\mathrm{f}_{\mathrm{i}}-\mathrm{f}_{0}\right|>\mathrm{F}_{\mathrm{s}} / 2 \text {, } \\
\mathrm{F}_{\mathrm{s}}=\text { phasor reporting } \\
\text { rate, } \mathrm{f}_{0}=\mathrm{F}_{\text {nominal }}\end{array}$ & $\begin{array}{l}<0.2 \% \text { of } \\
\text { input signal } \\
\text { magnitude }\end{array}$ & $\begin{array}{l}1.0 \% \text { of input } \\
\text { signal magnitude }\end{array}$ & 1 & $\begin{array}{l}10 \% \text { of input signal } \\
\text { magnitude }\end{array}$ & 1 \\
\hline
\end{tabular}


APPENDIX C

PMU Types Used in Performance Comparisons 


\section{APPENDIX C: PMU Types Used in Performance Comparisons}

New or revised PMU types are often tested in tandem with other PMU types (or PMU models) that are well understood, and in common use. This provides cross calibration data that may be needed to refine the consistency of measurements from the different instrument types. Also, by comparing results from the reference units against those of earlier tests, one can readily establish that the present tests are being performed correctly.

At present the following PMU types and models are used as reference units for performance comparisons:

- Macrodyne 1690M

- ABB RES521, usually with filter \#2 and frequency tracking on

- MATLAB model PMU_Box1\&4X30 for the 1690M

These are usually operated with an output rate of 30 sps, but with some exceptions for exploratory purposes.

\section{C.1 General Characteristics of the Macrodyne 1690M}

The Macrodyne 1690M is a realization of the basic algorithm presented in Phadke et al. (1983), but with additional filtering to reduce the exposure to out-of-band signals. Primary filtering consists of a one cycle "boxcar" in series with a four cycle boxcar, with response functions as shown in Figure 51 and Figure 52. Figure 52 through Figure 55, plus other comparisons in Hauer et al (2004), show that the associated model PMU_Box1\&4X30 replicates measured response of the $1690 \mathrm{M}$ very closely.

Figure 53 shows that filtering for the 1690M falls well short of the WECC standard. Effects of this are illustrated in Figure 54, which shows substantial PMU outputs for signal components above the Nyquist frequency. Such outputs are necessarily "aliased" to lower frequencies, and are easily mistaken for types of system behavior other than what they actually represent.

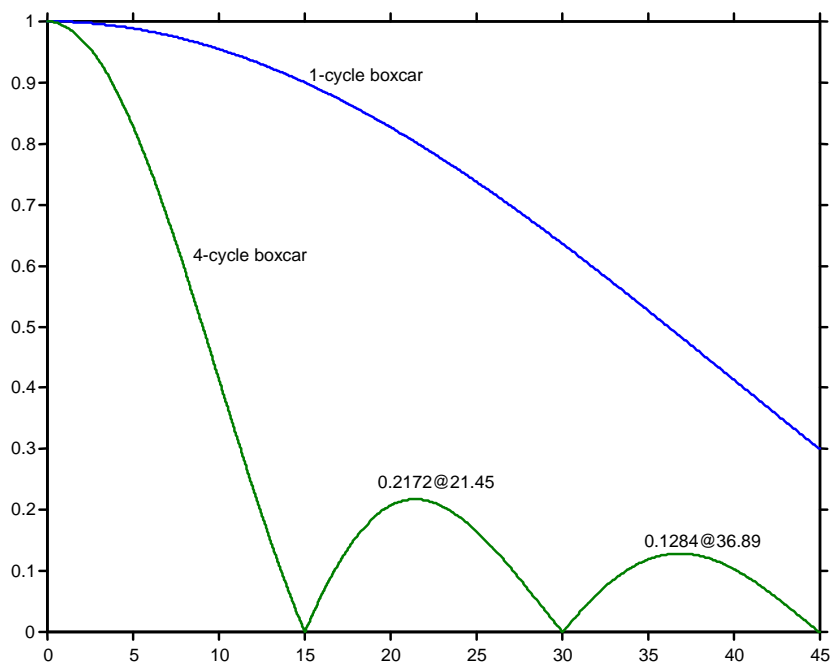

Figure 51. Two Stage Fourier Filter Approximating that of the Macrodyne 1690M PMU 


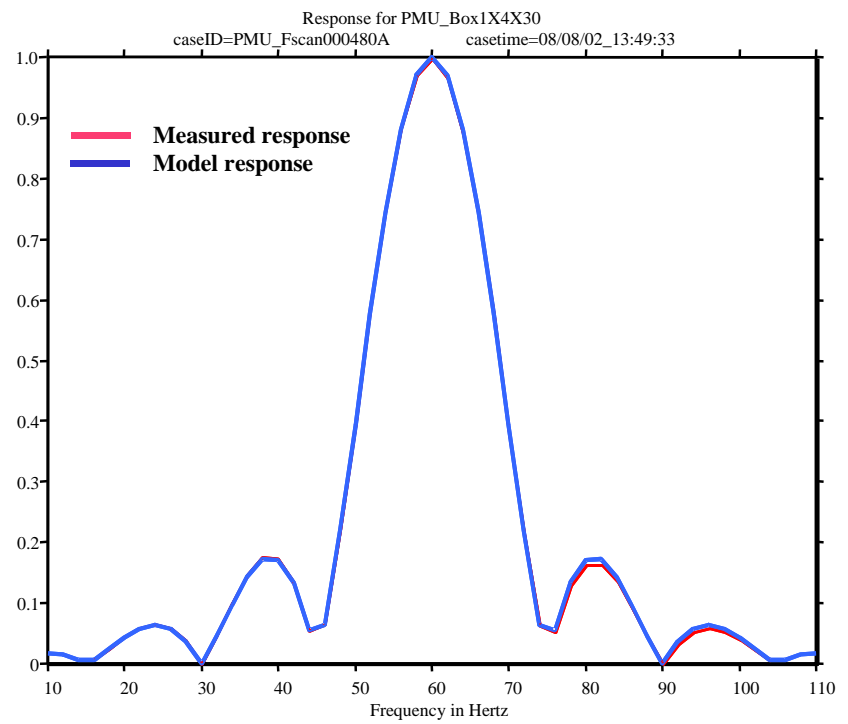

Figure 52. Model PMU_Box1X4X30 vs. Measured Response for the Macrodyne 1690M

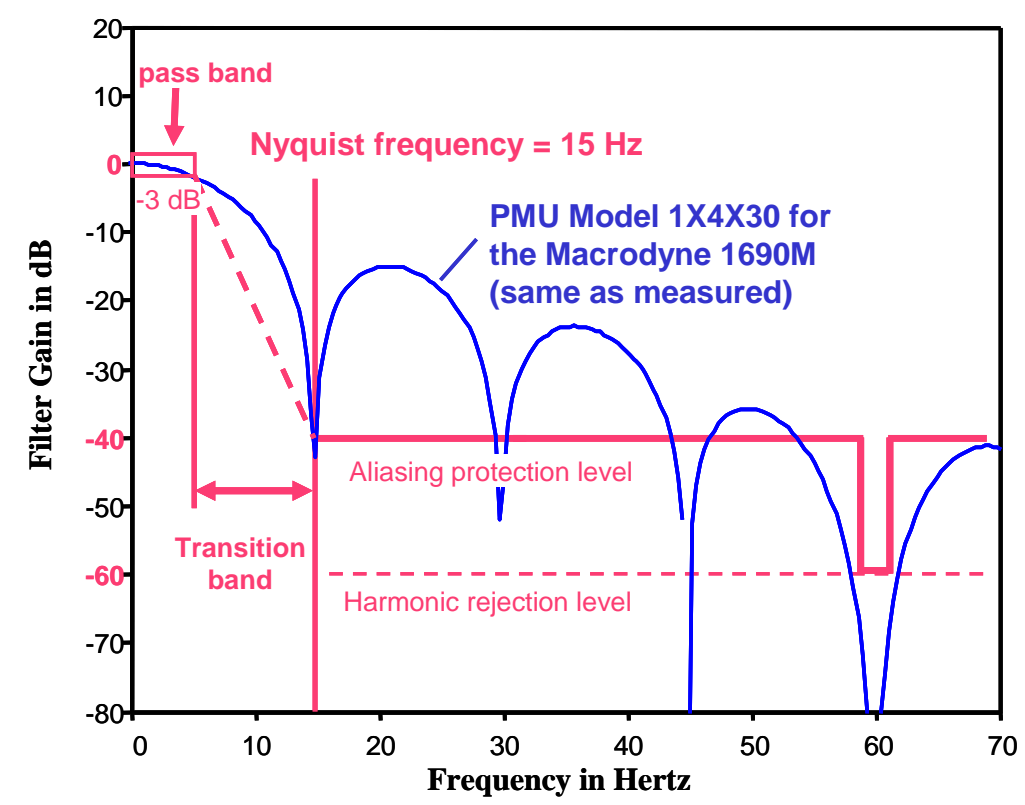

Figure 53. Macrodyne 1690M vs. WECC Filtering Standard 
IVIALU IVIaciuuyıle vuilaye viviay

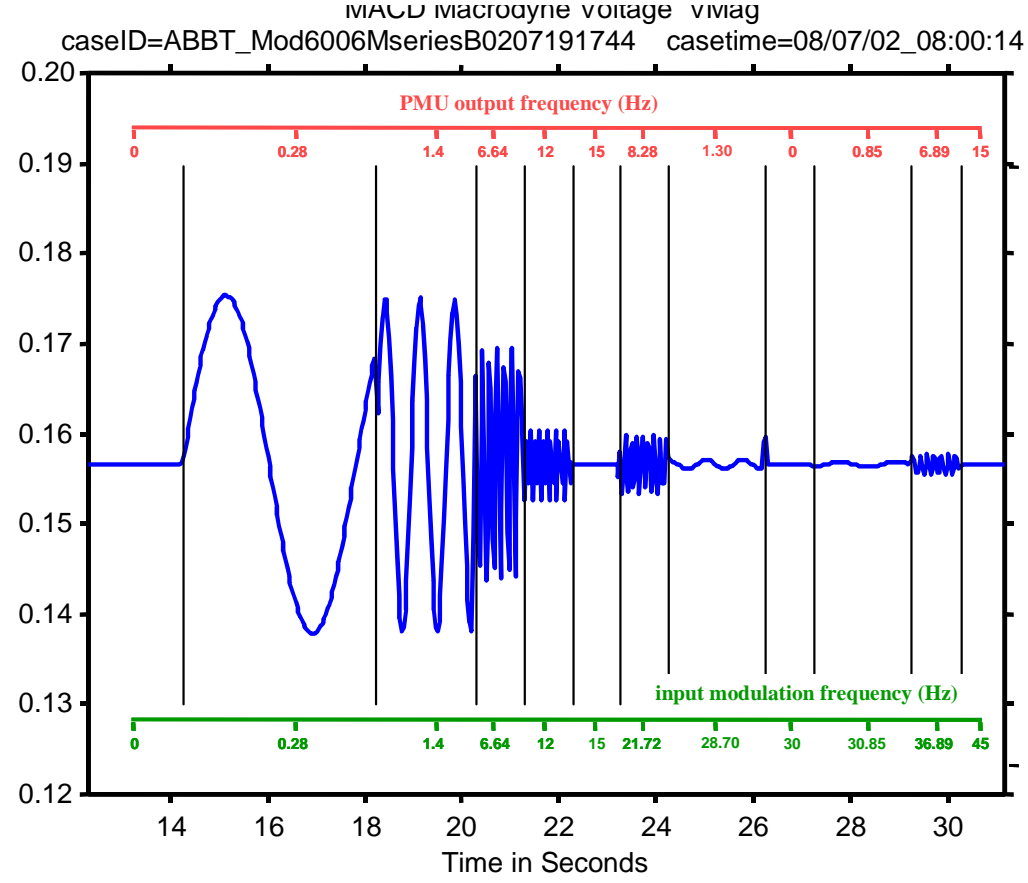

Figure 54. Modulation of Balanced 60.06 Hz Carrier, Macrodyne 1690M Test file PMU_AMod6006seriesA

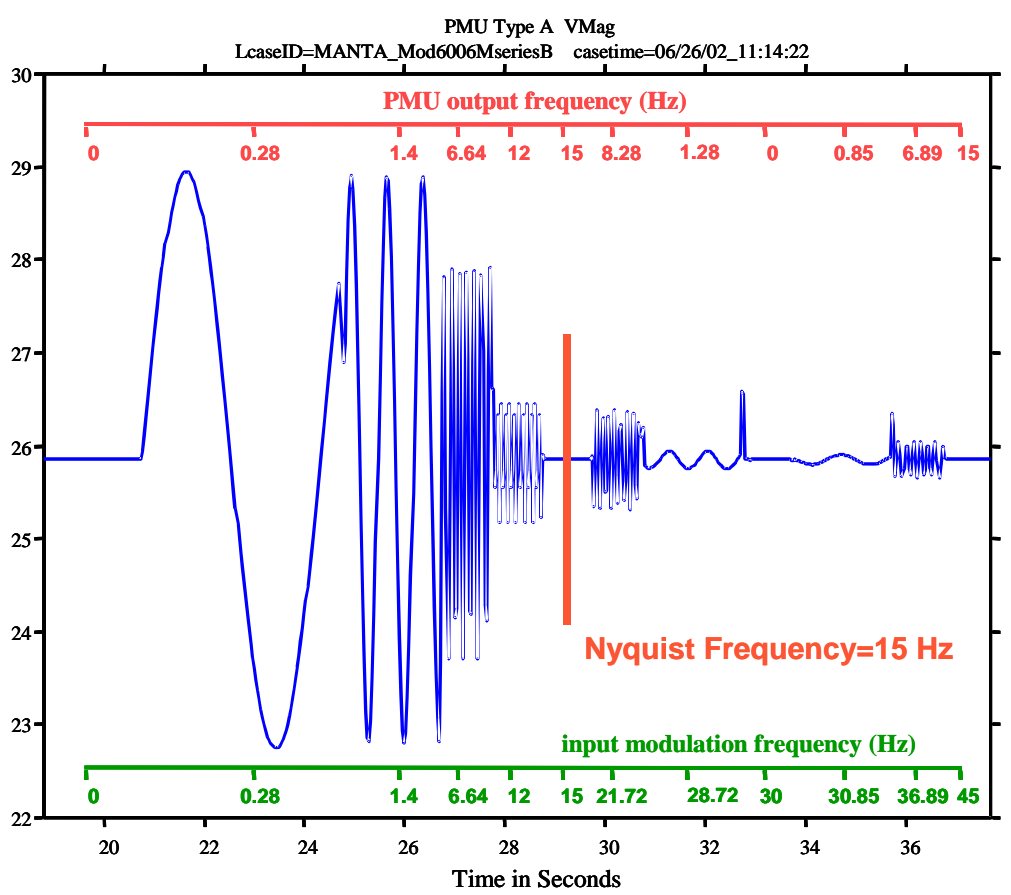

Figure 55. Modulation of Balanced 60.06 Hz Carrier, PMU Model PMU_Box1\&4X30 Test file PMU_AMod6006seriesA 


\section{C.2 General Characteristics of the ABB RES521}

The ABB model RES521 PMU can be operated with or without frequency tracking, and it provides six different filter options together with various settings for output timing. Figure 56 shows filter response as measured by the usual single-frequency scan with frequency tracking off. With frequency tracking on, the overall filtering becomes adaptive, and appropriate measurements can be obtained by a single-frequency scan of modulation applied to a representative carrier (such as $60 \mathrm{~Hz}$ ). This produces characteristics similar to those shown in Figure 56, but with the starting frequency shifted from $60 \mathrm{~Hz}$ to 0 .

Figure 57 and Figure 58 compare amplitude modulation response of the RES521 against that of the 1690M, with the RES521 set to filters \#2 and \#4 with frequency tracking on. Figure 57 shows that both PMUs have substantial response to inputs above the Nyquist frequency when the RES521 is set to filter \#2, but the RES521 may meet the WECC filtering requirement when operating with filter \#4.

Figure 58 shows that amplitude modulation of the $1690 \mathrm{M}$ produces spurious cross modulation ("crosstalk") in the PMU frequency signal. Corresponding cross modulation of the signal for voltage angle is also present, but it is somewhat more difficult to observe graphically.

Analysis in Hauer et al. (2004) shows that this cross modulation is a result of asymmetric filtering when the phasor reference frequency does not match the actual operating frequency of the power system. In the present case, the PMU filtering is effectively centered at $60 \mathrm{~Hz}$, whereas the signal spectrum is centered at $60.06 \mathrm{~Hz}$. This effect is regularly encountered in laboratory tests, except for those PMUs that adjust the reference frequency to match the operating frequency. Figure 58 shows that the RES521 does this very effectively.

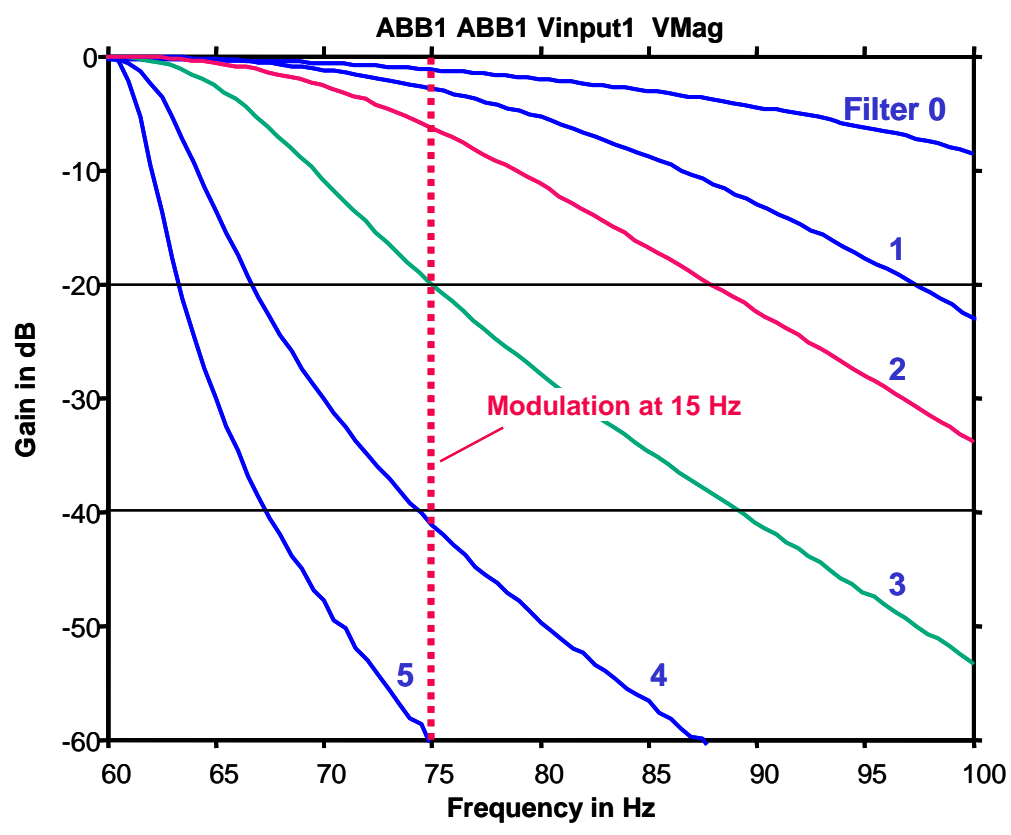

Figure 56. ABB RES4521 Filter Options (Adaptive Logic off) 

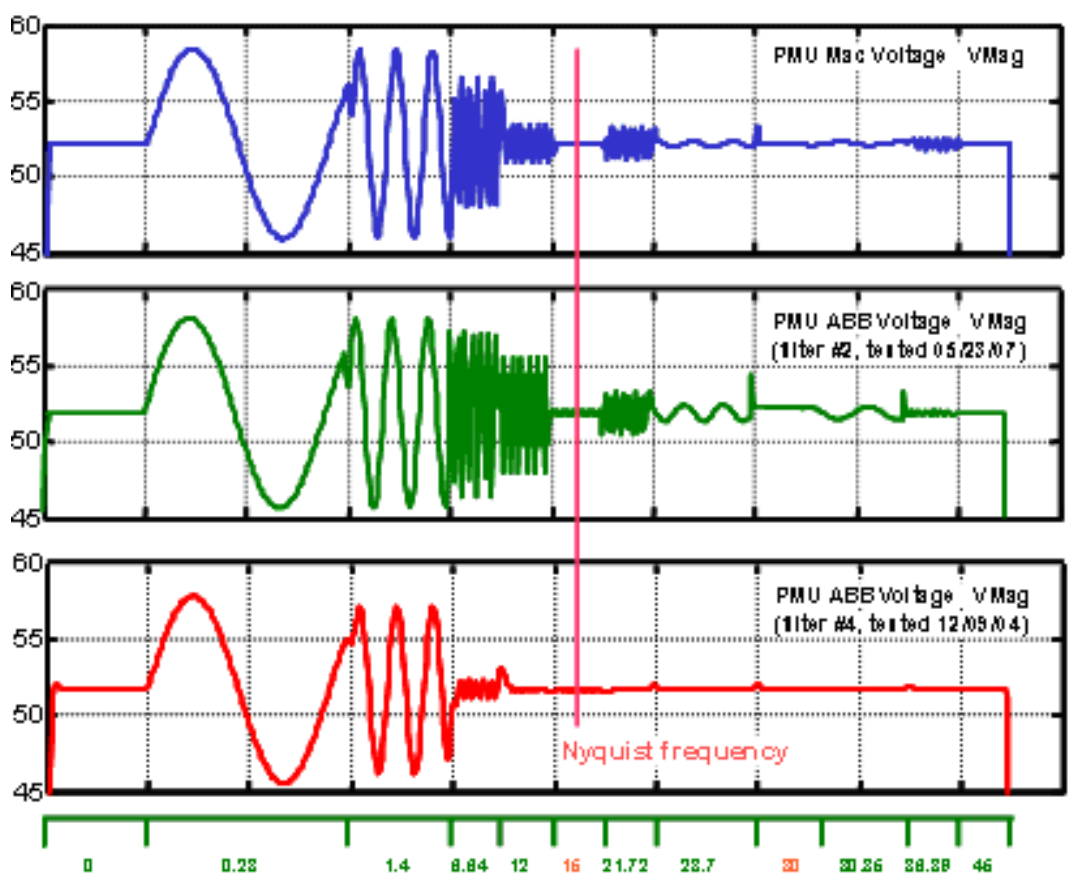

Modulation Frequency in $\mathrm{Hz}$

Figure 57. PMU Voltage Response to AM Modulation Scan:

Playback file PMU_Amod6006seriesA

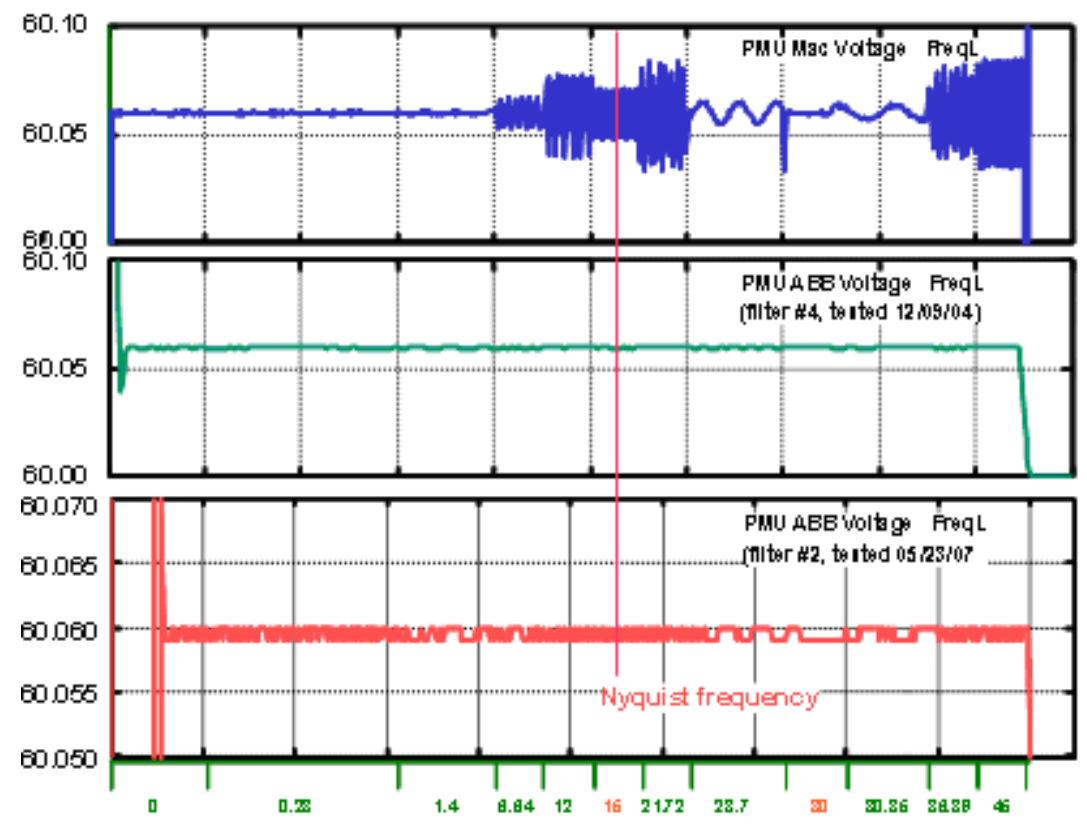

Modulation $\mathrm{F}$ requency in $\mathrm{Hz}$

Figure 58. PMU Frequency Response to AM Modulation Scan:

Playback file PMU_Amod6006seriesA 